UNIVERSIDADE DE SÃO PAULO

ESCOLA DE EDUCAÇÃO FÍSICA E ESPORTE

\title{
O EFEITO DAS RESTRIÇÕES DA TAREFA E DO AMBIENTE NO COMPORTAMENTO DE LOCOMOÇÃO NO MEIO AQUÁTICO
}

Ernani Xavier Filho

SÃO PAULO

2001 


\section{O EFEITO DAS RESTRIÇÕES DA TAREFA E DO AMBIENTE NO COMPORTAMENTO DE LOCOMOÇÃO NO MEIO AQUÁTICO}

ERNANI XAVIER FILHO

Dissertação apresentada à Escola de Educação Física e Esporte da Universidade de São Paulo, como requisito parcial para obtenção do grau de Mestre em Educação Física.

ORIENTADOR: PROF. DR. EDISON DE JESUS MANOEL 


\section{Xavier Filho, Ernani}

$\mathrm{O}$ efeito das restrições da tarefa e do ambiente no comportamento de locomoção no meio aquático / Ernani Xavier Filho. - São Paulo : [s.n.], 2001. xiv, 123p.

Dissertação (Mestrado) - Escola de Educação Física e Esporte da Universidade de São Paulo.

Orientador: Prof. Dr. Edison de Jesus Manoel.

1. Comportamento motor 2. Natação I. Título. 


\section{AGRADECIMENTOS}

Agradeço a todos aqueles que direta ou indiretamente contribuíram para a realização deste trabalho, especialmente:

Ao CRIADOR pela proteção, e pela felicidade de ter uma família maravilhosa e amigos inesquecíveis;

À Dulce, minha companheira, pelo apoio incondicional que sempre me ofereceu, sem o qual não seria possível concluir este trabalho;

Aos filhos, João Guilherme, Luiz Ernani e José Flávio pela paciência que tiveram comigo;

Ao Prof. Dr. Edison de Jesus Manoel, pelo incentivo e apoio irrestrito desde a primeira hora, que foram fundamentais na execução deste projeto;

Ao Prof. Dr. Go Tani, por suas críticas e sugestões feitas ao trabalho nas reuniões do LACOM e no Exame de Qualificação;

À Prof a Dr. ${ }^{a}$ Lilian Gobbi, por sua disponibilidade e pelas sugestões;

Aos amigos do grupo de mestrado João Santana, In memoriam, Sérgio, Marcos, Pedro, Lucília, Dourado, Giana, Kátia, Gustavo, Gladys e Cristiane pelo apoio mútuo e também pelas risadas que demos;

Ao Prof. Ms. Décio Barbosa de Souza e ao Prof. Dr. Valdir José Barbanti pelo irrestrito apoio ao Mestrado Interinstitucional UEL/USP;

Ao Prof. Ms. Luiz Cláudio e ao CENESP/UEL pela prontidão com que me atenderam e pelo material colocado à minha disposição;

À Prof a Ms. Maria Nilce Missel pelo incentivo e auxílio; 
Aos amigos do LACOM (Andrea, Andréa Cosolino, Cássia, Cássio, Dalton, Milena, Umberto, Herbert Welber, Suely, Kika e Regina), e à Luciana do Departamento de Pedagogia do Movimento do Corpo Humano;

À Inara e ao Chico, amigos que vim a conhecer melhor e cuja hospitalidade e amizade pude desfrutar;

Ao Luciano Basso, pelo auxílio nas infindáveis discussões sobre estatística;

Ao Roberto e família (Antônio e Dina) pela calorosa acolhida que tive em São Paulo;

À Anunciata, João Vermelho, Júnior e Rosa pelas sempre benvindas caronas;

Ao meu irmão Sérgio a Madalena, as sobrinhas Muriel e Stael e ao Marcos Locatelli pela colaboração quando da coleta de dados;

Aos professores e funcionários da Piraju Escola de Natação, que mantiveram o trabalho "em dia" durante o período em que estive ausente;

Ao Francisco, à Karina, aos acadêmicos Adevane, Carlos Fabrícia, Karina, Fernanda, Angélica, e ao João Guilherme e Luiz Ernani, pela participação na coleta de dados;

À tia Gertrudes, pela hospitalidade e pelas informações precisas sobre São Paulo no inicio desta empreitada;

Aos meus pais, Ernani e Zulma pelas orações e pelos conselhos de toda uma vida e ao querido "vô" Florindo por suas preocupações. 


\section{SUMÁRIO}

LISTA DE TABELAS ............................................. va. vi

LISTA DE FIGURAS............................................. ix

LISTA DE QUADROS.......................................... $\quad x$

LISTA DE ANEXOS....................................................

LISTA DE SIGLAS E SÍMBOLOS............................... xi

RESUMO .................................................................. xii

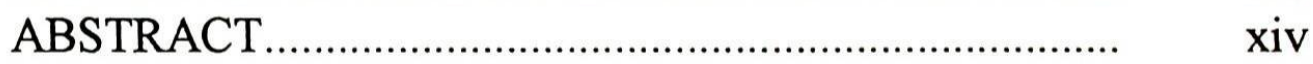

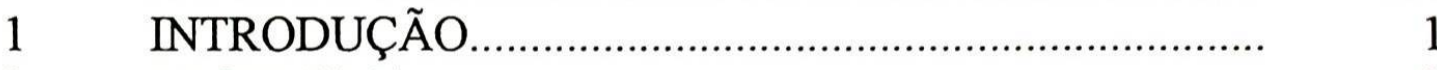

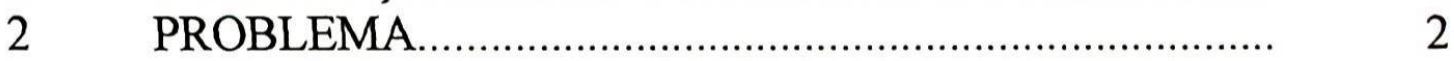

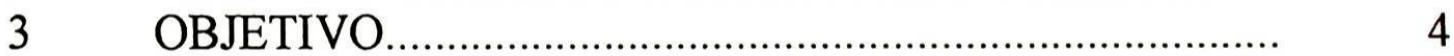

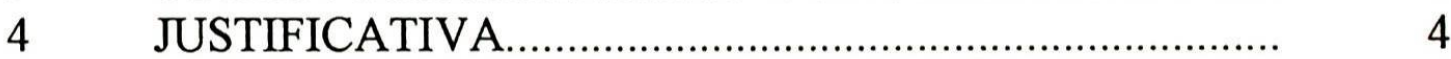

$5 \quad$ REVISÃO DA LITERATURA …….............................. 5

5.1 O estudo do desenvolvimento motor.................................. 5

5.2 Habilidades motoras e restrições..........................................

5.3 O desenvolvimento do nadar na primeira infância.............. 14

5.4 Análise da tarefa nadar.................................................. 27

$6 \quad$ QUESTÕES DE ESTUDO........................................... 28

$7 \quad$ MÉTODO

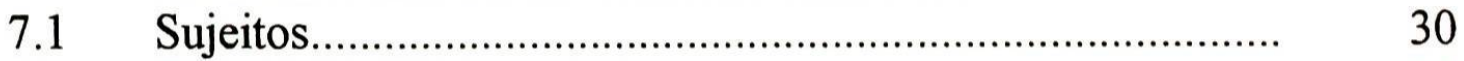

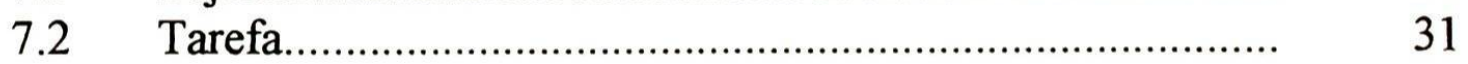

7.3 Procedimentos............................................................ 34

7.4 Níveis de desenvolvimento aquático modificado............... 35

$7.5 \quad$ Análise estatística......................................................... 38

$8 \quad$ RESULTADOS .......................................................... 39

8.1 Distribuição a amostra nos níveis de desenvolvimento aquático na condição 1 ....................................................... 39

8.2 Transições entre C1e C2 ................................................. 44

8.3 Transições entre $\mathrm{C} 1$ e C3 ................................................... 47

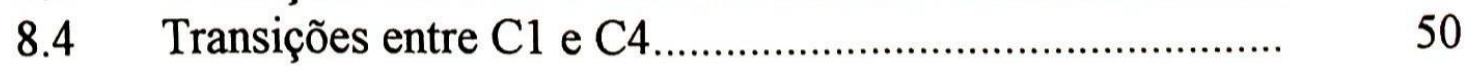

8.5 Comentários gerais sobre as condições em relação à 53

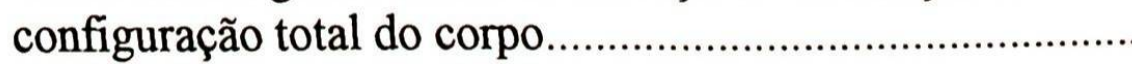

8.6 Análise por componentes. 
8.6.1 Posição do corpo............................................................. 54

8.6.2 Ação do braço............................................................... 57

8.6.3 Recuperação do braço.......................................................... 61

8.6.4 Ação da perna.................................................................. 65

8.6.5 Índice de consistência (IC) nas diferentes condições do

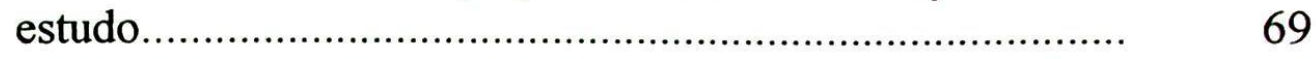

8.7 Análise dos parâmetros da ação......................................... 73

8.7.1 Comprimento médio da braçada......................................... 73

8.7.2 Freqüência média da braçada.............................................. $\quad 76$

8.7.3 Número de ciclos de braçada............................................... 79

8.7 .4 Velocidade...................................................................... $\quad 82$

8.8 Análise comparativa das medidas qualitativas e quantitativas........................................................ 90

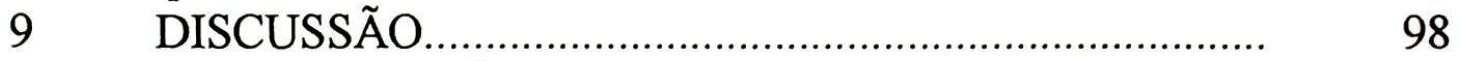

10 CONSIDERAÇÕES FINAIS............................................ 101 REFERÊNCIAS BIBLIOGRÁFICAS.............................. 104

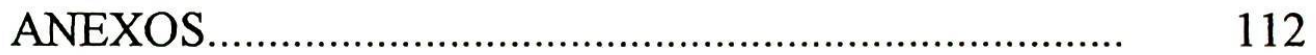




\section{LISTA DE TABELAS}

Página

TABELA 1 - Média de idade em meses e porcentagem por sexo da amostra.

TABELA 2 - Tempo de experiência e número de sujeitos.

TABELA 3 - Tempo de experiência e número de sujeitos no nível de desenvolvimento N7 por sexo.

TABELA 4 - Tempo de experiência e número de sujeitos no nível de desenvolvimento N6 por sexo.

TABELA 5 - Tempo de experiência e número de sujeitos no nível de desenvolvimento $\mathrm{N} 5$ por sexo.

TABELA 6 - Tempo de experiência e número de sujeitos no nível de desenvolvimento N4 por sexo.

TABELA 7 - Tempo de experiência e número de sujeitos no nível de desenvolvimento $\mathrm{N} 3$ por sexo.

TABELA 8 - Tempo de experiência e número de sujeitos no nível de desenvolvimento $\mathrm{N} 2$ por sexo.

TABELA 9 - Alterações no nível de desenvolvimento aquático na $\mathrm{C} 1$ para C2.

TABELA 10 - Alterações no nível de desenvolvimento aquático na $\mathrm{C} 1$ para C3

TABELA 11 - Alterações no nível de desenvolvimento aquático na $\mathrm{C1}$ para C2

TABELA 12 - Variações no comportamento ação dos braços nos grupos e condições

TABELA 13 - Ação do braço e o nível de significância nas diferentes condições do estudo.

TABELA 14 - Variação do componente recuperação do braço nos grupos e condições. 
TABELA 15 - Variação do compnente ação da perna nos grupos e condições. 66

TABELA 16 -Total de sujeitos por ïndice de consistência na C1. 70

TABELA 17 - Freqüência de indivíduos por grupo com $\mathrm{IC}=0,6$ nas condições do estudo .70

TABELA 18 - Freqüência de indivíduos por grupo com $\mathrm{IC}=0,8$ nas condições do estudo 71

TABELA 19 - Freqüência de indivíduos por grupo com IC =1,0 nas condições do estudo .72

TABELA 20 - Comprimento médio da braçada no nível 7 (m)....................... 74

TABELA 21 - Comprimento médio da braçada no nível $6(\mathrm{~m}) \ldots \ldots \ldots \ldots \ldots \ldots \ldots . . . . . . . . . . . .74$

TABELA 22 - Comprimento médio da braçada no nível $5(\mathrm{~m}) \ldots \ldots \ldots \ldots \ldots \ldots \ldots . . . . . . . . . . . . . .75$

TABELA 23 - Comprimento médio da braçada no nível 4 (m)...................... 75

TABELA 24 - Comprimento médio da braçada no nível $3(\mathrm{~m}) \ldots \ldots \ldots \ldots \ldots \ldots \ldots . . . . . . . . . . . . .75$

TABELA 25 - Comprimento médio da braçada no nível $2(\mathrm{~m}) \ldots \ldots \ldots \ldots \ldots \ldots \ldots . . . . . . . . . . . . .76$

TABELA 26 - Freqüência média de braçadas no nível 7 ( $\mathrm{n}^{\circ} \mathrm{de}$ repetições).

TABELA 27 - Freqüência média de braçadas no nível $6\left(n^{\circ}\right.$ de repetições).

TABELA 28 - Freqüência média de braçadas no nível $5\left(\mathrm{n}^{\circ} \mathrm{de}\right.$ repetições).

TABELA 29 - Freqüência média de braçadas no nível 4 (nº de repetições).

TABELA 30 - Freqüência média de braçadas no nível 3 ( $\mathrm{n}^{\circ}$ de repetições). .78

TABELA 31 - Freqüência média de braçadas no nível 2 ( $\mathrm{n}^{\circ}$ de repetições). .78

TABELA 32 - Número de ciclos por segundo no nível 7 nas condições de estudo. 
TABELA 33 - Número de ciclos por segundo no nível 7 nas condições de estudo.

TABELA 34 - Número de ciclos por segundo no nível 5 nas condições de estudo. 80

TABELA 35 - Número de ciclos por segundo no nível 4 nas condições de estudo.

TABELA 36 - Número de ciclos por segundo no nível 3 nas condições de estudo.

TABELA 37 - Número de ciclos por segundo no nível 2 nas condições de estudo.

TABELA 38 - Velocidade média $(\mathrm{m} / \mathrm{s})$ no nível 7. 83

TABELA 39 - Velocidade média $(\mathrm{m} / \mathrm{s})$ no nível 6. 83

TABELA 40 - Velocidade média $(\mathrm{m} / \mathrm{s})$ no nível 5 . ...................................... 84

TABELA 41 - Velocidade média $(\mathrm{m} / \mathrm{s})$ no nível 4 ....................................... 84

TABELA 42 - Velocidade média $(\mathrm{m} / \mathrm{s})$ no nível 3....................................... 84

TABELA 43 - Velocidade média (m/s) no nível 2...................................... 85

TABELA 44 - Comparação da distribuição das migrações dos níveis de desenvolvimento entre $\mathrm{C} 1$ e $\mathrm{C} 2$

TABELA 45 - Comparação da distribuição das migrações dos níveis de desenvolvimento entre $\mathrm{C} 1$ e $\mathrm{C} 3$ 92

TABELA 46 - Comparação da distribuição das migrações dos níveis de desenvolvimento entre $\mathrm{C} 1$ e $\mathrm{C} 4$..... 


\section{LISTA DE FIGURAS}

Página

FIGURA 1 - Modelo de desenvolvimento aquático de McGRAW adaptado de LANGENDORFER \& BRUYA (1995) ................... 16

FIGURA 2 - Modelo de desenvolvimento aquático deERBAUGH adaptado de LANGENDORFER \& BRUYA (1995)

FIGURA 3 - Modelo de desenvolvimento aquático deOKA et al. adaptado de LANGENDORFER \& BRUYA (1995)

FIGURA 4 - Modelo de desenvolvimento aquático de LANGENDORFER \& BRUYA (1995) 22

FIGURA 5 - Distribuição dos sujeitos na condição $\mathrm{C} 1$ 44

FIGURA 6 - Velocidade $(\mathrm{m} / \mathrm{s})$ dos grupos na condição $\mathrm{C} 1$ 86

FIGURA 7 - Velocidade $(\mathrm{m} / \mathrm{s})$ dos grupos na condição C2 87

FIGURA 8 - Velocidade $(\mathrm{m} / \mathrm{s})$ dos grupos na condição C3 88

FIGURA 9 - Velocidade $(\mathrm{m} / \mathrm{s})$ dos grupos na condição C4 89 


\section{LISTA DE QUADROS}

Página

QUADRO 1 - Análise geral da tarefa nadar 28

QUADRO 2 - Níveis de desenvolvimento aquático e condições experimentais

QUADRO 3 - Migração dos sujeitos na condição 2 em número e porcentagem.

QUADRO 4 - Migração dos sujeitos na condição 3 em número e porcentagem

QUADRO 5 - Migração dos sujeitos na condição 4 em número e porcentagem. 50

QUADRO 6 - Alterações dos componentes nos níveis C1 vs. C2 96

QUADRO 7 - Alterações dos componentes nos níveis $\mathrm{C} 1$ vs. $\mathrm{C} 3$ 97

QUADRO 8 - Alterações dos componentes nos níveis Clvs. C4 98 


\section{LISTA DE ANEXOS}

Página

ANEXO I - Lista de confrência de prontidão aquática ................................. 108

ANEXO II - Como usar a lista de de conferência ARA para obter objetividade e consistência ................................................... 112

ANEXO III - Ficha de registro e análise de dados........................................... 113

ANEXO IV - Tabela de classificação dos níveis de desenvolvimento ............. 115

ANEXO V - Classificação dos níveis adaptado de ROBERTON (1977)

ANEXO VI - Ambiente do experimento 


\section{LISTA DE SIGLAS ABREVIATURAS E SÍMBOLOS}

\begin{tabular}{|c|c|}
\hline & \\
\hline V1 & - Nadar em velocidade natural \\
\hline V2 & - Velocidade em velocidade máxima \\
\hline DIR 1 & - Nadar em linha reta \\
\hline DIR 2 & - Nadar contornando obstáculos \\
\hline V1DIR1 & - Nadar em velocidade natural em linha reta \\
\hline V1 DIR 2 & $\begin{array}{l}\text { - Nadar em velocidade natural mudando de } \\
\text { direção }\end{array}$ \\
\hline V2DIR1 & - Nadar em velocidade máxima em linha reta \\
\hline V2DIR 2 & $\begin{array}{l}\text { - Nadar em velocidade máxima mudando de } \\
\text { direção. }\end{array}$ \\
\hline N1 & - NÍVEL 1 \\
\hline $\mathrm{N} 2$ & - NÍVEL 2 \\
\hline N3 & - NÍVEL 3 \\
\hline N4 & - NÍVEL 4 \\
\hline N5 & - NÍVEL 5 \\
\hline N6 & - NÍVEL 6 \\
\hline N7 & - NÍVEL 7 \\
\hline N8 & - NÍVEL 8 \\
\hline $\mathrm{Cl}$ & - Condição 1 \\
\hline $\mathrm{C} 2$ & - Condição 2 \\
\hline $\mathrm{C} 3$ & - Condição 3 \\
\hline $\mathrm{C} 4$ & - Condição 4 \\
\hline Seg. & - Segundo \\
\hline $\mathrm{PC}$ & - Posição do corpo \\
\hline $\mathrm{AB}$ & - Ação do braço \\
\hline $\mathrm{RB}$ & - Recuperação do braço \\
\hline AP & - Ação da perna \\
\hline IC & - Índice de consistência \\
\hline $\mathrm{CMB}$ & - Comprimento médio da braçada \\
\hline FMB & - Freqüência média de braçada \\
\hline N. ${ }^{\circ}$ de CI & - Número de ciclos por segundo \\
\hline VM & - Velocidade média \\
\hline
\end{tabular}


RESUMO

O EFEITO DAS RESTRIÇÕES DA TAREFA E DO AMBIENTE NO COMPORTAMENTO DE LOCOMOÇÃO AQUÁTICA

\author{
Autor: ERNANI XAVIER FILHO \\ Orientador: PROF. DR. EDISON DE JESUS MANOEL
}

Várias restrições (ambientais, organísmicas, da tarefa) condicionam os padrões de coordenação motora, pouco se sabe sobre seus efeitos na habilidade nadar. Com esse fim, foi desenvolvida uma pesquisa com cinqüenta e seis indivíduos com idade variando de 72 a 144 meses. Eles foram subdivididos em sete grupos de acordo com seu desempenho numa tarefa de locomoção aquática realizada sem pressão do tempo e numa distância de oito metros. Três tarefas experimentais foram criadas a partir dessa onde manipulou-se uma restrição da tarefa (velocidade de locomoção) e uma restrição ambiental (colocação de obstáculos no trajeto). Quatro aspectos merecem destaques nos resultados: a) houve uma tendência para a permanência no estado de desenvolvimento ao longo das condições; b) quando houve mudança, ela ocorreu em função da restrição ambiental levando a padrões rudimentares da locomoção; c) o estado de desenvolvimento apresentado inicialmente só se associou a uma maior capacidade de adaptação na tarefa que combinava mudança de direção e velocidade, nesse caso, os indivíduos mais avançados apresentavam mudanças tanto no seqüenciamento quanto nos parâmetros; d) quando só a velocidade foi aumentada, as mudanças ficaram circunscritas aos parâmetros da ação.

Palavras chave: Nadar; nível de desenvolvimento; restrições; comportamento motor 


\begin{abstract}
THE EFFECT OF TASK AND ENVIRONMENTAL CONSTRAINTS UPON AQUATIC LOCOMOTORY BEHAVIOR
\end{abstract}

\author{
Author: ERNANI XAVIER FILHO \\ Adviser: PROF. DR. EDISON DE JESUS MANOEL
}

There are many constraints (environmental, organismic and task) acting upon patterns of motor coordination, though their effects on swimming is less known. To this end, a research was carried out with fifty-six subjects, age varying from 72 to 144 months. They were divided in seven subgroups according to their performance in an aquatic locomotory task performed without time pressure and over a distance of eight meters. The experimental tasks were created from the original task in which task (change maximum speed) and environmental (obstacles in the path) constraints were manipulated. Four aspects are worth pinpointing in the results: a) the main trend was one of permanence with the same developmental status along the tasks; b) when behaviour changes this occurred due to the environmental constraint leading to more rudimentary patterns of aquatic locomotion; c) the developmental status presented initially was associated to a greater adaptive capacity in the task combining changing direction and speed, in this case subjects with more advanced developmental status presented changes in sequencing as well as parameters; d) when only speed was increased, behaviour changes were restricted to the parameters.

Keywords: Swimming, developmental status, constraints, motor behaviour. 


\section{INTRODUÇÃO}

Os padrões de locomoção humana têm sido objeto de grande interesse no estudo do desenvolvimento motor. Os trabalhos objetivam descrever fatos associados à emergência e aquisição da locomoção bipedal (McGRAW, 1945; THELEN, 1986) assim como o seu aperfeiçoamento ao longo da primeira infância (BRIL \& BRENIĖRE, 1993). Ao contrário, pouco se conhece sobre o desenvolvimento da locomoção aquática.

Data da primeira metade do século o registro de estudos voltados para a descrição do nadar. O principal interesse era buscar explicações para a gênese do comportamento motor aquático de bebês e crianças. Por exemplo, WATSON (1919) defendia que essa aquisição seria condicionada pelo ambiente. Já McGRAW (1939) atribuía à maturação um papel central na regulação desse desenvolvimento.

É interessante notar que WATSON (1919) não observou qualquer comportamento organizado do bebê na água, enquanto McGRAW (1939) encontrou padrões de locomoção e controle respiratório bem definidos. Uma diferença importante entre esses dois estudos referia-se ao modo como os bebês foram introduzidos na água. WATSON (1919) os introduziu em decúbito dorsal enquanto McGRAW (1939), em decúbito ventral.

Os dados obtidos por WATSON (1919) e McGRAW (1939) sugerem que, independentemente do modelo a ser adotado para a explicação desse comportamento, deve-se considerar a relação do organismo com a tarefa e o ambiente.

A abordagem desenvolvimentista do nadar preconiza a existência de uma sequiência de desenvolvimento motor organizada de maneira progressiva, e 
comum a todos os sujeitos (LANGENDORFER \& BRUYA, 1995). Entretanto, as características da seqüência e os marcos comportamentais que definem cada estágio estão sujeitos às variações em razão da forma como as restrições da tarefa do ambiente e do organismo interagem (NEWELL,1986).

$\mathrm{O}$ presente projeto de pesquisa focaliza os efeitos das restrições da tarefa e do ambiente no desempenho das habilidades aquáticas em indivíduos com diferentes niveis de desenvolvimento da habilidade nadar.

\section{PROBLEMA}

Há duas explicações para o entendimento de como se dá o desenvolvimento motor no meio aquático. A versão tradicional sugere que o desenvolvimento seria fruto da maturação das estruturas do sistema nervoso central com conseqüência direta na produção de movimentos. Originalmente essa idéia foi colocada por GESELL na década de 20, mas foi McGRAW (1945) quem adotou uma postura mais radical ao afirmar que o desenvolvimento do comportamento se reduziria às alterações neurológicas (THELEN, 1987).

A transição de movimentos reflexos para movimentos voluntários era explicada por McGRAW (1945) a partir de uma mudança de controle do nível subcortical para o cortical na execução motora. Como veremos adiante, foi essa explicação que McGRAW (1939) utilizou ao descrever o desenvolvimento do nadar na primeira infância.

GESELL (1946) destacou a regularidade nas mudanças ao propor uma série de princípios que regem o desenvolvimento, como o da direção céfalocaudal e próximo-distal da auto-regulação flutuatória, além da própria maturação. 
A conseqüência desse posicionamento teórico foi a minimização do papel da experiência no desenvolvimento, confirmada por alguns estudos realizados nos anos 30 e 40. Foi só a partir dos anos 60 que o papel quase hegemônico da maturação foi questionado. Desde então, houve a gradual aceitação de uma concepção mais integrada da maturação e da experiência no processo de desenvolvimento motor (CONNOLLY, 1970).

O desenvolvimento concretizar-se-ia com a experiência do indivíduo no seu ambiente (MANOEL, 1999). A experiência canalizaria uma série de processos desde o nível genético até o social resultando na organização do comportamento orientado ao contato do indivíduo com o seu meio. Haveria, portanto, uma cadeia de influências recíprocas entre o nível genético e o celular, da célula para o órgão e desse para o comportamento (MANOEL, 1999). A investigação da atuação das restrições da tarefa e do organismo no comportamento se sustenta com essa fundamentação teórica.

NEWELL \& van EMERIK (1990) adotaram uma posição radical em relação aos estágios e fases de desenvolvimento motor. Eles afirmam que as seqüências de desenvolvimento identificadas nos últimos 60 anos devem muito mais às particularidades da tarefa e do ambiente em que os indivíduos foram testados e observados. Isso significaria que as alterações da tarefa e do ambiente em conjunção com restrições organísmicas levariam à modificação das seqüências.

A congruência entre dados de pesquisas sobre desenvolvimento motor e modelos teóricos elaborados para explicar esse processo indicam que as seqüências de desenvolvimento motor não devem ser vistas de forma absoluta, mas de forma relativa, ou seja, as fases ou estágios que a compõem são de natureza probabilística, pois sofrem influências de fatores ambientais, da tarefa e do organismo (ROBERTON, 1982). Dessa forma, a identificação dos efeitos 
dessa interação sobre os componentes das habilidades motoras em indivíduos que estariam supostamente em diferentes níveis de desenvolvimento pode fornecer subsídios que auxiliem na compreensão do desenvolvimento motor de uma forma geral e do desenvolvimento motor aquático em particular.

\section{OBJETIVO}

O presente estudo visa investigar como a habilidade nadar é influenciada por variações nas restrições da tarefa e do ambiente. Além disso, tem-se o propósito de verificar se o estado de desenvolvimento motor aquático é condicionado por essas restrições.

\section{JUSTIFICATIVA}

Como o desenvolvimento motor já não é mais visto como um processo determinado exclusivamente pela maturação, fica mais evidente a necessidade de identificar quais as características dos sujeitos que compõem a experiência na aquisição dos padrões motores no meio aquático.

Assim, o entendimento de como fatores do organismo, meio ambiente e tarefa interferem na formação de padrão tem um interesse acadêmico e prático. O interesse acadêmico reside na tentativa de compreender como o estado de desenvolvimento motor é maleável diante de condições da tarefa e do ambiente (LANGENDORFER \& BRUYA, 1995). O interesse prático reside no fato de que o conhecimento sobre como o indivíduo se organiza perante esses fatores pode fornecer subsídios sobre como estruturar a tarefa e o ambiente nos programas de natação oferecidos à população em geral. 
Na busca de uma definição do que seja desenvolvimento motor um conceito é central: o de mudança. Para HAYWOOD (1993), o desenvolvimento motor corresponde a um processo de mudanças que se inicia na concepção e que continua até o final da vida do indivíduo. As mudanças são de natureza qualitativa implicando a aquisição de habilidades de orientação, locomoção e manipulação.

CLARK \& WHITALL (1989) descreveram quatro períodos no estudo do desenvolvimento motor: Precursor (1797-1928), Maturacional (19281946), Normativo Descritivo (1946-1970) e, finalmente, Orientado ao Processo (1970 até os dias atuais).

No Periodo Precursor, o estudo do desenvolvimento motor não era sistemático, sendo mais caracterizado pela descrição de comportamentos de bebês e crianças. É o período no qual se encontram as famosas biografias de bebês. Escritos entre os séculos XVII e XIX, esses trabalhos buscavam desvendar as origens do desenvolvimento humano.

No Periodo Maturacional, sob a influência da Biologia e da Embriologia, os estudos de desenvolvimento motor apresentaram um rápido crescimento. O desenvolvimento era visto como resultado direto da maturação de estruturas do sistema nervoso. A aprendizagem e a aculturação eram influências consideradas secundárias no desenvolvimento. Nesse periodo, os trabalhos publicados passaram das descrições individuais do comportamento de bebês para estudos em grupos, tendo como alicerce a crença de que o desenvolvimento motor envolvia o aparecimento de forma regular e padronizada. Autores como 
GESELL, McGRAW, SHIRLEY e outros produziram dados que, tomados em conjunto, levaram à identificação de seqüências universais de desenvolvimento. De acordo com CLARK \& WHITALL (1989), são dessa época as melhores informações que se têm sobre mudanças de comportamento motor dos bebês e de crianças até os cinco anos de idade.

Os estudos no Periodo Normativo Descritivo continuaram a ser influenciados pela hipótese maturacional. Entretanto, há pelo menos duas diferenças em relação ao período anterior. Primeiro, os pesquisadores, em sua maioria, eram professores de Educação Física com interesse na investigação de habilidades motoras de crianças em idade escolar (sete aos dezoito anos de idade). Segundo, as pesquisas passaram a enfocar o desenvolvimento motor "per se", ou seja ele deixou de ser visto apenas como uma etapa do desenvolvimento cognitivo ou do desenvolvimento em geral. Durante esse período foram descritas e propostas as "seqüências de desenvolvimento motor" das habilidades básicas ou padrões fundamentais de movimento. Os estudos descritivos também procuravam correlacionar a performance motora com o crescimento fisico.

O Periodo Normativo Descritivo não foi pródigo em inovações teóricas no estudo do desenvolvimento; entretanto, a preocupação em correlacionar medidas antropométricas e desempenho nas habilidades motoras antecipou uma tendência atual capitalizada pela abordagem dos sistemas dinâmicos.

A grande "virada" no estudo do fenômeno desenvolvimento motor se deu no início da década de 70 , com a revisão do papel da maturação e a adoção da abordagem de processamento de informações na investigação desse processo (cf. CONNOLLY, 1970). Isso restabeleceu o interesse dos pesquisadores pelo desenvolvimento das habilidades motoras. CLARK \& WHITALL (1989) denominaram esse período de Abordagem Orientada ao 
Processo. O comportamento motor passou a ser visto como resultado de processos de percepção, planejamento, memória, programação e feedback. Assim, o desenvolvimento motor resultaria de mudanças em cada um desses processos ( cf. KEOGH, 1977; THOMAS, 1980).

$\mathrm{Na}$ abordagem orientada ao processo, as dicotomias maturação contraposta à experiência, inato contraposto a adquirido começaram a ser postas de lado em favor de uma visão mais integrada entre organismo e ambiente. $O$ desenvolvimento motor até então era explicado por um determinismo genético (vide a hipótese maturacional); a partir daí passa a ser entendido como um processo sob a influência de várias causas cujas origens vão desde o gene até o ambiente (FORD \& LERNER, 1992).

Atualmente, o desenvolvimento motor é descrito como um processo em que se alternam estados de estabilidade e instabilidade em direção a uma maior complexidade. Num dado momento o comportamento resulta da combinação de diferentes subsistemas cuja taxa de mudança é diversa. As alterações em alguns desses subsistemas podem desencadear alterações macroscópicas no sistema levando a modificações qualitativas na organização do comportamento. A seqüência de desenvolvimento motor identificada por tantos pesquisadores no passado seria resultante da interação de diferentes subsistemas ao invés de serem causadas única e exclusivamente pela maturação.

Habilidades motoras e restrições

As mudanças do comportamento motor foram sempre atribuídas a uma única causa, a maturação. NEWELL (1986) tem preconizado que, além da maturação, a seqüência de desenvolvimento é resultado da atuação de vários fatores. NEWELL lança mão do conceito de "restrição"( do inglês "constraints") 
para explicar como isso ocorreria. Restrições condicionam as possiveis configurações de um sistema. Uma restrição sobre a ação motora é definida como uma redução no número de graus de liberdade independentemente do mecanismo de redução (VEREIJKEN \& BONGAARDT, 1999). Segundo NEWELL (1986), as restrições se originam: a) no organismo, b) no ambiente, c) na tarefa.

As restrições organísmicas podem ser estruturais (por exemplo, peso corporal, altura, proporções de segmentos corporais, etc.) e funcionais (por exemplo, maturação do sistema nervoso, motivação, etc.). As restrições ambientais são aquelas presentes no local onde a ação está sendo executada, como as forças fisicas externas ao sujeito (força de gravidade, iluminação, calor, densidade do meio onde o indivíduo se encontra etc.). As restrições da tarefa dizem respeito a imposições sobre a forma da execução para que seja possível alcançar o objetivo da tarefa. NEWELL (1986) classificou as restrições na tarefa em três categorias: a) meta da tarefa; b) regras que impõem especificações ou restringem a dinâmica das respostas; c) implementos ou máquinas que restringem a dinâmica das respostas.

Como já foi colocado anteriormente, NEWELL \& van EMERIK (1990) afirmam que as tradicionais seqüências de desenvolvimento motor descritas em estudos clássicos dos anos 30 e 40 seriam resultantes da forma particular com que as restrições do organismo, ambiente e tarefa, foram arranjadas. Pouco se sabe ainda sobre o impacto das restrições na tarefa em interação com as restrições do organismo no processo de desenvolvimento. Entretanto, alguns estudos têm procurado mapear as influências das restrições da tarefa e ambientais na organização das habilidades motoras básicas (por exemplo LANGENDORFER， 1987a; MARQUES, 1995; OLIVEIRA， 1997; ROBERTON, 1987). 
Ainda que seja possível reconhecer a importância da coordenação e do controle nas ações habilidosas, nem todas as correntes que explicam o desenvolvimento motor dão o mesmo valor às restrições na construção dos padrões de coordenação.

OLIVEIRA (1997) afirma que, com as restrições, o papel da prescrição exercido pelos programas motores é minimizado, uma vez que elas atuariam na redução dos graus de liberdade do sistema para torná-lo mais eficiente e manejável com respeito ao controle. Quando as restrições são alteradas, ocorrem mudanças nos padrões de coordenação que, por sua vez, acarretarão mudanças desenvolvimentistas.

Contudo, quando se trata de associar restrições ao desenvolvimento, é importante que se faça uma distinção na maneira como as restrições atuam entre duas situações: a) restrições que criam condições ou dão suporte para que uma capacidade latente se manifeste levando a um padrão de coordenação que, no entanto se desmantela, uma vez que a restrição é retirada ou modificada, b) restrições que geram novos padrões, os quais permanecem mesmo quando elas deixam de exercer influência. A primeira forma de atuação pode ser ilustrada pelo estudo de von HOFSTEN (1993). Nesse trabalho, bebês com idade variando entre seis e oito meses foram colocados em uma cadeira especial que fixava o seu tronco criando um controle artificial da postura. Nessa condição, a freqüência de movimentos manuais para a interceptação de uma bola em movimento aumentaram. Entretanto, quando os bebês são retirados desse aparato e retornam à posição de decúbito dorsal, a freqüência e a qualidade de movimentos manuais diminuem. Ou seja, o experimentador conseguiu "criar" um nível de desenvolvimento avançado no subsistema postura levando à emergência de comportamentos organizados de busca e preensão manual de objetos. 
Em relação à segunda situação temos estudos sobre a marcha prélocomotora em bebês. Quando os bebês são colocados e sustentados pela cintura numa esteira motorizada eles apresentam passadas alternadas. Num experimento realizado com nove bebês a partir de um mês de idade, o estímulo para a marcha foi dado com alterações na velocidade da esteira (THELEN \& ULRICH, 1991). Como resultado, todas as crianças testadas apresentaram rápida melhora na performance entre o terceiro e o sexto mês, demonstrando também melhora nos ajustes do padrão de coordenação das pernas quando eles eram submetidos a diferentes velocidades. Esse experimento mostrou que a estimulação da marcha pré-locomotora em esteiras favoreceria o aparecimento da marcha independente entre o sexto e o décimo segundo mês. O desenvolvimento poderia ser caracterizado pelo aumento da variabilidade e sensibilidade quando da introdução das restrições e sua posterior retirada (THELEN \& ULRICH, 1991).

Segundo MANOEL \& CONNOLLY (1997), um dos aspectos importantes para o desenvolvimento refere-se à construção de estruturas cognitivas, como sub-rotinas, programas motores, esquemas, entidades que de alguma forma dirigem a organização e a produção de padrões de movimento. Dessa forma, outra fonte de restrição a ser considerada refere-se à interação entre a intenção e a realização de resultados ambientais que se concretiza mediante a implementação de um programa de ação. A intenção, unida a um programa de ação, pode representar uma restrição ao comportamento motor, atuando da mesma forma como as outras restrições (MANOEL, 1999). Segundo CHOSHI (2000), estudar como essas restrições internas são construídas com a prática e a experiência é uma das principais metas para o estudo da aquisição de habilidades motoras.

As restrições internas são construídas pelo sujeito a partir de sua experiência na tarefa motora. Ela reflete a compreensão que o indivíduo tem 
sobre a relação entre meio e fim numa dada ação. MANOEL \& OLIVEIRA (2000) consideram que os tradicionais estágios de desenvolvimento motor para os padrões fundamentais de movimento seriam dependentes também desse tipo de restrição. Esses autores investigaram o comportamento do arremesso em que crianças foram colocadas em duas situações, arremessar à distância e a um alvo. Os resultados indicaram que enquanto a mudança de objetivo da tarefa, do arremesso à distância para o alvo, ocasionou uma modificação descendente nos níveis de desenvolvimento dos componentes do arremesso na maioria dos sujeitos, isso não ocorreu de forma mais marcante nas crianças mais avançadas (no estágio maduro). Isso explicaria, por exemplo, o baixo desempenho (escore obtido) dessas crianças no arremesso ao alvo. Elas acabaram utilizando um padrão de arremesso pouco ajustado às demandas da tarefa. Elas reduziram poucos graus de liberdade diante das demandas de precisão na tarefa de arremesso ao alvo. Esse resultado indica alguns pontos que merecem atenção. Primeiro, as crianças com um padrão avançado no arremesso à distância, apresentaram um padrão inadequado para o arremesso ao alvo. Isso sugere que o estágio maduro no qual elas foram classificadas está superestimando o seu estágio de desenvolvimento motor. Segundo, a alteração na restrição da tarefa (distância para alvo) não foi suficiente para modificar o padrão de arremessar na dimensão exigida. Esses aspectos indicam que a construção da restrição interna, expressa na formação de uma programa de ação, pode desempenhar um papel crucial no desenvolvimento motor. A crescente influência da abordagem dos sistemas dinâmicos fez com que o papel de representações mentais fosse minimizado ao extremo. Talvez o total abandono das representações seja no mínimo prematuro para explicar a organização de habilidades motoras. 
Dessa forma, o estudo sobre os efeitos das restrições nos padrões de movimento deve compreender também o papel da intenção e a forma com que programas de ação são elaborados.

BARELA \& BARELA (1997) propõem que uma maneira de examinar como as restrições estão de fato influenciando o comportamento motor seria verificar o grau de estabilidade dos padrões observados. O aumento ou a diminuição da estabilidade do comportamento estariam associados a momentos diferentes no desenvolvimento. Maior instabilidade no comportamento é indicativo de que o indivíduo está prestes a transitar para um novo estado de desenvolvimento.

Comentando a capacidade dos sujeitos para modificar o comportamento em face das restrições, MANOEL \& PELLEGRINI (1985) apontam que essa capacidade estaria relacionada ao estágio de desenvolvimento motor dos sujeitos. Aqueles que estivessem em níveis mais avançados teriam maiores condições de manipular os seus graus de liberdade e, por conseguinte, de promover mais ajustes no comportamento. Visão semelhante do problema é oferecida por ROBERTON (1987) e LANGENDORFER (1987a, 1990) quando comentam as dificuldades que os iniciantes apresentam para ajustar os seus comportamentos.

A aquisição de um estado avançado no padrão fundamental de movimento pode ser caracterizado por dois tipos de mudanças denominados por KEOGH (1978) como: ganho de consistência e constância. O ganho de consistência reflete um processo gradual de definição do plano motor. Inicialmente, a criança não sabe exatamente como realizar a tarefa, por isso seu comportamento é muito inconsistente. Gradualmente, ela descobre o meio mais apropriado para a solução motora e, assim, busca sempre repetir o mesmo padrão de movimento. Uma vez que a mesma resposta passa a ser realizada de forma 
consistente, a criança começa a variar o padrão do movimento, ou seja, variações passam a ser introduzidas dentro do plano motor. Essas variações qualificam a constância motora, cujo ganho permite maior flexibilidade para adequar-se às exigências de novas tarefas e situações desconhecidas (KEOGH, 1978). Parece haver uma relação de correspondência entre consistência e constância, entre flexibilidade e padronização no desenvolvimento (KEOGH \& SUGDEN, 1995).

A formação de uma programa de ação (refletida no ganho de consistência) e a capacidade de gerar variações no programa de ação (refletida no ganho de constância) correspondem a um processo influenciado pela forma com que as restrições da tarefa, do ambiente e do organismo, interagem. Para entender esse processo, um aspecto importante seria considerar a relação entre as estruturas da tarefa e do desenvolvimento motor. HIGGINS \& SPAETH (1972) foram os primeiros a destacar o papel das restrições na formação de padrões. Esses autores indicaram a importância de efetuar uma análise das demandas e fatores da tarefa em relação ao estado de desenvolvimento motor do indivíduo. HERKOWITZ (1978) procurou mostrar uma forma operacional para conduzir essa análise, identificando primeiro os fatores que compõem uma dada tarefa motora (Análise Geral da Tarefa). Na seqüência, são estabelecidos níveis, do simples para o complexo, em cada fator (Análise Específica da Tarefa). Por exemplo, na tarefa de rebater encontram-se fatores relevantes como tamanho do implemento a ser utilizado, tamanho do objeto a ser propulsionado e a previsibilidade de sua trajetória. Com a enumeração desses fatores, pôde-se identificar os seus níveis e verificar que a tarefa de rebater seria construída de inúmeras formas, essa estruturação e seu impacto no comportamento é pouco conhecido (ROBERTON, 1989). A carência de informações sobre o impacto das restrições na formação de padrões de movimentos motivou o presente trabalho. 
Em vista desse interesse são descritos a seguir o desenvolvimento do nadar na primeira infância e a análise da tarefa nadar.

\section{$5.3 \quad \mathrm{O}$ desenvolvimento do nadar na primeira infância}

A habilidade nadar é vista como a soma de processos adaptativos da flutuação, propulsão e respiração. FREUDENHEIM (1995) argumenta que o nadar envolve o domínio da estabilidade e integração de habilidades motoras básicas. Conceito semelhante foi proposto por LANGENDORFER \& BRUYA (1995) para quem o nadar é algo mais do que somente o aprendizado dos quatro estilos oficiais de natação.

Para o deslocamento no meio líquido é importante considerar os seguintes fatores da tarefa nadar: densidade do meio líquido; distância a ser percorrida; direção do deslocamento; previsibilidade do meio. A orientação no meio líquido é outro fator importante, pois as vias respiratórias necessitam ser posicionadas acima do nível da água continua ou intermitentemente. $\mathrm{O}$ desenvolvimento do nadar estará associado a esses fatores da tarefa.

Isso pode ser verificado já no estudo clássico de McGRAW (1939), em que 42 bebês com idade variando entre onze dias e dois anos e meio foram observados no meio aquático. As observações foram repetidas a diferentes intervalos dentro de um período aproximado de 20 meses, totalizando 445 registros dos 42 bebês, com uma média de dez observações em cada um deles. $\mathrm{O}$ primeiro aspecto importante dessa investigação foi a constatação de que, ao serem colocados na posição de decúbito ventral na água, os recém-nascidos efetuavam movimentos coordenados de membros superiores e inferiores eficazes para a locomoção no meio aquático. Esse foi um fato inusitado na época, pois acreditava-se que tais sujeitos não possuíam qualquer capacidade para se adaptar 
ao meio liquido. Outro fato interessante foi a constatação de regressões no comportamento quando esses sujeitos, por volta dos seis aos 12 meses de idade, apresentavam movimentos desorganizados ao serem colocados no meio líquido. Ao redor dos 24 meses de idade, McGRAW (1939) registrou o que seria a aparição dos movimentos voluntários de "remadas" e "chutes" apresentados por crianças com alguma experiência aquática.(FIGURA 1)

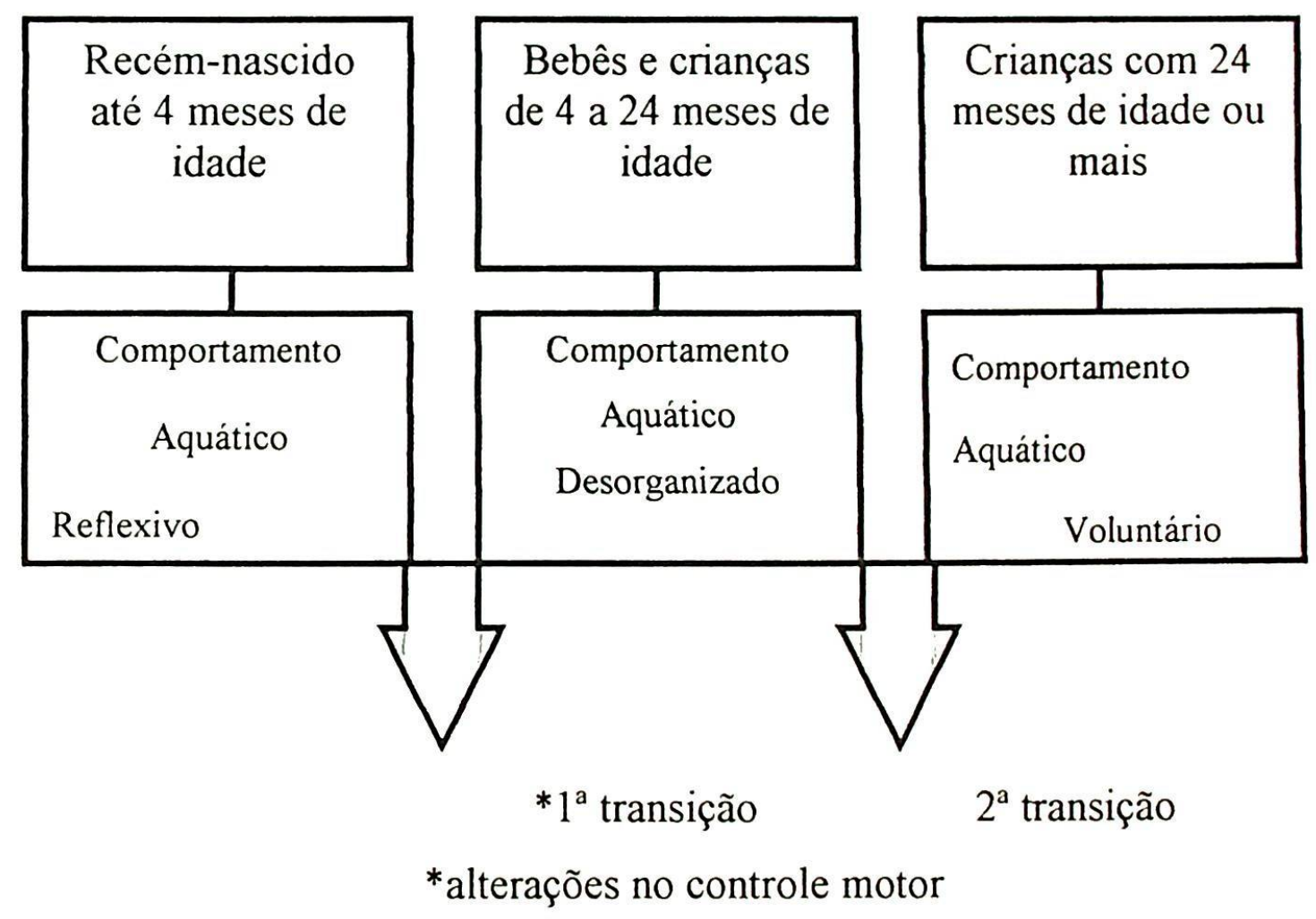

FIGURA 1-Modelo de desenvolvimento aquático de McGRAW(1939) adaptado de LANGENDORFER \& BRUYA (1995).

Com base nessas observações, McGRAW (1939) propôs que a seqüência de desenvolvimento do nadar constituía-se de três etapas ou fases: a) fase reflexiva; b) fase desorganizada; c) fase voluntária. Essa seqüência, segundo o principal modelo teórico da área nos anos 30 seria fruto de alterações no controle causadas pela maturação do sistema nervoso. As mudanças de 
comportamento observadas e descritas no estudo de McGRAW (1939) se referiam a três aspectos principais:
a) Movimentos das Extremidades
b) Controle Postural
c) Controle Respiratório

Os movimentos de extremidades consistiam de flexões e extensões alternadas dos membros inferiores e superiores, além de flexão lateral do tronco correspondente à flexão dos membros inferiores. Esses movimentos, que até os quatro primeiros meses são reflexivos e possuem um padrão rítmico, tornam-se desordenados e quase desaparecem após esse período. Por volta dos dois anos de idade, movimentos similares, especialmente dos membros inferiores, são encontrados mas já com controle voluntário. No que se refere à eficiência dos movimentos, o nadar reflexo era suficientemente potente para provocar deslocamentos ao redor de 1,5 m ou mais em bebês de até quatro meses. Na fase do nadar voluntário, os deslocamentos podem chegar até a $3 \mathrm{~m}$ sem nenhum apoio. Na fase de comportamento desorganizado, a ação dos membros inferiores praticamente desaparece, não permitindo, portanto, deslocamentos no meio líquido.

Outro elemento observado por McGRAW foi o controle postural dos bebês no meio líquido. Até os quatro meses de idade, eles têm um bom controle corporal o que permite uma locomoção eficaz, ainda que a posição de decúbito não possa ser modificada. No período entre quatro meses e o primeiro ano de vida, há a perda do controle postural, fato que se reflete na tendência dos bebês afundarem ao serem colocados na água. Já a capacidade das crianças em permanecer na posição ventral reaparece por volta do segundo ano de vida.

McGRAW (1939) ainda ressaltou um terceiro elemento: o controle respiratório. Na fase do nadar reflexo, o controle respiratório é deveras eficiente, 
permitindo aos bebês ficarem periodos prolongados submersos sem se afogar. $\mathrm{Na}$ fase do comportamento desorganizado, verificou-se a perda do controle respiratório, resultando em grande ingestão de água. O controle respiratório volta a aparecer, já sob certo controle voluntário, na terceira fase de desenvolvimento aquático. Ainda, segundo McGRAW (1939), em nenhum momento foi possível observar nos bebês a capacidade ou intenção de elevar a cabeça acima do nível d'água com objetivo de fazer a respiração. Por outro lado, nas crianças com mais de dois anos de idade existe a tendência em manter ou assumir a posição vertical com o intuito de manter a cabeça fora d'água.

De acordo com as observações feitas por McGRAW (1939), pode-se concluir que a habilidade de manter-se na posição ventral na água aliada à capacidade de movimentação dos membros é sinal crucial de desenvolvimento das crianças. Uma outra questão levantada por McGRAW (1939) foi que as alterações no comportamento aquático observadas nos bebês estariam associadas a mudanças em outras atividades motoras como o andar ereto, por exemplo. Como o interesse principal não era o comportamento motor aquático, McGRAW (1939) não se ateve a observar outros comportamentos do nadar voluntário em fases posteriores.

ERBAUGH (1978), tendo por base os estudos realizados por McGRAW na década de 30, investigou o nadar voluntário nos anos préescolares. ERBAUGH identificou habilidades e sub-habilidades que comporiam a competência motora no meio líquido. O propósito do seu estudo foi estabelecer uma correlação entre a idade dos praticantes e a performance exigida na execução das tarefas pelas crianças. Para possibilitar a quantificação dessas informações foi estabelecida uma escala pela qual o número de tarefas em cada uma das subcategorias, bem como as condições gerais da performance, fossem descritas, possibilitando aos observadores categorizar 0 estágio de 
desenvolvimento das crianças (FIGURA 2). O sistema de classificação é composto por nove subcategorias discriminadas a seguir: a) entrada e saída da água; b) locomoção de frente; c) locomoção de costas; d) respiração; e) pernadas; f) mergulhos; g) apanhar objeto no fundo da piscina; h) nadar com obstáculos.

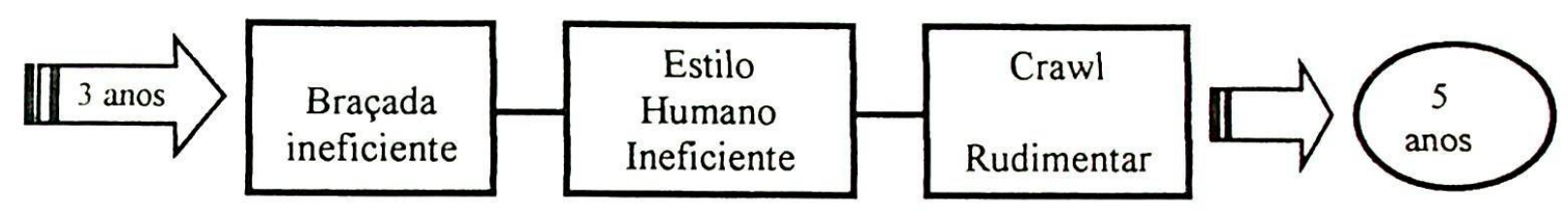

\section{Comportamento Voluntário para Locomoção Frontal}

FIGURA 2-Modelo de desenvolvimento aquático de ERBAUGH adaptado de LANGENDORFER \& BRUYA (1995).

Em trabalhos subseqüentes, ERBAUGH $(1980,1986)$ utilizou-se desse instrumento juntamente com metodologia longitudinal para descrever as mudanças do comportamento motor em crianças com idade entre 36 e 60 meses. Além das categorias de movimentos já citados, ERBAUGH (1980) considerou a independência do aluno em relação ao professor, a distância percorrida pelas crianças na execução de cada tarefa e a posição corporal em conjunto com a ação de membros superiores e inferiores.

ERBAUGH (1986) destacou as seguintes mudanças em seu estudo longitudinal: a) aumento da distância nadada; b) melhora na capacidade de propulsão com os braços; c) pernada alternada do nado de crawl mais evoluída; d) melhora na habilidade de se manter na horizontal; e) melhora na capacidade de manter a cabeça no nível da água. Como o instrumento mostrou-se sensível à mudança ao longo do tempo, ERBAUGH (1986) considerou-o apropriado para 
detectar como tais alterações ocorrem no desenvolvimento motor aquático na primeira e segunda infância.

Outro estudo que considerou o nadar dentro de uma perspectiva desenvolvimentista foi o descrito por OKA, OKAMOTO, TOKUYAMA \& KUMAMOTO (1983). O chamado modelo de "Mudanças na Ação da Pernada" ou "Modelo Japonês" identifica as alterações regulares na organização muscular e nos padrões da ação da pernada relacionados à idade. Isso possibilitou aos pesquisadores identificar que a ação da pernada passa do "pedalar", utilizado por crianças de 30 meses, para um padrão maduro de pernada, utilizado predominantemente por crianças aos 72 meses (FIGURA 3).

\section{Modelo da Ação da Pernada}

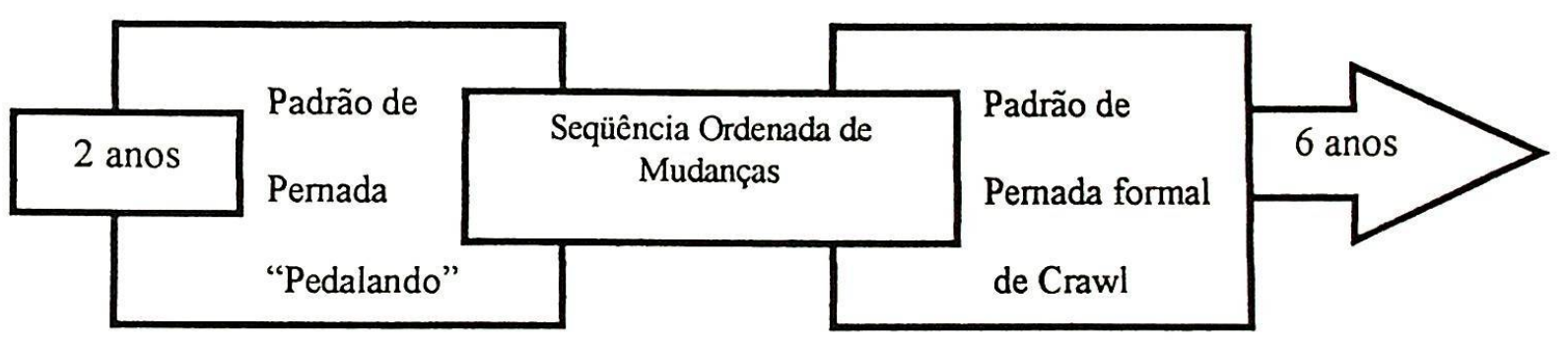

FIGURA 3-Modelo de desenvolvimento aquático de OKA et al. (1983)

No estudo de WEIKI \& HOUBEN (1983) 40 crianças foram observadas por um período de quatro anos, em que foram descritas as mudanças ocorridas no padrão de movimento da pernada. Observou-se que existiam sete padrões de ação da pernada, sendo que quatro deles, apresentados entre o $3^{\circ}$ e 0 $10^{\circ}$ mês, foram considerados reflexos. Esses padrões apresentam grande similaridade com os que McGRAW (1939) descreveu na fase dos movimentos reflexos; tais movimentos foram descritos como bruscos, repetitivos e estereotipados. Os outros três padrões de ação da pernada descritos no estudo

\footnotetext{
${ }^{1}$ Movimento ciclico e alternado de membros inferiores caracterizado pela flexão das pernas à altura dos joelhos
} 
tinham caráter voluntário e eram executados de maneira alternada. Eles apareciam entre o $11^{\circ}$ e o $20^{\circ}$ mês, e a propulsão ocorria com os sujeitos na posição de decúbito ventral, sendo que o padrão mais eficiente segundo esse estudo foi o padrão "pedalada"2.

LANGENDORFER \& BRUYA (1995) propuseram outro modelo de seqüência com base em suas observações sobre o desenvolvimento motor aquático de crianças na primeira infância. Eles levantaram a hipótese segundo a qual alterações de movimentos ocorridos nos componentes ação do braço, ação da perna, e posição do corpo, seriam suficientemente consistentes para definir estágios ou padrões de desenvolvimento motor aquático. Para a ação do braço, o padrão inicial foi descrito como sendo constituído por ações rápidas e curtas dos braços com a recuperação sendo realizada predominantemente dentro d'água. Posteriormente, as braçadas seriam mais longas - tipo "ação/reação" - com movimentos longos e lentos, culminando com braçadas mais avançadas tipo "palmateio"3. Na ação das pernas, foi verificado um movimento alternado tipo "pedalada" para os padrões iniciais, passando para um padrão final mais eficiente com pernadas alternadas do tipo utilizado no nado de crawl. Por último, no item posição do corpo, houve um decréscimo no ângulo do corpo em relação à água, variando de aproximadamente $85^{\circ}$ nos iniciantes para aproximadamente $10^{\circ}$ nos sujeitos com padrão avançado (FIGURA 4).

\footnotetext{
2 ato de obter deslocamento pela ação cíclica de membros inferiores

${ }^{3}$ movimento vigoroso realizado principalmente pelas mãos e que conferem grande sustentação e propulsão ao nadador.
} 
Ação de Braços
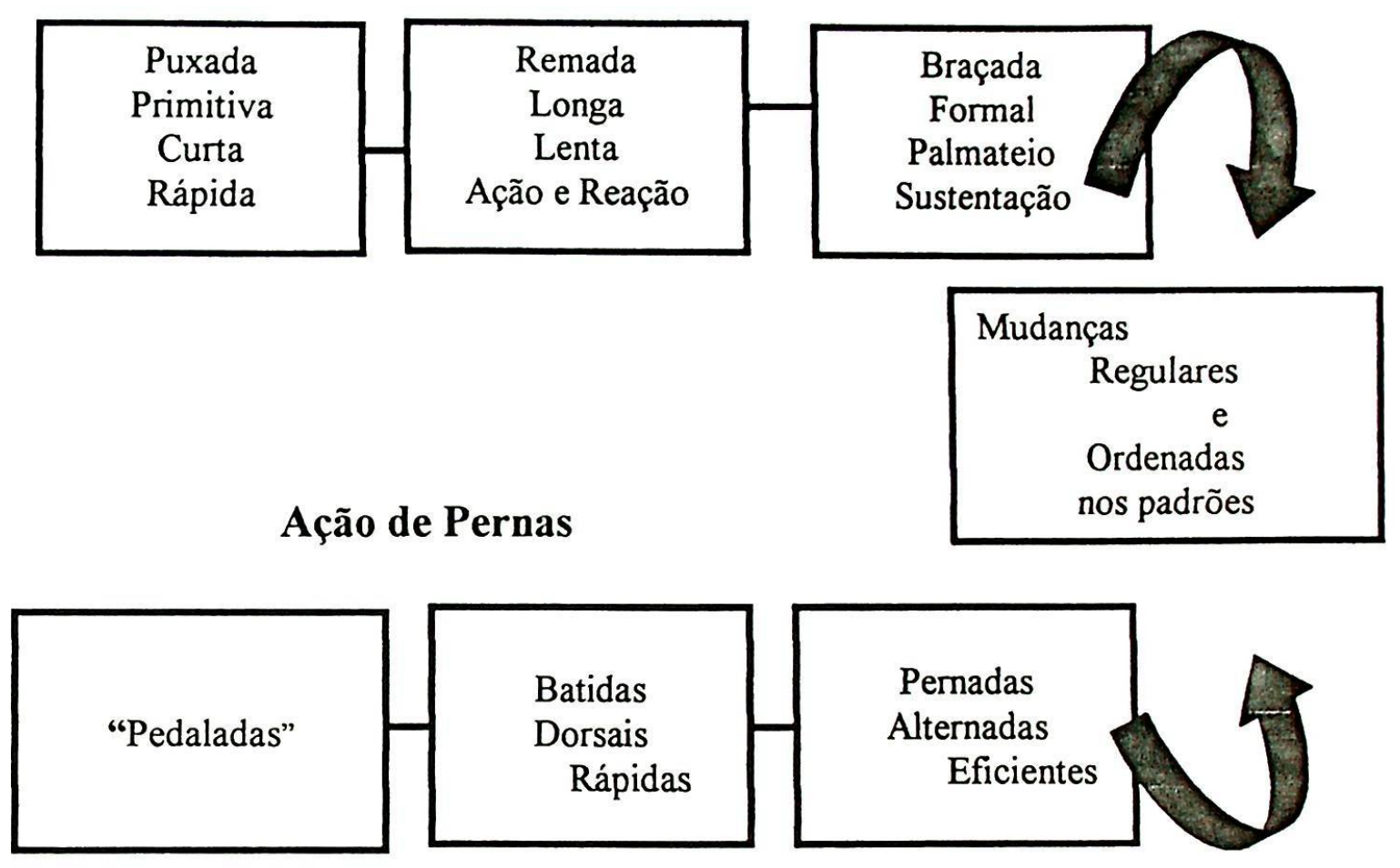

FIGURA 4-Modelo de desenvolvimento aquático de LANGENDORFER \& BUYA (1995)

LANGENDORFER \& BRUYA (1995) propuseram um modelo de seqüência de desenvolvimento da locomoção aquática que sintetiza os principais aspectos do desenvolvimento descritos por vários autores ao longo dos últimos 50 anos. A seqüência é constituída de cinco níveis descritos a seguir:

a) Sem padrão de locomoção independente na água: a criança não apresenta movimentação autônoma na água.

b) Padrão "Cachorrinho": estilo frontal caracterizado por movimentos alternados de membros inferiores, com flexão de joelhos. A 
ação dos braços é feita de maneira alternada e em círculos, sem que seja feita recuperação fora da água. O corpo permanece na vertical ou com ligeira inclinação em relação à superfície da água.

c) Padrão "Humano" Inicial: estilo frontal caracterizado por movimentos alternados de membros inferiores com ligeira flexão de joelhos, a ação dos braços é feita em padrões retilíneos com recuperação fora da água, a respiração é feita com a cabeça girando para ambos os lados, a posição do corpo é ligeiramente inclinada em relação à água.

d) Padrão de Crawl Rudimentar: estilo frontal caracterizado pela ação contínua de braços com pernada contínua sem flexão dos joelhos, com padrão variado e inconstante de respiração, posição do corpo ligeiramente inclinada em relação à superfície da água.

e) Padrão Crawl Avançado ou outro estilo formal: estilo frontal com padrões definidos de braços, pernas e respiração; usualmente a posição corporal é a horizontal.

Os componentes do modelo de prontidão aquática consistem de sete elementos que servem como parâmetros para a classificação dos níveis de desenvolvimento proposto por LANGENDORFER \& BRUYA (1995).

Cada componente possui níveis de proficiência que possibilitam a classificação do indivíduo em um nível ou estágio de desenvolvimento. Os componentes motores básicos para a prontidão aquática seriam: a) Orientação Aquática e Ajustamentos; b) Entrada na Água; c) Controle Respiratório; d) Flutuabilidade e Posição do Corpo; e) Ação do Braço; f) Ação da Perna; g) Combinação de movimentos. ${ }^{4}$

${ }^{4}$ Combinação de movimentos corresponde à configuração total do corpo já descrita com os niveis 1 a 5 . 


\section{a) Orientação Aquática e Ajustamentos}

Nesse componente foram identificados três estágios

1-Não apresenta entrada voluntária e demonstra medo

2-Entrada voluntária hesitante com algum sinal de medo

3-Entrada voluntária sem hesitação

\section{b) Entrada na Água}

Nesse componente são analisadas as formas pelas quais o aprendiz tem acesso à água em que são identificados cinco estágios ou níveis.

1-Não apresenta entrada voluntária

2-Entrada assistida em pé

3-Entrada voluntária em pé

4-Entrada de cabeça assistida

5-Entrada voluntária de cabeça

\section{c) Controle Respiratório}

No componente controle respiratório pode-se observar um seqüência ordenada de mudanças que vai desde o controle reflexivo da respiração até a repetição rítmica e voluntária da respiração.

1-Controle respiratório reflexivo (bloqueio)

2-Controle para cuspir ou assoprar (expiração)

3-Imersão voluntária da face

4-Bloqueio voluntário da respiração 
5-Respiração rítmica voluntária
d) Flutuabilidade

O padrão de flutuabilidade muda em uma seqüência ordenada e regular que vai desde a flutuação assistida até a flutuação ventral ou dorsal sem assistência.

1-Sem flutuação

2-Flutuação com assistência

3-Flutuação com apoio

4-Flutuação ventral ou dorsal sem assistência

e) Posição do Corpo

A posição do corpo na locomoção frontal foi classificada de acordo com a variação do angulo formado pelo corpo em relação à superficie e pode variar da posição vertical até a posição horizontal
1-Vertical $\quad\left(90^{\circ}\right.$ a $\left.45^{\circ}\right)$
2-Inclinado $\left(44^{\circ}\right.$ a $\left.20^{\circ}\right)$
3-Nivelado $\left(19^{\circ}\right.$ a $\left.10^{\circ}\right)$
4-Horizontal (menos que $10^{\circ}$ )
f) Ação do Braço

No componente ação do braço são identificadas duas fases: propulsão e recuperação, a primeira com quatro níveis e a segunda com cinco. 


\section{Propulsão}

1- Nenhuma ação propulsiva dos braços

2-Empurrão descendente pequeno

3- Empurrar-puxar longo

4-Tração com mudanças de direção

5-Propulsão com movimentos de sustentação

\section{Recuperação}

1-Nenhuma ação de recuperação dos braços

2-Nenhuma recuperação de braço acima da água

3-Recuperação de braço rudimentar

4-Recuperação com braços estendidos

5-Recuperação de braços com cotovelo flexionado

\section{g) Ação da Perna}

No componente ação da perna podem-se observar mudanças ordenadas de padrões que vão desde a o nível 1 em que quase não há ação aparente de pernada passando pela ação de pedalar na vertical, ação trêmula das pernas e movimentos com flexão dos joelhos até chegar ao tipo de pernada utilizada em nados formais tipo crawl ou costas.

As alterações nos padrões de pernada precedem as alterações do componente braço (ERBAUGH, 1978, 1980, 1986; LANGENDORFER, 1987b).

1-Nenhuma ação aparente de pernada

2-Ação de flexão/extensão "pedalada" na posição vertical 
3-Ação de pernas rudimentar "tremula"

4-Ação de pernas "dobradas"

5-Perna estendida tipo "crawl"

Há um estreito relacionamento entre os modelos de seqüência utilizados por ERBAUGH, (1978), OKA et al. (1983), e LANGENDORFER \& BRUYA (1995). Em todos eles existe a preocupação com a consistência e a prontidão das crianças na obtenção do comportamento aquático esperado. Há ainda um modelo descrito por REID \& BRUYA (1984), no qual se encontra a idéia de estudar o desenvolvimento das crianças no meio líquido através da observação do componente entrada das crianças na água. A categorização dos comportamentos de entrada no meio líquido seriam, então, um meio de detectar alterações no padrão de desenvolvimento motor das crianças. Contudo, há que se observar a existência de diferentes padrões de habilidade e de idade que não estão bem definidos e podem interferir na identificação das tendências do desenvolvimento.

Em todos os modelos apresentados não houve a preocupação em verificar possíveis variações na progressão preconizada devido a particularidades do ambiente e da tarefa proposta. A apreciação conjunta da análise da tarefa nadar e a seqüência de desenvolvimento do nadar nos remete a uma série de questionamentos sobre como sujeitos em diferentes estágios de desenvolvimento irão responder às variações nas restrições da tarefa e do ambiente. $\mathrm{O}$ foco do presente trabalho será exatamente esse. Optou-se pela utilização do modelo proposto por LANGENDORFER \& BRUYA (1995), por ser esse um instrumento que descreve os padrões de locomoção aquática de forma mais abrangente, além de possuir critérios claros de reprodutibilidade e objetividade (ver ANEXO II). Além disso, há a necessidade de verificar a consistência e a 
robustez do modelo para associar padrões de locomoção a estágios de desenvolvimento diante de modificações nas restrições da tarefa e no ambiente.

\subsection{Analise da tarefa nadar.}

A análise da tarefa nadar pode ser feita com base no modelo de análise desenvolvimentista da tarefa proposto por HERKOWITZ (1978).

No QUADRO 1 são identificadas: a) velocidade de execução, b) direção do deslocamento, c) distância a ser percorrida e d), previsibilidade do ambiente. Com a combinação dos diferentes níveis de cada fator é possível caracterizar condições em que a tarefa pode ser considerada simples ou complexa.

QUADRO 1-Análise geral a tarefa nadar

\begin{tabular}{|cccc|}
\hline $\begin{array}{c}\text { Velocidade de } \\
\text { deslocamento }\end{array}$ & $\begin{array}{c}\text { Distância de } \\
\text { deslocamento }\end{array}$ & $\begin{array}{c}\text { Direção de } \\
\text { deslocamento }\end{array}$ & $\begin{array}{c}\text { Previsibilidade } \\
\text { durante o } \\
\text { Baixa }\end{array}$ \\
Média & Média & Sem mudança & Facilmente \\
& Longa & Com pequenas & previsivel \\
Alta & mudanças & \\
& & & Dificilmente \\
& & previsivel
\end{tabular}

Como será visto adiante, optou-se no presente estudo, pela manipulação das restrições da tarefa (velocidade de deslocamento) e do ambiente (direção do deslocamento). 
Com o propósito de melhor orientar a descrição do comportamento em face das variações nas restrições da tarefa, foi elaborada uma série de questões:

Primeiro, procurou-se verificar como os indivíduos vão se ajustar às variações nas restrições. Dentro da abordagem de sistemas dinâmicos, preconizase que as alterações nas restrições podem levar à emergência de padrões mais avançados. Isso significa que a ordem do mais simples para o mais complexo na tarefa não implicaria necessariamente progressões no comportamento. Dessa forma elaborou-se a seguinte questão:

1. Com o aumento no grau de dificuldade das tarefas haverá a tendência de apresentação de padrões mais primitivos?

Como os padrões são condicionados pela configuração das restrições, pressupõe-se que os estágios ou níveis de desenvolvimento seriam resultantes da confluência de diferentes restrições. Alterações em uma delas geraria novos padrões. MANOEL \& OLIVEIRA (2000) têm argumentado que a categorização tradicional dos estágios pode estar captando formas de organização motora menos suscetíveis a variações nas restrições da tarefa. De fato, ROBERTON (1987) não encontrou grande variação comportamental quando restrições da tarefa arremessar foram modificadas. A explicação para tal resultado foi que os indivíduos estavam num estágio pré-transição desenvolvimentista.

Nesse sentido foi elaborada a seguinte questão: 
2. O estado de desenvolvimento motor dos sujeitos (identificado a partir de uma condição natural) condicionará o grau em que os sujeitos modificam os padrões diante das variações das restrições da tarefa?

Como a possibilidade de o indivíduo apresentar novos padrões parece estar associada à estabilidade do seu comportamento atual, foi elaborada a seguinte questão:

3. O grau de estabilidade apresentado por cada indivíduo irá predizer sua capacidade de se ajustar às variações nas restrições da tarefa?

As alterações nas restrições da tarefa podem ocasionar ajustes comportamentais de natureza variada. MANOEL \& OLIVEIRA (2000) buscaram identificar ajustes de dois tipos. As modificações nos níveis de desenvolvimento corresponderiam a ajustes no seqüenciamento da ação e correspondentemente implicariam em novos programas de ação. As modificações na velocidade e tempo de movimento foram consideradas ajustes paramétricos. Assim é possível identificar como o indivíduo modifica a sua ação, com alterações mais microscópicas - paramétricas ou mais macroscópicas seqüenciamento. Dessa forma foi elaborada a seguinte questão:

4. Quais os tipos de ajuste (paramétrico ou seqüencial) efetuados por cada grupo em cada condição?

No presente estudo, as modificações seqüenciais foram consideradas a partir de alterações nos níveis de desenvolvimento da configuração total do corpo ou por componente. As modificações paramétricas foram descritas a partir de alterações na velocidade média, amplitude e freqüência média de braçada e número de ciclos de braçada. 


\section{Sujeitos}

A caracterização da amostra é de fundamental importância no presente estudo. Além da idade, foi considerado o grau de experiência dos indivíduos em tarefas motoras aquáticas.

Participaram do estudo 56 crianças com idade entre 72 e 144 meses. 29 do sexo masculino $(51,78 \%)$ e 27 do sexo feminino (48,21\%), com a média de idade, em meses, de 95,17 e 94,66 respectivamente. Os indivíduos participavam em pelo menos seis meses de programas formais em escolas de natação na cidade de Londrina e Apucarana no norte do Paraná (TABELA 1).

TABELA 1-Média de idade em meses e porcentagem por sexo da amostra estudada.

\begin{tabular}{cccc}
\hline SEXO & IDADE (meses) & N & $\%$ \\
\hline MASCULINO & 95,17 & 29 & 51,78 \\
FEMININO & 94,66 & 27 & 48,21 \\
\hline
\end{tabular}

Pode-se observar na TABELA 2 a distribuição dos sujeitos agrupados por sexo e pelo tempo médio de participação em programas formais de natação bem como a média e o desvio padrão em cada um dos níveis observados. Esse dado foi considerado, pois esperava-se obter resultados diferentes para os sujeitos que fossem classificados em níveis mais avançados de desenvolvimento aquático. 
O tempo de participação dos sujeitos nos programas formais de natação variou de no mínimo seis meses e de no máximo 24 meses sendo, que o tempo médio de experiência é de 18 meses.

TABELA 2-Tempo de experiência e número de sujeitos.

Experiência em aulas de natação Total de sujeitos

Sem experiência anterior

6 meses 14

6-12 meses 17

12- 24 meses 25

Total de sujeitos 56

Média em meses 24,89

Desvio padrão em (meses) $\pm 22,89$

Tarefa

As tarefas experimentais foram construídas de forma a se promoverem variações nas restrições da tarefa e do ambiente. De acordo com as análises geral específica da tarefa foram considerados os seguintes fatores: velocidade de deslocamento, distância a ser percorrida, direção de deslocamento e previsibilidade do ambiente (ANEXO VI).

$\mathrm{Na}$ velocidade de deslocamento foram identificados dois níveis:

V1= velocidade natural na execução da tarefa

V2= velocidade máxima na execução da tarefa

A distância do trajeto foi mantida foi mantida sem alteração, independentemente da velocidade solicitada. Para efeito da análise dos padrões 
motores, foram considerados apenas os $6 \mathrm{~m}$ intermediários do percurso total. A distância de $8 \mathrm{~m}$ foi definida com base em estudo piloto. A partir dele, concluiuse que ela permitiria uma boa visualização dos sujeitos. Além disso, acima dessa distância o esforço requerido dos sujeitos poderia ocasionar fadiga.

A direção do deslocamento no meio líquido foi manipulada de duas formas:

DIR1 = Nadar o percurso determinado em linha reta, sem mudança de direção.

DIR2 = Nadar o percurso determinado contornando obstáculos (bóias).

No caso de DIR 2, as crianças foram solicitadas a contornarem as bóias de sinalização dispostas a cada $2 \mathrm{~m}$, alternando a passagem por cada bóia, ora pela direita, ora pela esquerda.

A tarefa foi realizada em condições de alta previsibilidade do ambiente. Optou-se pela manutenção da condição de alta previsibilidade pelas seguintes razões: a) dificuldade de operacionalização encontrada para o controle da previsibilidade durante a execução do experimento: com o passar das tentativas o sujeito acaba antecipando qual condição irá acontecer; b) outro inconveniente foi a dificuldade em distinguir essa condição da condição que envolve a mudança de direção.

De acordo com os níveis de cada fator foram criadas quatro tarefas com as seguintes condições:

CONDIÇÃO 1 (V1-DIR1): Velocidade natural, sem mudança de direção. A partir do desempenho nessa condição, os sujeitos foram classificados 
nos diferentes niveis de desenvolvimento motor aquático, de acordo com o modelo modificado de LANGENDORFER \& BRUYA, (1995).

CONDIÇÃO 2 (V1-DIR2): Velocidade natural, com mudança de direção.

CONDIÇÃO 3(V2- DIR1): Velocidade máxima, sem mudança de direção,

CONDIÇÃO 4(V2- DIR2): Velocidade máxima, com mudança de direção.

No QUADRO 2 são apresentadas as condições experimentais e os grupos definidos de acordo com o estado de desenvolvimento motor observado na condição 1 . Por esse motivo a condição 1 foi omitida. O nível 1 do modelo de seqüência também não é apresentado, posto que nesse nível os sujeitos não apresentam locomoção independente. 
QUADRO 2-Niveis de desenvolvimento e condições experimentais.

\begin{tabular}{|l|c|c|c|}
\hline $\begin{array}{c}\text { NÍVEIS DE } \\
\text { DESENVOLVIMENTO }\end{array}$ & CONDIÇÃO 2 & CONDIÇÃO 3 & CONDIÇÃO 4 \\
\hline $\begin{array}{l}08 \text { “Crawl" c/ perna de 2 } \\
\text { tempos }\end{array}$ & V1 DIR 2 & V2 DIR1 & V2 DIR2 \\
\hline 07 “Crawl" avançado & V1 DIR 2 & V2 DIR1 & V2 DIR 2 \\
\hline 06 "Crawl" intermediário & V1 DIR 2 & V2 DIR1 & V2 DIR2 \\
\hline 05 “Crawl" rudimentar & V1 DIR 2 & V2 DIR1 & V2 DIR2 \\
\hline 04 "Humano Inicial” & V1 DIR 2 & V2 DIR1 & V2 DIR2 \\
\hline 03 "Coordenação inicial" & V1 DIR 2 & V2 DIR1 & V2 DIR2 \\
\hline 02 "Cachorrinho" & V1 DIR 2 & V2 DIR1 & V2 DIR2 \\
\hline
\end{tabular}

\subsection{Procedimentos}

Cada sujeito foi instruído individualmente sobre as tarefas. Todos puderam experimentar cada uma das tarefas. Após certificar-se que a tarefa foi compreendida, foram feitas marcas nos pulsos de cada sujeito para facilitar a observação durante a análise dos movimentos no vídeo. A seguir o experimentador solicitou que o sujeito iniciasse a tentativa. Foram realizadas cinco repetições em cada condição. O tempo de execução de cada tentativa foi cronometrado, entretanto, a informação sobre o tempo não foi dada ao sujeito. Nas condições (V2-DIR1) e ( V2DIR2) o indivíduo foi informado sobre o tempo como forma de motivá-lo a empreender máxima velocidade. 
Para o registro dos dados referentes aos padrões de locomoção foram utilizadas duas câmaras de alta definição marca Panasonic camerascope SVHS Movie Modelo AG 456-VP, com velocidade de gravação de 33-35 mm/s. Uma filmadora foi colocada acima do nivel da água, enquanto que a outra foi colocada abaixo do nivel da água para possibilitar a visualização do padrão submerso.

As imagens colhidas foram analisadas quadro por quadro pelos avaliadores por meio do equipamento de reprodução Panasonic Video Cassette Reciever Modelo AG-1980-P, com velocidade de reprodução $33-35$ mm/s, 30 quadros por segundo.

As tentativas de cada sujeito foram filmadas e o tempo total de execução foi cronometrado e anotado na ficha individual (ANEXO III). Posteriormente os sujeitos tiveram os seus "tapes" analisados por três profissionais de natação para que fosse feita a classificação do comportamento, como será descrito a seguir. Devido à diversidade dos padrões de locomoção aquática apresentados pelos sujeitos foram incluídas novas categorias na lista de checagem proposta por LANGENDORFER \& BURYA (1995).

\section{4}

\section{Níveis de desenvolvimento aquático modificado}

O modelo de desenvolvimento aquático inicialmente adotado foi o de LANGENDORFER \& BRUYA (1995) .Entretanto, alguns comportamentos não foram abarcados por esse modelo. Dessa forma, optou-se pela criação de novos níveis como serão vistos a seguir.

Nível 1 (N1) Sem padrão de locomoção independente na água: a criança não apresenta movimentação autônoma na água. 
Nível 2 (N2) Padrão "Cachorrinho": estilo frontal caracterizado por movimentos alternados de membros inferiores, com flexão de joelhos. A ação dos braços é feita de maneira alternada e em círculos, sem que seja feita recuperação fora da água. O corpo permanece na vertical ou com ligeira inclinação em relação à superficie da água.

Nível 3 (N3) Padrão “Coordenação Inicial”: estilo frontal caracterizado por movimentos alternados de membros superiores com ação de propulsão variando de puxadas curtas e rápidas para puxadas longas; em ambos existe uma parada dos braços à frente do corpo. O padrão respiratório vai do simples controle respiratório, com parada para inspiração, até o padrão respiratório frontal sem apoio. A ação da perna pode estar entre a pernada "tremula" e o padrão rudimentar do crawl. A posição do corpo em relação ao nível da água depende da ação da perna, mas o padrão mais freqüente é o inclinado.

Nível 4 (N4) Padrão "Humano" Inicial: estilo frontal caracterizado por movimentos alternados de membros inferiores com ligeira flexão natural de joelhos. A ação dos braços é feita em padrões retilíneos com recuperação fora da água; a respiração pode ser executada com a cabeça virando para ambos os lados, sendo que a inspiração ocorre de um lado e a expiração ocorre do outro. Sobre a posição do corpo ela é ligeiramente inclinada em relação à água. A ação da perna varia do movimento tremulo podendo chegar até a ação da perna do crawl rudimentar.

Nível 5 (N5) Padrão de Crawl Rudimentar: estilo frontal de movimentação alternada de membros superiores e inferiores e cuja principal característica é a instabilidade dos componentes que podem variar de acordo com a intensidade do nado. A respiração não segue um padrão definido e pode ser 
realizada em diferentes momentos do nado com elevação da cabeça ou mesmo somente ser realizada com os sujeito diminuindo o ritmo das braçadas.

Nível 6 (N6) Padrão de Crawl Intermediário: estilo frontal caracterizado pela ação contínua de braços com pernada contínua sem flexão dos joelhos, com padrão variado e inconstante de respiração, com cabeça alta em relação à posição do corpo, o que faz com que a posição de nado seja ligeiramente inclinada em relação à superficie da água. Outra característica do padrão é a ação descontínua dos braços com parada à frente do corpo para facilitar a respiração.

Nível 7 (N7) Padrão Crawl Avançado: estilo frontal com padrões definidos de braços cuja ação se baseia em movimentos de palmateio visando utilizar forças de sustentação para obter um melhor desempenho. A ação das pernas é feita com movimentos alternados com padrão de seis batidas por ciclo de braçadas. A respiração tem um padrão rítmico bem definido e geralmente a respiração à lateral é utilizada podendo, em muitos casos, ser verificada a respiração bilateral. A posição corporal em relação à água é a horizontal.

Nível 8 (N8) Padrão Crawl Avançado com Pernada de Dois Tempos: nesse estilo, o diferencial está na ação da perna que se movimenta em padrões regulares de duas batidas por ciclo de braçadas ao passo que os demais componentes do nado se identificam com o padrão avançado de pernada de seis tempos, isto é, a braçada com palmateio e respiração rítmica lateral ou bilateral. A posição do corpo é a horizontal. 
A análise estatística foi conduzida de forma separada para as duas classes de medidas, qualitativas e quantitativas.

Para as medidas qualitativas a preocupação foi identificar as diferenças significativas entre os níveis de desenvolvimento motor aquático dos sujeitos, nas condições experimentais. Para esse fim foi utilizado o teste nãoparamétrico de FRIEDMAN (1937) para medidas repetidas. A verificação do loco das diferenças foi realizada com o teste não-paramétrico de WILCOXON (1945) para medidas pareadas. Utilizando-se a Técnica de Bonferroni ajustou-se o nível de significância para $p<0,016$. A adoção desse procedimento tornou o teste muito mais rigoroso para identificar as diferenças significativas, diminuindo a possibilidade de ocorrência do erro tipo I (GREEN, SALKINEL \& ANKEY, 2000; UGRINOWITSCH, 1997; UGRINOWITSCH \& MANOEL, 1999). Os dados obtidos foram tabulados e analisados através do pacote estatístico "SPSS" for Windows versão 8.0.

As medidas quantitativas referem-se à velocidade média, amplitude de braçadas, número de ciclos e freqüência média de braçadas. Para a verificação do grau de significância estatística das diferenças foi calculada uma série de analises de variância utilizando-se o teste não-paramétrico para medidas repetidas de FRIEDMAN (1937) para cada um dos grupos (em todas as condições) e em cada uma das variáveis. Para verificar onde essas diferenças foram significativas utilizou-se o teste não-paramétrico de WILCOXON (1945) para medidas pareadas. Utilizando-se a Técnica de Bonferroni ajustou-se o nível de significância para $\mathrm{p}<0,016$. A adoção desse procedimento tornou o teste muito mais rigoroso para identificar as diferenças significativas e, ao mesmo tempo, diminuiu a possibilidade do erro tipo I (GREEN et al., 2000; 
UGRINOWITSCH, 1997; UGRINOWITSCH et al., 1999). Os dados obtidos foram tabulados e analisados através do pacote estatístico "SPSS" for Windows versão 8.0 .

8

\section{RESULTADOS}

Em primeiro lugar será apresentada a distribuição de freqüência dos sujeitos nos níveis de desenvolvimento aquático observadas em cada uma das condições do estudo, tendo sido usado para isso a configuração total do corpo. Num segundo momento, quando se comparam as diferentes condições do estudo tanto para a configuração total do corpo quanto por componentes, são apresentados os resultados das transições observadas em cada nível. Finalmente serão apresentados os dados referentes às medidas paramétricas.

\subsection{Distribuição da amostra nos níveis de desenvolvimento aquático na condição 1}

Foram classificados 13 sujeitos no nível N7, sendo nove do sexo masculino e quatro do sexo feminino. O tempo médio de participação nos programas de natação do grupo masculino foi de 21 meses. O grupo feminino experimentou um tempo de prática de 24 meses. A idade média do grupo N7 é de 106 meses. 
TABELA 3-Tempo de experiência, idade média e número de sujeitos no N7 por sexo.

\begin{tabular}{|l|c|c|c|}
\hline $\begin{array}{l}\text { Experiência em aulas de } \\
\text { natação }\end{array}$ & $\begin{array}{c}\text { Total de sujeitos } \\
\text { nível 7 feminino }\end{array}$ & $\begin{array}{c}\text { Total de sujeitos } \\
\text { nivel 7 masculino }\end{array}$ & $\begin{array}{c}\text { Idade Média em } \\
\text { meses }\end{array}$ \\
\hline Sem experiência anterior & - & - & - \\
\hline 6 meses & & 1 & \\
\hline $6-12$ meses & 1 & 3 & \\
\hline $12-24$ meses & 4 & 5 & \\
\hline Total de sujeitos & 5 & 7 & 106,96 \\
\hline Média em meses & 18 & 16,29 & 14,32 \\
\hline Desvio padrão (meses) & $\pm 6,57$ & $\pm 7,52$ & \\
\hline
\end{tabular}

O grupo N6 foi composto por 13 sujeitos, sendo seis do sexo masculino e sete do sexo feminino. O tempo médio de experiência dos meninos foi de 18 meses. O grupo feminino teve um tempo médio de participação ao redor de 16 meses. A idade média do grupo N6 foi de aproximadamente 93 meses (TABELA 4).

TABELA 4-Tempo de experiência, idade média e número de sujeitos no N6 por sexo.

\begin{tabular}{|c|c|c|c|}
\hline $\begin{array}{l}\text { Experiência em aulas de } \\
\text { natação }\end{array}$ & $\begin{array}{c}\text { Total de sujeitos } \\
\text { nivel } 6 \text { masculino }\end{array}$ & $\begin{array}{l}\text { Total de sujeitos } \\
\text { nivel } 6 \text { feminino }\end{array}$ & $\begin{array}{c}\text { Idade Média em } \\
\text { meses }\end{array}$ \\
\hline Sem experiência anterior & - & - & \\
\hline 6 meses & & 1 & \\
\hline $6-12$ meses & 3 & 3 & \\
\hline 12- 24 meses & 3 & 3 & \\
\hline Total de sujeitos & 6 & 7 & \\
\hline Média em meses & 18 & 16,29 & 93,23 \\
\hline Desvio padrão (meses) & $\pm 6,57$ & $\pm 7,52$ & 17,77 \\
\hline
\end{tabular}

O grupo do N5 foi composto por seis sujeitos do sexo masculino com uma média de experiência de 17 meses. Houve apenas uma menina no N5 
que tinha 12 meses de experiência em aulas de natação. A idade média desse grupo foi de aproximadamente 88 meses (TABELA 5).

TABELA 5 Tempo de experiência, idade média e número de sujeitos no N5 por sexo.

\begin{tabular}{lccc}
\hline $\begin{array}{l}\text { Experiência em aulas de } \\
\text { natação }\end{array}$ & $\begin{array}{c}\text { Total de sujeitos } \\
\text { nível N5 masculino }\end{array}$ & $\begin{array}{c}\text { Total de sujeitos } \\
\text { nível N5 feminino }\end{array}$ & $\begin{array}{c}\text { Idade média em } \\
\text { meses }\end{array}$ \\
\hline Sem experiência anterior & - & - & \\
6 meses & - & 1 & \\
$6-12$ meses & - & 2 & \\
12-24 meses & 1 & 6 & \\
Total de sujeitos & 1 & 17 & 88,50 \\
Média em meses & 12 & $\pm 7,97$ & 15,63 \\
Desvio padrão (meses) & - & & \\
\hline
\end{tabular}

A TABELA 6 apresenta os dados do grupo N4 composto por quatro sujeitos do sexo masculino e sete sujeitos do sexo feminino. O tempo médio de experiência do grupo masculino foi de 12 meses enquanto que no grupo das meninas o tempo médio foi aproximadamente de 13 meses. A idade média desse grupo ficou próximo dos 92 meses. 
TABELA 6-Tempo de experiência, idade média e número de sujeitos no N4 por sexo.

\begin{tabular}{lccc}
\hline $\begin{array}{l}\text { Experiência em aulas de } \\
\text { natação }\end{array}$ & $\begin{array}{c}\text { Total de sujeitos nivel } \\
\text { N4 masculino }\end{array}$ & $\begin{array}{c}\text { Total de sujeitos nivel } \\
\text { N4 feminino }\end{array}$ & $\begin{array}{c}\text { Idade Média em } \\
\text { meses }\end{array}$ \\
\hline Sem experiência anterior & - & - & - \\
6 meses & 2 & 2 & \\
$6-12$ meses & 1 & 3 & \\
12- 24 meses & 1 & 2 & \\
Total de sujeitos & 4 & 7 & 92,40 \\
Média em meses & 12 & 13,71 & 17,93 \\
Desvio padrão (meses) & $\pm 8,49$ & $\pm 7,52$ & \\
\hline
\end{tabular}

Os indivíduos classificados no N3 foram num total de nove, sendo três do sexo masculino e seis do sexo feminino. O tempo médio de experiência em natação foi de 12 meses para as meninas e de oito meses para os meninos. A idade média do grupo foi aproximadamente 92 meses (TABELA 7).

TABELA 7-Tempo de experiência, idade média e número de sujeitos no N3 por sexo.

\begin{tabular}{lccc}
\hline $\begin{array}{l}\text { Experiência em aulas de } \\
\text { natação }\end{array}$ & $\begin{array}{c}\text { Total de sujeitos } \\
\text { nivel N3 masculino }\end{array}$ & $\begin{array}{c}\text { Total de sujeitos } \\
\text { nivel N3 feminino }\end{array}$ & $\begin{array}{c}\text { Idade Média em } \\
\text { meses }\end{array}$ \\
\hline Sem experiência anterior & - & - & \\
6 meses & 2 & 2 & \\
6-12 meses & 1 & 3 & \\
12- 24 meses & - & 1 & 92 \\
Total de sujeitos & 3 & 6 & 15,87 \\
Média em meses & 8 & 12 & \\
Desvio padrão(meses) & $\pm 3,46$ & $\pm 6,57$ & \\
\hline
\end{tabular}


No grupo N2 houve apenas de um menino com 24 meses de experiência em aulas de natação e duas meninas com 12 meses de experiência. A idade média desse grupo foi de aproximadamente 88 meses (TABELA 8).

TABELA 8-Tempo de experiência, idade média e número de sujeitos no N2 por sexo.

\begin{tabular}{lccc}
\hline $\begin{array}{l}\text { Experiência em aulas de } \\
\text { natação }\end{array}$ & $\begin{array}{r}\text { Total de sujeitos nível } \\
\text { N2 masculino }\end{array}$ & $\begin{array}{c}\text { Total de sujeitos nível } \\
\text { N2 feminino }\end{array}$ & $\begin{array}{c}\text { Idade Média em } \\
\text { meses }\end{array}$ \\
\hline Sem experiência anterior & - & - & \\
6 meses & - & - & \\
$6-12$ meses & - & 2 & \\
$12-24$ meses & 1 & - & 88 \\
Total de sujeitos & 1 & 2 & 6,93 \\
Média em meses & - & 12 & \\
Desvio padrão (meses) & - & 0 & \\
\hline
\end{tabular}

De forma geral, o maior número de indivíduos foi categorizado nos níveis N3 a N7 que variaram de oito a 13 sujeitos. Os dois extremos, grupos N2 N8, tiveram três e um sujeito respectivamente (FIGURA 5). 


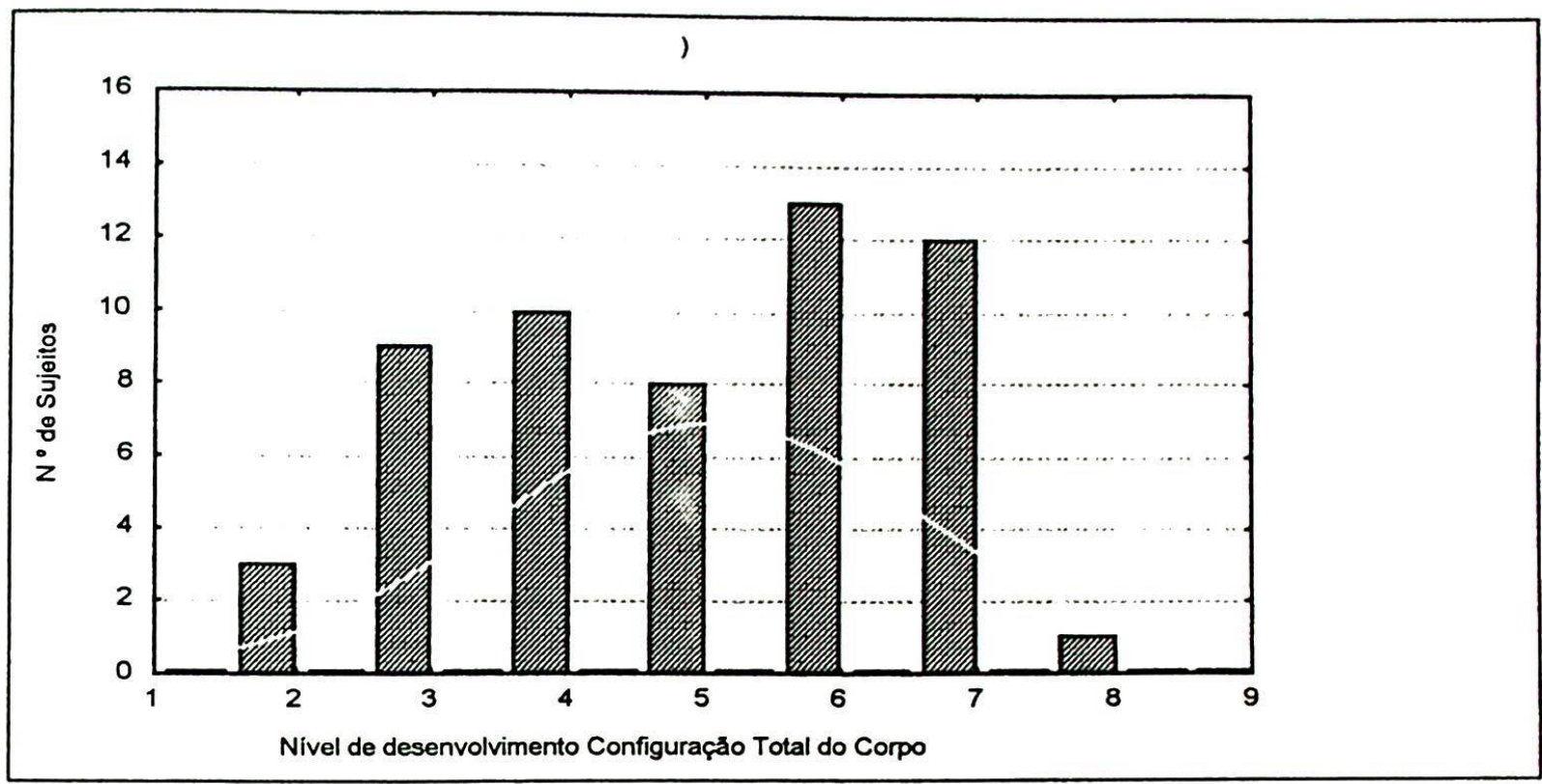

FIGURA 5-Distribuição dos sujeitos por nivel na condição C1.

8.2

Transições entre C1 e C2

A tendência geral da amostra foi pela manutenção do comportamento, posto que em torno de $60 \%$ dos indivíduos se mantiveram no mesmo nível de desenvolvimento (ver QUADRO 2). A análise de variância simples de FRIEDMAN (1937) indicou a existência de diferenças estatisticamente significativas, $\left(\chi^{2}=50,672, p<0,000\right)$, embora 0 teste de WILCOXON (1945) não tenha detectado o sítio dessas diferenças. 
QUADRO 2-Migração dos sujeitos na condição 2 em número e em porcentagem.

\begin{tabular}{|c|c|c|c|c|c|c|c|c|c|}
\hline & & & & ondição & C-1 & & & & Total \\
\hline & NIVEL & 2 & 3 & 4 & 5 & 6 & 7 & 8 & \\
\hline & 2 & 3 & 4 & 1 & & & & & 8 \\
\hline & & $5,4 \%$ & $7,1 \%$ & $1,8 \%$ & & & & & $14,3 \%$ \\
\hline & 3 & & 4 & 3 & & & & & 7 \\
\hline & & & $7,1 \%$ & $5,4 \%$ & & & & & $12,5 \%$ \\
\hline & 4 & & 1 & 6 & 3 & 1 & & & 11 \\
\hline ن & & & $1,8 \%$ & $10,7 \%$ & $5,4 \%$ & $1,8 \%$ & & & $19,6 \%$ \\
\hline 㞼 & 5 & & & & 5 & 3 & 2 & & 10 \\
\hline 응 & & & & & $8,9 \%$ & $5,4 \%$ & $3,6 \%$ & & $17,9 \%$ \\
\hline & 6 & & & & & 9 & 4 & & 13 \\
\hline & & & & & & $16,1 \%$ & $7,1 \%$ & & $23,2 \%$ \\
\hline & 7 & & & & & & 6 & & 6 \\
\hline & & & & & & & $10,7 \%$ & & $10,7 \%$ \\
\hline & 8 & & & & & & & 1 & 1 \\
\hline & & & & & & & & $1,8 \%$ & $1,8 \%$ \\
\hline Total & $\mathbf{N}^{\circ}$ & 3 & 9 & 10 & 8 & 13 & 12 & 1 & 56 \\
\hline & $\%$ & $5,4 \%$ & $16,1 \%$ & $17,9 \%$ & $14,3 \%$ & $23,2 \%$ & $21,4 \%$ & $1,8 \%$ & $100,0 \%$ \\
\hline
\end{tabular}

A inspeção do comportamento dos individuos dentro de cada grupo indica que dois deles não apresentaram qualquer alteração (TABELA 9). Isso ocorreu justamente em grupos opostos N2 e N8. Isso indica que por caminhos diferentes os dois grupos fizeram ajustes no comportamento sem incorrer em mudanças no seqüenciamento da ação. A seguir o grupo com maior porcentagem 
de permanência foi o N6 (69,2\%) seguido do N5 (62,5\%) e do N4 (60\%). Os padrões nesses níveis caracterizaram-se pela ausência da respiração bilateral ou lateral, ou seja a cabeça é mantida fixa com imersões e submersões irregulares por meio de flexão e extensão. Esse procedimento facilita a visualização dos obstáculos. Essa pode ser a explicação para uma menor permanência dos sujeitos no N7 (50\%). Nesse nível, a respiração é bilateral com o sujeito mantendo o rosto dentro da água, apenas fazendo um giro lateral para respirar. Isso poderia ter causado uma maior dificuldade para a visualização das bóias. Para contornar essa dificuldade os sujeitos elevam a cabeça ocasionando dessa forma a "queda" do quadril e conseqüentemente uma alteração descendente entre os níveis. $O$ mesmo raciocínio pode ser aplicado para dar conta das mudanças que em menor porcentagem ocorreram sempre em direção descendente, com apenas uma exceção (um indivíduo que foi do N3 para o N4).

TABELA 9-Alterações no nível de desenvolvimento aquático na $\mathrm{C} 1$ para $\mathrm{C} 2$.

\begin{tabular}{ccccc}
\hline C1-C2 & $\begin{array}{c}\text { Permanecem } \\
\%\end{array}$ & $\begin{array}{c}\text { Mudam } \\
\%\end{array}$ & $\begin{array}{c}\text { Ascendente } \\
\%\end{array}$ & $\begin{array}{c}\text { Descendente } \\
\%\end{array}$ \\
\hline N2 (n=03) & 100,00 & - & - & - \\
N3 (n=09) & 44,50 & 55,50 & 11,20 & 44,30 \\
N4 $(n=10)$ & 60,00 & 40,00 & - & 40,00 \\
N5 $(n=08)$ & 60,00 & 40,00 & - & 40,00 \\
N6 $(n=13)$ & 62,50 & 37,50 & - & 37,50 \\
N7 $(n=12)$ & 50,00 & 30,80 & - & 30,80 \\
N8 $(n=01)$ & 100,00 & - & - & - \\
\hline
\end{tabular}

A C2 envolve não só maior demanda visual para a orientação do deslocamento, como também maior ajuste na postura. As mudanças 
descendentes podem estar associadas às tentativas de estabilidade corporal. Isto é, ao elevar a cabeça momentaneamente o posicionamento na água é modificado ocasionando um aumento do ângulo do corpo em relação à linha d'água. Sendo esse ângulo um dos critérios utilizados para definir o nível de desenvolvimento aquático, a sua alteração levou, conseqüentemente, a uma mudança no nível de desenvolvimento dos sujeitos. Essa demanda de ajuste da posição corporal foi sentida em todos os níveis, porém somente no N7 houve diferença estatisticamente significante $(Z=-2,449, p<0,014)$.

\subsection{Transições entre C1 e C3}

A tarefa em C3 exigia do sujeito empreender velocidade máxima no deslocamento. Pode-se supor que os ajustes necessários a essa restrição da tarefa seriam acomodados por modificações paramétricas. De fato, a porcentagem de permanência aumentou $(71,4 \%)$ em relação à condição anterior (C1 vs. C2). Entretanto, é interessante notar que, quando houve mudança, ela ocorreu predominantemente na direção ascendente $(21,4 \%)$, fato que pode ser interpretado como uma melhoria na programação da ação (QUADRO 3). 
QUADRO 4-Migração dos sujeitos na condição 3 em número e em porcentagem.

\begin{tabular}{|c|c|c|c|c|c|c|c|c|c|}
\hline \multicolumn{9}{|c|}{ Condição C-1 } & Total \\
\hline \multirow{14}{*}{ 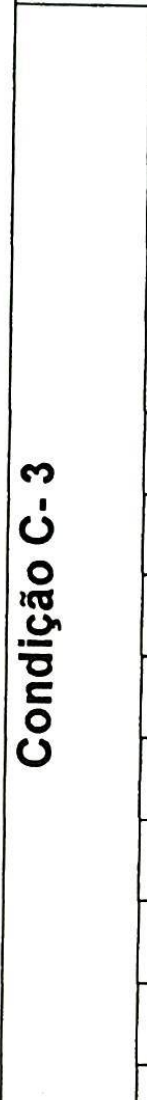 } & NÍVEL & 2 & 3 & 4 & 5 & 6 & 7 & 8 & \\
\hline & 2 & 1 & & & & & & & 1 \\
\hline & & $1,8 \%$ & & & & & & & $1,8 \%$ \\
\hline & 3 & 1 & 4 & & & & & & 5 \\
\hline & & $1,8 \%$ & $7,1 \%$ & & & & & & $8,9 \%$ \\
\hline & 4 & 1 & 4 & 8 & 2 & & & & 15 \\
\hline & & $1,8 \%$ & $7,1 \%$ & $14,3 \%$ & $3,6 \%$ & & & & $26,8 \%$ \\
\hline & 5 & & 1 & & 4 & 2 & & & 7 \\
\hline & & & $1,8 \%$ & & $7,1 \%$ & $3,6 \%$ & & & $12,5 \%$ \\
\hline & 6 & & & 2 & 2 & 10 & & & 14 \\
\hline & & & & $3,6 \%$ & $3,6 \%$ & $17,9 \%$ & & & $25,0 \%$ \\
\hline & 7 & & & & & 1 & 12 & & 13 \\
\hline & & & & & & $1,8 \%$ & $21,4 \%$ & & $23,2 \%$ \\
\hline & 8 & & & & & & & 1 & 1 \\
\hline \multirow{3}{*}{ Total } & & & & & & & & $1,8 \%$ & $1,8 \%$ \\
\hline & $\mathbf{N}^{\circ}$ & 3 & 9 & 10 & 8 & 13 & 12 & 1 & 56 \\
\hline & $\%$ & $5,4 \%$ & $16,1 \%$ & $17,9 \%$ & $14,3 \%$ & $23,2 \%$ & $21,4 \%$ & $1,8 \%$ & $100,0 \%$ \\
\hline
\end{tabular}

Como seria esperado, a alteração na restrição da tarefa nas C2 e C3 geraram padrões diferentes. Com o aumento da velocidade há uma maior permanência sugerindo a predominância de ajustes paramétricos. Todavia quando há mudança no seqüenciamento ela incorre em melhoria da ação, ou seja, em mudança ascendente nos níveis de desenvolvimento. 
De qualquer forma, reforçando a constatação de uma maior tendência à permanência, não foram encontradas diferenças estatisticamente significantes com a condução da análise de variância simples de FRIEDMAN (1937).

Contrariamente à $\mathrm{C} 2$, os grupos que não modificaram o padrão de movimento foram o N7 e o N8 (TABELA 10). Esses grupos apresentaram o padrão de nado crawl, reconhecidamente mais eficiente para o empreendimento de velocidade máxima. Assim, não haveria por que mudar o padrão. É interessante que os indivíduos do N2 mostraram uma maior tendência à mudança ascendente $(66,7 \%)$. Eles migraram para o $\mathrm{N} 3$ e o $\mathrm{N} 4$ os quais, embora sejam padrões rudimentares, são padrões intermediários em direção ao nado crawl.

Um resultado anômalo foi apresentado pelos grupos N5 e N6. Dentre os indivíduos que mudaram o comportamento, parte deles mudou na direção descendente, isto é, apresentando um padrão mais rudimentar. Isso pode indicar que o padrão apresentado na $\mathrm{Cl}$ era instável e fruto, talvez, de uma transição recente.

TABELA 10-Alterações no nível de desenvolvimento aquático na $\mathrm{Cl}$ para $\mathrm{C} 3$.

\begin{tabular}{ccccc}
\hline C1-C3 & $\begin{array}{c}\text { Permanecem } \\
\mathbf{\%}\end{array}$ & $\begin{array}{c}\text { Mudam } \\
\mathbf{\%}\end{array}$ & $\begin{array}{c}\text { Ascendente } \\
\mathbf{\%}\end{array}$ & $\begin{array}{c}\text { Descendente } \\
\%\end{array}$ \\
\hline N2 (n=03) & 33,33 & 66,66 & 66,66 & - \\
N3 (n=09) & 44,44 & 55,56 & 11,11 & 44,45 \\
N4 (n=10) & 80,00 & 20,00 & 20,00 & - \\
N5 (n=08) & 50,00 & 50,00 & 25,00 & 25,00 \\
N6 $(\mathbf{n = 1 3})$ & 76,90 & 23,10 & 7,70 & 15,40 \\
N7 $(\mathbf{n = 1 2})$ & 100,00 & - & - & - \\
N8 $(\mathbf{n = 0 1 )}$ & 100,00 & - & - & - \\
\hline
\end{tabular}




\subsection{Transição de C1 para C4}

A condição $\mathrm{C} 4$ exigia mudanças na velocidade ( nadar o mais rápido possível) e na direção (contornar as bóias). A tendência geral foi de permanência posto que $60 \%$ dos indivíduos não alteraram o padrão. Dentre os cerca de $40 \%$ que mudaram, apenas 3,6 \% mudaram na direção ascendente, enquanto 35,8\% apresentaram um padrão mais rudimentar. A análise de variância simples de FRIEDMAN (1937) detectou diferenças estatisticamente significantes $\left(\chi^{2}=50,672, p<0,000\right)$; o sítio dessas alterações se deu no N7 onde o teste nãoparamétrico para medidas não pareadas de WILCOXON (1945) apontou diferenças significativas $(Z=-2,449, \mathrm{p}<0,014)$ (ver QUADRO 5). 
QUADRO 5-Migrações do sujeitos na condição 4 em número e porcentagem.

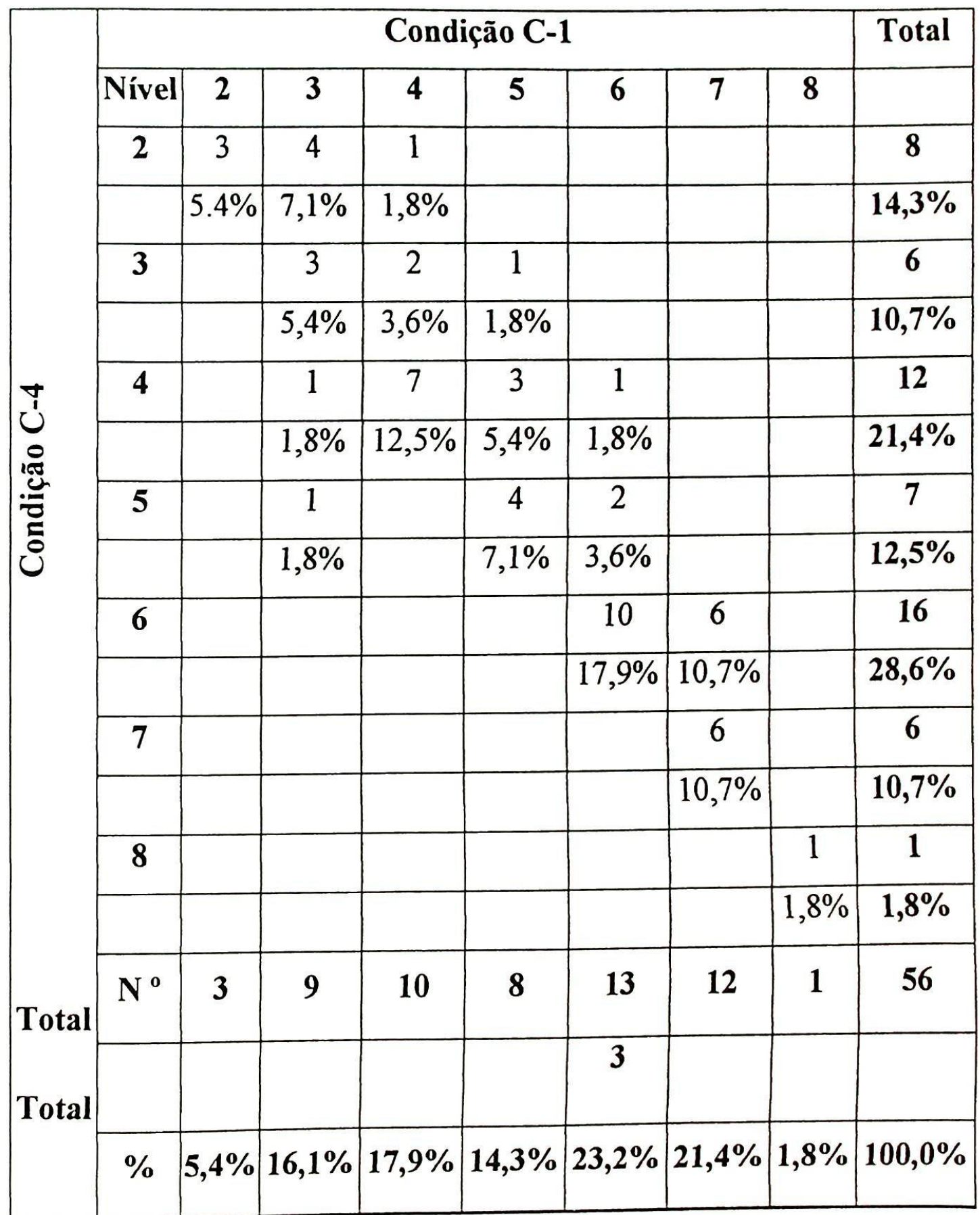

A tendência à permanência é evidente nos grupos N2 e N8 (100\%) e nos grupos $\mathrm{N} 4(70 \%)$ e N6 (76,9\%) (TABELA 11). Os grupos N5 e N7 apresentaram valores iguais para a permanência (50\%) e mudanças $(50 \%)$. O N3 
foi o único grupo em que a porcentagem de mudanças $(66,6 \%)$ foi maior que a de permanência $(33,4 \%)$.

TABELA 11-Alterações no nível de desenvolvimento aquático na $\mathrm{C} 1$ para $\mathrm{C} 4$.

\begin{tabular}{ccccc}
\hline C1-C4 & $\begin{array}{c}\text { Permanecem } \\
\%\end{array}$ & $\begin{array}{c}\text { Mudam } \\
\%\end{array}$ & $\begin{array}{c}\text { Ascendente } \\
\%\end{array}$ & $\begin{array}{c}\text { Descendente } \\
\%\end{array}$ \\
\hline N2 $(\mathbf{n}=\mathbf{0 3})$ & 100,00 & - & - & - \\
N3 $(\mathbf{n}=\mathbf{0 9})$ & 33,40 & 66,60 & 22,30 & 44,30 \\
N4 $(\mathbf{n}=\mathbf{1 0})$ & 70,00 & 30,00 & - & 30,00 \\
N5 $(\mathbf{n}=\mathbf{0 8})$ & 50,00 & 50,00 & - & 50,00 \\
N6 $(\mathbf{n}=\mathbf{1 3})$ & 76,90 & 23,10 & - & 23,10 \\
N7 $(\mathbf{n}=\mathbf{1 2})$ & 50,00 & 50,00 & - & 50,00 \\
N8 $(\mathbf{n = 0 1 )}$ & 100,00 & - & - & - \\
\hline
\end{tabular}

Reforçando a idéia de que a $\mathrm{C} 4$ é a mais dificil dentre as demais condições, está o fato de as mudanças terem sido em sua maioria na direção descendente. A exceção foi $\mathrm{N} 3$ em que $22,3 \%$ dos sujeitos progrediram nos níveis de desenvolvimento.

As migrações observadas dentro dos grupos representaram de uma maneira clara que quando se alterou apenas um aspecto paramétrico da tarefa, no caso a velocidade, a tendência foi que os indivíduos apresentaram padrões mais "evoluídos" podendo, portanto, ser classificados em níveis mais avançados.

As condições em que houve a necessidade de mudança de direção incorreram numa maior incidência de comportamentos mais elementares entre os sujeitos. As mudanças de direção obrigam a que haja uma mudança de seqüenciamento e a que se elabore, por conseguinte, um novo programa de ação para dar conta desse aumento de complexidade. 


\subsection{Comentários gerais sobre as condições em relação à configuração total do corpo}

No geral, a manipulação das restrições da tarefa não foi grande o suficiente para causar mudanças abrangentes entre os indivíduos. Em todas as condições, mais da metade dos sujeitos não alteraram o comportamento. Isso pode significar que grande parte dos sujeitos tinha um padrão estável, sendo que os ajustes devem ter sido de ordem paramétrica ou confinados a alguns componentes da habilidade. Essas possibilidades são investigadas a seguir. Antes disso, vale ressaltar que a $\mathrm{C} 3$ foi onde houve menor número de mudança entre os sujeitos $(28,6 \%)$. Entretanto, essa foi a condição em que as mudanças tenderam a ser ascendentes (21,4\% dos sujeitos).

Já na C4 ocorreu o inverso. Essa condição gerou mais mudanças (ao redor de $39 \%$ dos sujeitos) e na direção descendente (em torno de 36\%). Dessa forma, é possível dizer que, em relação às mudanças, o aumento de velocidade (C3) tende a induzir uma melhora no padrão, enquanto as mudanças de direção (C2) induzem à execução de padrões mais primitivos. A mudança de direção é uma restrição que se sobrepõe à mudança de velocidade, posto que a freqüência e direção de mudanças em C4 parecem ser similares às observadas em C2.

\subsection{Analise por componentes}

A análise do padrão mediante a configuração total do corpo tem a vantagem da síntese, permitindo uma categorização global do comportamento apresentado. Entretanto, essa forma de análise tem como desvantagem a perda de informações sobre como o padrão é mantido ou modificado. A análise por componentes permite focalizar em mais detalhe o padrão. Assim, será possível 
identificar que componente é mais instável ou estável, quando o individuo transita entre as condições.

\subsubsection{Posição do corpo}

O componente posição do corpo (PC) consiste de quatro níveis. Com a condução de uma análise de variância simples de FRIEDMAN (1937) foram identificadas mudanças significantes para os indivíduos em estágios de desenvolvimento mais avançados $\left(\chi^{2}=89,379, \mathrm{p}<0.001\right)$. Para verificar o nível e a condição em que essas diferenças foram significantes aplicou-se o teste de WILCOXON (1945). Esse teste identificou que o sítio das alterações encontravase nos níveis N5, N6 e N7.

No N5 houve alteração significativa da $\mathrm{C} 1$ para $\mathrm{C} 4(\mathrm{Z}=-2,565 \mathrm{p}<$ 0,010), ou seja, a posição do corpo foi modificada quando houve mudança de direção combinada com aumento da velocidade. Para o N6, a mudança significativa ocorreu também da $\mathrm{Cl}$ para $\mathrm{C} 4(Z=-3,219, \mathrm{p}<0,001)$. Já no $\mathrm{N} 7$ as alterações significativas ocorreram em duas condições $C 1$ para $C 2(Z=-2,449, p<$ $0,014)$ e na $C 1$ para $C 4(Z=-3,126, p<0,002)$. Em ambos os grupos as mudanças ocorreram predominantemente na $\mathrm{C} 4$. Apenas o grupo N7 apresentou mudanças em $\mathrm{C} 2$ e todas elas foram em direção a niveis mais elementares (ver TABELA 12). 
TABELA 12-Variação da posição do corpo nas diferentes condições e o nivel de significância.

\begin{tabular}{ccccccccc} 
& Grupo & N2 & N3 & N4 & N5 & N6 & N7 & N8 \\
Condição & & & & & & & & \\
C1-C2 & - & - & - & - & - & $0,014^{*}$ & - \\
C1-C3 & - & - & - & - & - & - & - \\
C1-C4 & - & - & - & $0,010^{*}$ & $0,001^{*}$ & $0,002^{*}$ & - \\
\hline
\end{tabular}

*Significante ao nível $\mathrm{p}<0,016$

Os grupos em níveis mais rudimentares e intermediários não modificaram a posição do corpo (PC) significativamente. Apenas os indivíduos em níveis mais avançados o fizeram e ainda assim de forma predominante na condição em que velocidade e direção foram alteradas. A ocorrência dessas mudanças pode estar associada ao fato de esses indivíduos serem mais habilidosos. Por exemplo, quanto maior é a velocidade mais próximo à superficie estará o corpo do nadador, possibilitando com isso que ele seja classificado em níveis mais avançados. Vários autores (por exemplo COSTILL, MAGLISHO \& RICHARDSON, 1992; COUNSILMAN, 1968; HAY, 1981; MAGLISHO,1986; REIS, 1972) afirmam que quanto maior é a velocidade de deslocamento na água melhor será a posição do corpo. À medida que os sujeitos são classificados em níveis mais avançados eles parecem demonstrar um maior controle sobre esse componente.

A ausência de alterações nos demais níveis sugere que para os demais grupos a PC seja bem estável ainda que a posição corporal não esteja muito próxima da superficie o que acaba dificultando o deslocamento desses sujeitos. 
As mudanças ocorridas na posição do corpo em cada condição são apresentadas pelos QUADROS 6, 7,8.

Observa-se que essas alterações quase sempre foram em direção a níveis elementares nas condições em que houve mudança de direção, (C2 e C4). $\mathrm{Na}$ C4, 10 sujeitos foram classificados no nível 1 "vertical", o nível mais elementar desse componente. Já na condição com alteração de velocidade houve uma tendência dos sujeitos em alterar a posição do corpo em direção à níveis mais avançados.

QUADRO 6-Mudanças na posição do corpo na $\mathrm{C} 1$ vs. C2.

\begin{tabular}{|r|r|r|r|r|r|r|}
\hline \multicolumn{7}{|c|}{ Mudanças na posição do corpo entre C1 vs.C2 } \\
\hline \multirow{3}{*}{$\sim$} & 1 & 2 & 3 & 4 & TOTAL \\
\cline { 2 - 7 } & & 2 & 22 & & 18 & 40 \\
\cline { 2 - 7 } & & 3 & 8 & 1 & 2 & 11 \\
\cline { 2 - 7 } & & 4 & 3 & & 2 & 5 \\
\cline { 2 - 7 } & TOTAL & & 33 & 1 & 22 & 56 \\
\hline
\end{tabular}

*Significante ao nível $\mathrm{p}<0,016$

QUADRO 7-Mudanças na posição do corpo na C1 vs. C3.

\begin{tabular}{|r|r|r|r|r|r|r|}
\hline \multicolumn{7}{|c|}{ Mudanças na posição do corpo entre C1 vs.C3 } \\
\hline \multirow{3}{*}{$\infty$} & \multicolumn{7}{|c|}{ PC 1 } \\
\cline { 2 - 7 } & & 1 & 2 & 3 & 4 & TOTAL \\
\cline { 2 - 7 } & & 2 & 28 & & 5 & 33 \\
\cline { 2 - 7 } & & 3 & - & 1 & - & 1 \\
\cline { 2 - 7 } & TOTAL & 4 & 6 & & 16 & 22 \\
\cline { 2 - 7 } & & & 34 & 1 & 21 & 56 \\
\hline
\end{tabular}


QUADRO 8-Mudanças na posição do corpo na $\mathrm{Cl}$ vs. C4.

\begin{tabular}{|c|c|c|c|c|c|c|}
\hline \multicolumn{7}{|c|}{ Variação da posição do corpo entre Cl vs.C4 } \\
\hline \multirow{6}{*}{\begin{tabular}{l}
$\forall$ \\
\hdashline
\end{tabular}} & \multicolumn{6}{|c|}{ PC 1} \\
\hline & & 1 & 2 & 3 & 4 & TOTAL \\
\hline & & 1 & 7 & 1 & 2 & 10 \\
\hline & & 2 & 6 & - & 6 & 12 \\
\hline & & 3 & 9 & - & 9 & 18 \\
\hline & & 4 & 11 & - & 5 & 16 \\
\hline & TOTAL & & 33 & 1 & 22 & 56 \\
\hline
\end{tabular}

*Significante ao nível $\mathrm{p}<0,016$

\subsubsection{Ação do braço}

O componente ação do braço $(\mathrm{AB})$ consiste de cinco níveis. $\mathrm{A}$ inspeção dos dados entre as condições (TABELA 13) leva à constatação de que $\mathrm{AB}$ mudou de forma significativa como foi detectado pela ANOVA simples de FRIEDMAN $(1937)\left(\chi^{2}=52,817, \mathrm{p}<0,000\right)$.

O teste não-paramétrico de WILCOXON (1945) foi conduzido para identificar o sítio das alterações nas diferentes condições. Assim houve diferenças significativas na $\mathrm{AB}$ para o $\mathrm{N} 3$ na condição $\mathrm{C} 2$ para $\mathrm{C} 4(\mathrm{Z}=-2,428, \mathrm{p}<$ 0,015); para o N6 na condição $C 1$ para $C 2(Z=-2,565, \mathrm{p}<0,010)$ e $C 1$ para $C 4$ $(Z=-3,051), p<0,002)$ e no N7 na condição $C 1$ para $C 4(Z=-2,496, p<0,013)$. 
TABELA 13-Variações no componente ação do braço nos grupos e condições.

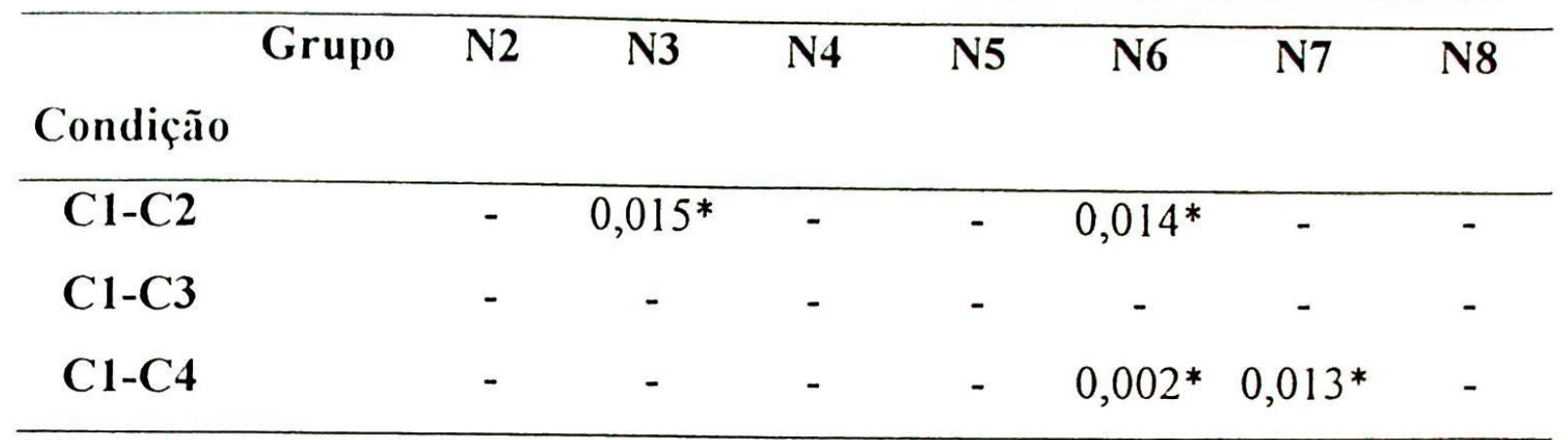

* Significante ao nível de $\mathrm{p}<0,016$

As alterações seqüenciais no $\mathrm{AB}$ ocorreram quando foi solicitada a mudança de direção ou mudança de direção associada à alteração da velocidade.

Observou-se que na transição C1-C2 dois grupos apresentaram diferenças significativas na $A B$ ( N3 e N6), enquanto que na $C 4$ apenas os sujeitos dos grupos mais avançados apresentaram alterações significativas nesses componentes. Os QUADROS 9,10 e 11 apresentam a direção dessas alterações em cada uma das condições do estudo.

$\mathrm{Na}$ transição $\mathrm{C} 1-\mathrm{C} 2$ verifica-se uma tendência à progressão nos níveis de desenvolvimento. No nível 2 havia 11 indivíduos na $\mathrm{C} 1$. $\mathrm{Na} \mathrm{C} 2$, apenas três permaneceram no nível 2 os demais progrediram para os níveis 3 (sete indivíduos) e nível 4 (um indivíduo). No nível 3 havia 20 indivíduos na $\mathrm{Cl}$, já na passagem para $\mathrm{C} 2,11$ permaneceram no nível 3, mas sete foram para o nível 4 e dois foram para o nível 5. No nível 4 havia 13 indivíduos na $\mathrm{Cl}$ e desses, seis permaneceram na $\mathrm{C} 2$ mas seis progrediram para o nível 5. Apenas um indivíduo foi para o nível 3. Finalmente, no nível 5 todos os indivíduos (12) permaneceram na C2 (QUADRO 9). 
QUADRO 9-Variações no componente ação do braço entre C1 vs. C2.

\begin{tabular}{|c|c|c|c|c|c|c|c|}
\hline \multicolumn{8}{|c|}{ Variação da posição do corpo entre C1 vs.C2 } \\
\hline \multirow{8}{*}{ 安 } & \multicolumn{7}{|c|}{$\mathrm{AB}-2$} \\
\hline & & 1 & 2 & 3 & 4 & 5 & TOTAL \\
\hline & 1 & - & - & - & - & - & . \\
\hline & 2 & - & 3 & 7 & 1 & - & 11 \\
\hline & 3 & - & 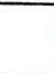 & 11 & 7 & 2 & 20 \\
\hline & 4 & - & - & 1 & 6 & 6 & 13 \\
\hline & 5 & - & - & - & - & 12 & 12 \\
\hline & Total & - & 3 & 19 & 14 & 20 & 56 \\
\hline
\end{tabular}

*Significante ao nível $\mathrm{p}<0,016$

$\mathrm{Na}$ transição $\mathrm{C} 1-\mathrm{C} 3$ ocorreram mudanças em todos os niveis. No nível 2 havia onze indivíduos na $\mathrm{Cl}$ dos quais nove permaneceram no mesmo nível na C3. Dois indivíduos progrediram para o nível 3.

Dos vinte sujeitos no nível 3 quatro mudaram para o nível 2 e cinco foram para o nível 5 . $\mathrm{Na} \mathrm{C1}$ havia 13 sujeitos no nível 4, dos quais três foram para o nível 5 e um para o nível 3. No nível 5, 12 sujeitos estavam na $\mathrm{Cl}$ e desses dois foram para o nível 4, enquanto que dez permaneceram no mesmo nível (QUADRO 10)

Para a transição C1-C3 foi possível observar uma estabilidade nos níveis extremos (2 e 5) do componente $A B$, enquanto que os níveis intermediários ( 3 e 4 ) apresentaram um pequeno crescimento, ainda que não confirmado estatisticamente (QUADRO 10). 
QUADRO 10-Variações no componente ação do braço entre $\mathrm{C} 1$ vs. C3.

\begin{tabular}{|c|c|c|c|c|c|c|c|}
\hline \multicolumn{8}{|c|}{ Variação da posição do corpo entre $\mathrm{Cl}$ vs.C3 } \\
\hline \multirow{8}{*}{$\bar{q}$} & \multicolumn{7}{|c|}{ AB-3 } \\
\hline & & 1 & 2 & 3 & 4 & 5 & TOTAL \\
\hline & 1 & - & - & - & - & - & - \\
\hline & 2 & - & 9 & 2 & - & - & 11 \\
\hline & 3 & - & 4 & 11 & 5 & - & 20 \\
\hline & 4 & - & - & 1 & 9 & 3 & 13 \\
\hline & 5 & - & - & - & 2 & 10 & 12 \\
\hline & TOTAL & - & 13 & 14 & 16 & 13 & 56 \\
\hline
\end{tabular}

Para a transição $\mathrm{Cl}$-C4 houve uma tendência à permanência. Isso ocorreu para o nível 2, 3 e 4 ( ver QUADRO 10). Já no nível 5 todos apresentaram mudanças descendentes, isto é, dez foram para o nível 4 e dois para o nível 3.

QUADRO 11-Variações no componente ação do braço entre $\mathrm{C} 1$ vs. C4.

\begin{tabular}{|r|r|r|r|r|r|r|r|}
\hline \multicolumn{7}{|c|}{ Variação da posição do corpo entre C1 vs.C4 } \\
\hline \multirow{4}{*}{$\bar{*}$} & \multicolumn{7}{|c|}{ AB-4 } \\
\cline { 2 - 8 } & & 1 & 2 & 3 & 4 & 5 & TOTAL \\
\cline { 2 - 8 } & 1 & - & - & - & - & - & - \\
\cline { 2 - 8 } & 2 & - & 7 & 4 & - & - & 11 \\
\cline { 2 - 8 } & 3 & - & 3 & 16 & 1 & - & 20 \\
\cline { 2 - 8 } & 4 & - & - & 11 & 2 & - & 13 \\
\hline & - & - & 2 & 10 & - & 12 \\
\hline
\end{tabular}

*Significante ao nível $\mathrm{p}<0,016$ 


\subsubsection{Recuperação do braço}

O componente recuperação dos braços (RB) consiste de cinco níveis. A análise de variância simples de FRIEDMAN (1937) identificou algumas variações significantes dos níveis de desenvolvimento entre as condições $R B\left(\chi^{2}=89.699, \mathrm{p}<0,000\right)$.

$\mathrm{O}$ teste não-paramétrico para medidas repetidas de WILCOXON (1945) apontou diferenças significativas para os níveis N3 $(Z=-2,646), p<$ 0,008), N4 $(Z=-2,449), p<0,014), N 6(Z=-3,464, P<0,001)$ e N7 $(Z=-3,127, p<$ 0,002). Em todos os casos isso ocorreu da condição $C 1$ para C4 (ver TABELA 14).

TABELA 14-Variação do componente recuperação do braço nos grupos e condições.

$\begin{array}{llllllll}\text { Nível } & \mathrm{N} 2 & \mathrm{~N} 3 & \mathrm{~N} 4 & \mathrm{~N} 5 & \mathrm{~N} 6 & \mathrm{~N} 7 & \mathrm{~N} 8\end{array}$

\section{Condição}

\begin{tabular}{lllllll}
\hline $\mathrm{C} 1-\mathrm{C} 2$ & - & - & - & - & -
\end{tabular}

$\begin{array}{llcclll}\mathbf{C} 1-\mathrm{C} 3 & - & - & - & - & - \\ \mathrm{C} 1-\mathrm{C} 4 & - & 0,008^{*} & 0,014^{*} & - & 0,001^{*} & 0,002^{*}\end{array}$

* Significante ao nível $\mathrm{p}<0,016$

A tendência apresentada pelos sujeitos com respeito ao componente (RB) foi de estabilidade em todas as condições do estudo. As diferenças estatisticamente significantes foram observadas na C4 nos grupos N3 e N4 que apresentaram uma RB rudimentar e nos grupos N6 e N7 que mostraram uma recuperação com o "cotovelo alto". Dependendo da condição, os sujeitos 
migravam para a recuperação com os braços estendidos. Os QUADROS 12, 13 e 14 apresentam as alteraçõe do componente $\mathrm{RB}$ nas condições de estudo.

$\mathrm{Na}$ transição $\mathrm{C} 1-\mathrm{C} 2$, o nível 2 se mantém praticamente inalterado; com os niveis 3, 4 e 5 apresentando mudanças na direção descendente. No nível 4 , isso corresponde a quase $50 \%$ dos indivíduos. Das três crianças que se classificaram no nível 2, quando executaram a condição $\mathrm{C} 2$, uma permaneceu no mesmo nível e duas alteraram a sua performance, indo para o nível 3. No nível 3 encontramos vinte e três crianças, das quais 18 (a maioria) permaneceram no mesmo nível e quatro mudaram em direção descendente para o nível 2 e somente uma progrediu para o nível 4 . No nível 4 foram classificados 17 sujeitos, sendo que 11 permaneceram no mesmo nível na condição C2 e seis migraram em direção descendente para o nível 3. Finalmente, para o nível 5 tivemos 13 sujeitos classificados, sendo que nessa transição oito permaneceram enquanto que cinco alteraram para níveis mais elementares, quatro para o nível 4 e uma para o nível 3 (QUADRO 12). 
QUADRO 12-Variações no componente recuperação do braço entre $\mathrm{Cl}$ vs. C2.

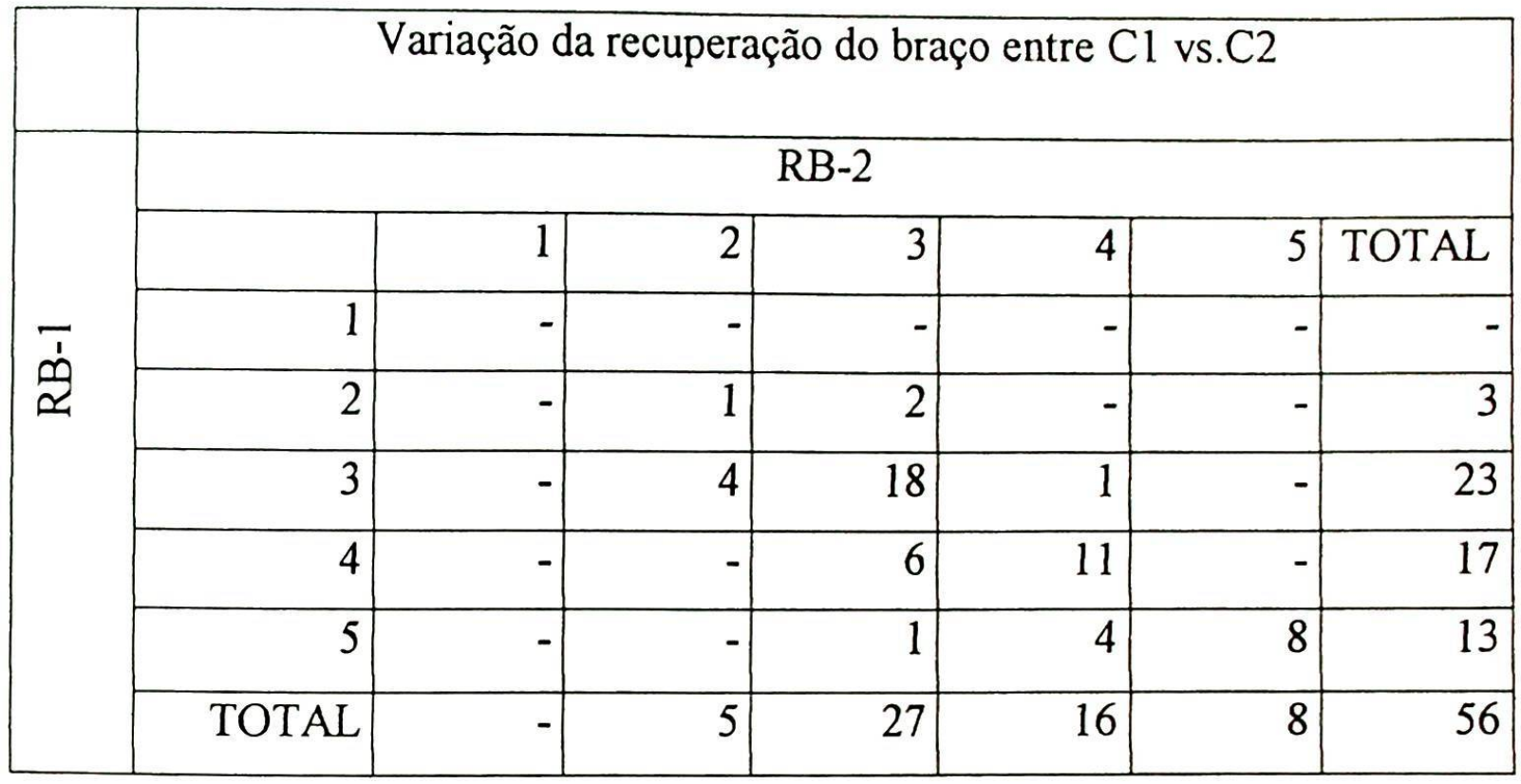

$\mathrm{Na}$ transição C1-C3, os sujeitos pouco alteraram, pois a maioria permaneceu em seus níveis iniciais. No nível 2, os três indivíduos permaneceram. No nível 3 foram classificados 23 sujeitos dos quais 17 permaneceram nesse nível, houve uma mudança descendente para o nível 2 e cinco mudanças ascendentes, uma para o nível 5 e quatro para o nível 4 . No nível 4, dos 17 classificados apenas cinco mudaram, quatro na descendente para 0 nível 3 e uma na ascendente para o nível 5. Finalmente, no nível 5 houve apenas uma mudança e essa foi em sentido descendente para o nível 4 (QUADRO 13). 
QUADRO 13-Variações no componente recuperação do braço entre C1 vs. C3.

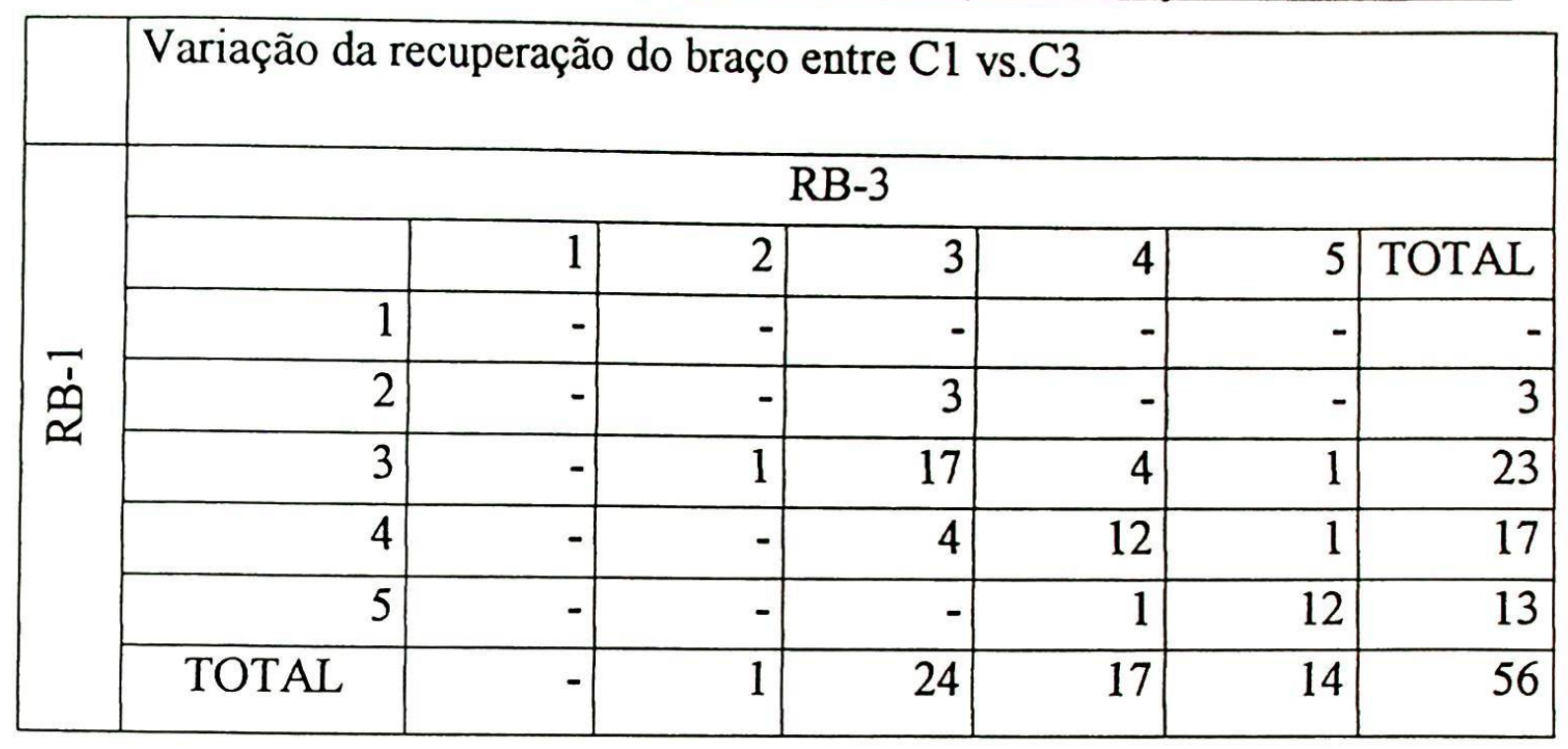

Na transição C1-C4 em que os sujeitos também apresentaram uma tendência à estabilidade, as mudanças foram predominantemente na direção descendente com apenas quatro em direção ascendente (três do nivel 3 para o nível 4 e uma do nível 4 para o nivel 5). Assim, no nível 2 os três sujeitos permaneceram em seus respectivos níveis. No nível 3 foram classificados 23 sujeitos, sendo que 16 permaneceram, quatro mudaram para o nível 2 e três mudaram para o nível 4 . No nível 4, dos 17 classificados 10 permaneceram, seis foram para o nível 3 e um foi para o nível 5. Por fim, para o nível 5 todas as mudanças foram em direção descendente, sendo cinco para o nível 4 e uma para o nível 3 (QUADRO 14). 
QUADRO 14-Variações no componente recuperação do braço entre $\mathrm{Cl}$ vs. C4.

\begin{tabular}{|r|r|r|r|r|r|r|r|}
\hline \multicolumn{7}{|c|}{ Variação da recuperação do braço entre C1 vs.C4 } \\
\hline & \multicolumn{7}{|c|}{ RB-4 } \\
\cline { 2 - 8 } & & 1 & 2 & 3 & 4 & 5 & TOTAL \\
\cline { 2 - 8 } & 1 & - & - & - & - & - & - \\
\cline { 2 - 8 } & 2 & - & 3 & - & - & - & 3 \\
\cline { 2 - 8 } & 3 & - & 4 & 16 & 3 & - & 23 \\
\cline { 2 - 8 } & 4 & - & - & 6 & 10 & 1 & 17 \\
\cline { 2 - 8 } & TOTAL & - & 7 & 23 & 18 & 8 & 56 \\
\hline
\end{tabular}

\subsubsection{Aça da perna}

O componente ação da perna consiste de seis níveis de desenvolvimento. Algumas situações interessantes puderam ser verificadas nesse componente, principalmente em relação aos níveis mais elementares. Vale lembrar que para esses níveis o aumento de velocidade é, freqüentemente, sinônimo de uma ação mais vigorosa da pernada.

A análise de variância simples para os dados referentes ao componente AP nos diferentes grupos e condições indicou diferenças significativas $\left(\chi^{2}=45,468, p<0,000\right)$. O teste não-paramétrico para medidas pareadas de WILCOXON (1945) apontou diferenças significativas para os níveis N6 $(Z=-3,035), p<0,002)$ e para o nível $N 7(Z=-2,449, p<0,014)$ sempre na condição C4 (ver TABELA 15). 
TABELA 15-Variação do componente ação da perna (AP) nos grupos e condições.

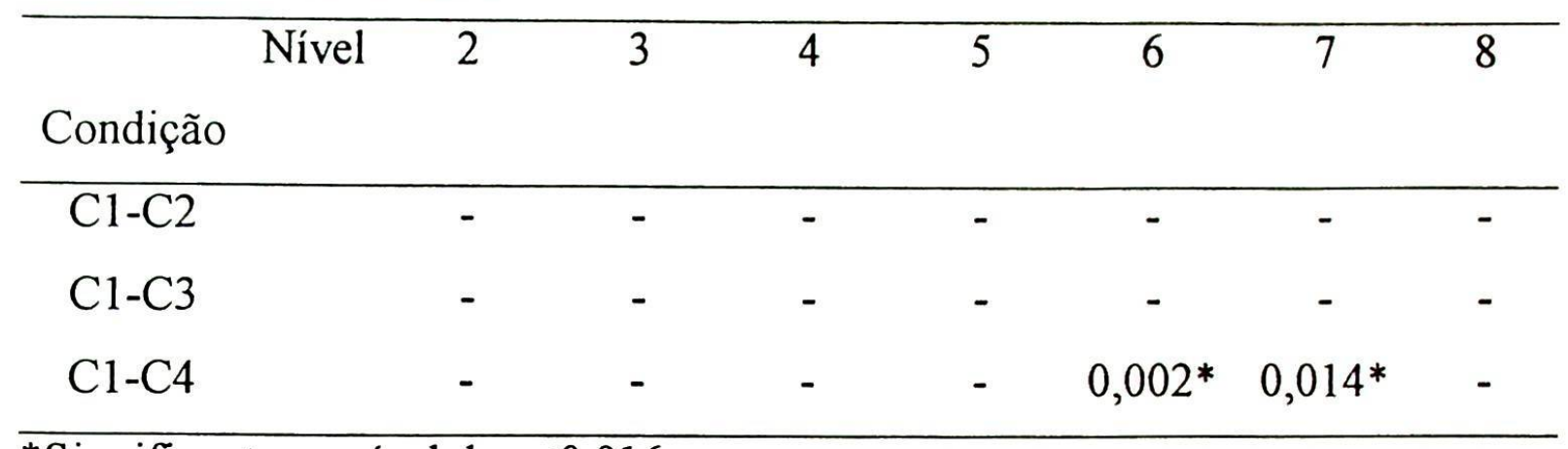

*Significante ao nível de $\mathrm{p}<0,016$

Vale comentar o resultado encontrado para o N8, Padrão crawl avançado com pernada de dois tempos. Nesse nível só havia um indivíduo que se utilizava da pernada dois tempos típica de situações de nado prolongado para equilibrar o corpo. Esse tipo de pernada já foi diversas vezes descrito por autores dentro da natação competitiva (COSTILL et al.,1992; COUNSILMAN, 1968; MAGLISHO, 1986; REISCHELE, 1993). Para esses autores, a utilização da pernada de dois tempos é uma alternativa que os nadadores "de fundo" utilizam para poupar energia em provas de longa duração tais como os 800 e 1500 metros livres e também travessias. Outro aspecto a ser enfocado refere-se ao efeito da alteração da velocidade. Sempre que isso foi solicitado houve um aumento da freqüência da pernada; entretanto isso não ocorreu com o indivíduo do N8. Nessa situação, ele aumentou a velocidade com base numa ação mais rápida da braçada.

Para o componente AP só foi observada diferença estatística nos níveis mais evoluídos (N6 e N7) na C4. A tendência apresentada por esses grupos foi de uma pernada mais eficiente que pudesse sustentar a posição do 
corpo quando houvesse a necessidade de mudança de direção. As alterações observadas nas transições C1-C2,C1-C3 e C1-C4 são apresentadas a seguir nos QUADROS 15, 16, 17.

A tendência à permanência é evidente na transição $\mathrm{C} 1-\mathrm{C} 2$. As mudanças, quando ocorreram, foram predominantemente de ordem descendente. No nível 3, quatro indivíduos migraram para o nível 2. No nível 4 oito indivíduos migraram para o nível 3 , enquanto que no nível 5 seis indivíduos migraram para o nível 4 (QUADRO 15)

QUADRO 15-Variações no componente ação da perna entre C1 vs. C2.

\begin{tabular}{|c|c|c|c|c|c|c|c|c|}
\hline & Variação d & & $a$ en & $\overline{\mathrm{C} 1 \mathrm{v}}$ & & & & \\
\hline & & & & $\mathrm{AP}$ & & & & \\
\hline & & 1 & 2 & 3 & 4 & 5 & 6 & TOTAL \\
\hline$\uparrow$ & 1 & - & - & - & - & - & - & 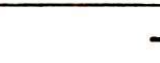 \\
\hline 究 & 2 & - & 1 & - & - & - & - & 1 \\
\hline & 3 & - & 4 & 18 & 1 & - & - & 23 \\
\hline & 4 & - & - & 8 & 11 & - & - & 19 \\
\hline & 5 & - & - & - & 6 & 6 & - & 13 \\
\hline & 6 & - & - & - & - & - & 1 & 1 \\
\hline & TOTAL & - & 5 & 26 & 18 & 6 & 1 & 56 \\
\hline
\end{tabular}

$\mathrm{Na}$ transição $\mathrm{C} 1-\mathrm{C} 3$, encontrou-se progressões nos níveis 2 (três indivíduos foram para o nível 3) e nível 3 (quatro indivíduos para o nível 4 e um para o nível 5). No nível 4 as mudanças foram predominantemente na direção descendente. Cinco indivíduos do nível 4 foram para o nível 3, 12 permaneceram e um indivíduo foi para o nível 5 e dois indivíduos do nível 5. No nível 5 permaneceram e um foi para o nível 4 (QUADRO 16). 
QUADRO 16-Variações no componente ação da perna entre $\mathrm{Cl}$ vs. C3.

\begin{tabular}{|c|c|c|c|c|c|c|c|c|}
\hline & \multicolumn{8}{|c|}{ Variação da ação da perna entre C1 vs.C3 } \\
\hline \multirow{9}{*}{$\hat{\tilde{d}}$} & \multicolumn{8}{|c|}{ AP-1 } \\
\hline & & 1 & 2 & 3 & 4 & 5 & 6 & TOTAL \\
\hline & 1 & - & - & - & - & - & - & - \\
\hline & 2 & - & 4 & 3 & - & - & - & 7 \\
\hline & 3 & - & 1 & 18 & 4 & & - & 23 \\
\hline & 4 & - & - & 5 & 12 & 1 & - & 18 \\
\hline & 5 & - & - & - & 2 & 5 & - & 7 \\
\hline & 6 & - & - & - & - & - & 1 & 1 \\
\hline & TOTAL & - & 5 & 26 & 18 & 6 & 1 & 56 \\
\hline
\end{tabular}

$\mathrm{Na}$ transição $\mathrm{Cl}-\mathrm{C} 4$, nota-se uma predominância da mudança em direção descendente. Dois indivíduos do nível 3 foram para o nível 2, enquanto oito indivíduos do nível 4 foram para os níveis 3 (sete) e 2 (um). No nível 5, 17 indivíduos foram para níveis inferiores, 12 para o nível 4 e cinco para o nível 3 (QUADRO 17). 
QUADRO 17-Variações no componente ação da perna entre $\mathrm{Cl}$ vs. C4.

\begin{tabular}{|c|c|c|c|c|c|c|c|c|}
\hline & Variação da & da & na e & $\mathrm{Cl}$ & & & & \\
\hline \multirow{9}{*}{$\begin{array}{l}\dot{1} \\
\stackrel{2}{4}\end{array}$} & \multicolumn{8}{|c|}{$\mathrm{AP}-1$} \\
\hline & & 1 & 2 & 3 & 4 & 5 & 6 & TOTAL \\
\hline & 1 & - & - & - & - & - & - & - \\
\hline & 2 & - & 2 & 3 & - & - & - & 5 \\
\hline & 3 & - & 2 & 11 & - & - & - & 13 \\
\hline & 4 & - & 1 & 7 & 6 & - & - & 14 \\
\hline & 5 & - & - & 5 & 12 & 6 & - & 23 \\
\hline & 6 & - & - & - & - & & 1 & 1 \\
\hline & TOTAL & - & 5 & 26 & 18 & 6 & 1 & 56 \\
\hline
\end{tabular}

*Significante ao nível de $\mathrm{p}<0,016$

\subsection{5 Índice de consistência (IC) nas diferentes condições do estudo}

O grau de estabilidade do comportamento em cada condição pode estar associado à permanência ou mudança quando os sujeitos transitam de uma condição para outra. A seguir são apresentados os dados sobre a consistência do comportamento calculado a partir do índice proposto por BARELA \& BARELA (1997), com base na categorização feita pela configuração total do corpo.

Na condição 1, o número de sujeitos cujo índice de consistência é 0,6 representa pouco mais do que $8 \%$ do total da amostra. A distribuição dos mesmos foi a seguinte: dois sujeitos em N3 um em N4, um em N5 e um em N6 (TABELA 16). No índice de consistência 0,8 encontrou-se perto de $15 \%$ da amostra e finalmente no índice 1,0 encontrou-se a maioria dos indivíduos com $76 \%$. Assim, grande parte da amostra apresenta alto índice de consistência. É 
interessante verificar como os grupos se comportam em relação a esse índice de consistência ao longo das condições

TABELA 16-Total de sujeitos por índice de consistência na condição C1.

Índice de Consistência Número de sujeitos Porcentagem

\begin{tabular}{lrr}
\hline $\mathrm{IC}=0,6$ & 5 & 8,90 \\
$\mathrm{IC}=0,8$ & 8 & 14,20 \\
$\mathrm{IC}=1$ & 43 & 76,79 \\
TOTAL & 56 & 100,00
\end{tabular}

Significante ao nível $\mathrm{p}<0,005$

Considerando os indivíduos com IC $=0,6$, a análise de variância de FRIEDMAN (1937) não identificou diferenças significantes (TABELA 17).

TABELA 17-Freqüência de indivíduos por grupo com $\mathrm{IC}=0,6$ nas condições do estudo.

\begin{tabular}{|c|c|c|c|c|c|c|c|c|}
\hline IC $=0,6$ & \multicolumn{2}{|c|}{$\begin{array}{c}\text { Sujeitos } \\
\%\end{array}$} & \multicolumn{2}{c|}{$\begin{array}{c}\text { Sujeitos } \\
\%\end{array}$} & \multicolumn{2}{c|}{$\begin{array}{c}\text { Sujeitos } \\
\%\end{array}$} & \multicolumn{2}{c|}{$\begin{array}{c}\text { Sujeitos } \\
\%\end{array}$} \\
\hline ND & \multicolumn{2}{|c|}{ C1 } & \multicolumn{2}{c|}{ C2 } & \multicolumn{2}{c|}{ C3 } & \multicolumn{2}{c|}{ C4 } \\
\hline 2 & - & - & 1 & 20,00 & & - & 1 & 20,00 \\
\hline 3 & 2 & 40,00 & - & - & - & - & - & - \\
\hline 4 & 1 & 20,00 & 3 & 60,00 & 2 & 40,00 & - & - \\
\hline 5 & 1 & 20,00 & 1 & 20,00 & 2 & 40,00 & 3 & 60,00 \\
\hline 6 & 1 & 20,00 & - & - & 1 & 20,00 & 1 & 20,00 \\
\hline 7 & - & - & - & - & - & - & - & - \\
\hline 8 & - & - & - & - & - & - & - & - \\
\hline Totais & 5 & 100,00 & 5 & 100,00 & 5 & 100,00 & 5 & 100,00 \\
\hline
\end{tabular}

ND = Nível de desenvolvimento 
Nos indivíduos com $\mathrm{FC}=0,8$ foi possível detectar alterações entre os níveis de desenvolvimento nas condições do experimento. O teste de FRIEDMAN (1937) apontou diferença significativa entre as condições $\left(\chi^{2}=11,930, \mathrm{p}<0,008\right)$. No entanto, não foi possivel identificar em qual dos níveis ocorreu essa alteração. Considerando os resultados é possivel inferir que as diferenças poderiam estar na condição $\mathrm{C} 3$, visto que o teste de WILCOXON (1945) resultou em $Z=-1,85$ e $p<0,063$, valor que está próximo do limite de corte.

TABELA 18-Frequêencia dos indivíduos por grupo com $\mathrm{IC}=0,8$ nas condições do estudo.

\begin{tabular}{|r|r|r|r|r|r|r|r|r|}
\hline IC $=0,8$ & \multicolumn{2}{|c|}{$\begin{array}{c}\text { Sujeitos } \\
\%\end{array}$} & \multicolumn{2}{c|}{$\begin{array}{c}\text { Sujeitos } \\
\%\end{array}$} & \multicolumn{2}{c|}{$\begin{array}{c}\text { Sujeitos } \\
\%\end{array}$} & \multicolumn{2}{c|}{$\begin{array}{c}\text { Sujeitos } \\
\%\end{array}$} \\
\hline ND & \multicolumn{2}{|c|}{$\mathrm{C} 1$} & \multicolumn{2}{c|}{$\mathrm{C} 2$} & \multicolumn{2}{c|}{$\mathrm{C} 3$} & \multicolumn{2}{c|}{$\mathrm{C} 4$} \\
\hline 2 & 3 & 37,50 & 4 & 50,00 & 1 & 12,50 & 4 & 50,00 \\
\hline 3 & 2 & 25,00 & 1 & 12,50 & 2 & 25,00 & & \\
\hline 4 & 1 & 12,50 & 1 & 12,50 & 2 & 25,00 & 2 & 25,00 \\
\hline 5 & 1 & 12,50 & 1 & 12,50 & - & - & - & - \\
\hline 6 & - & 0 & 1 & 12,50 & 2 & 25,00 & 2 & 25,00 \\
\hline 7 & 1 & 12,50 & 1 & 12,50 & 1 & 12,50 & - & - \\
\hline 8 & - & - & - & - & - & - & - & - \\
\hline Totais & 8 & 100,00 & 8 & 8 & 8 & 100,00 & 8 & 100,00 \\
\hline
\end{tabular}

* Significante ao nível de $\mathrm{p}<0,05$

ND = Nivel de desenvolvimento

Os grupos com IC= 1 apresentaram alterações entre os níveis de desenvolvimento nas condições do experimento. O teste de FRIEDMAN (1937) apontou diferença significativa $\left(\chi^{2}=97,409 \mathrm{p}<0,000\right)$. 
A condução do teste não-paramétrico para medidas pareadas de WILCOXON (1945) apontou diferenças significativas em C2, $(Z=-3,75467, \mathrm{p}<$ $0,000)$ e em $C 4(Z=-0,83205, p<0,000)$ (TABELA 19).

TABELA 19-Freqüência dos indivíduos por grupo com $\mathrm{IC}=1,0$ nas condições do estudo.

\begin{tabular}{|c|c|c|c|c|c|c|c|c|}
\hline $\mathrm{IC}=0,1$ & \multicolumn{2}{|c|}{$\begin{array}{c}\text { Sujeitos } \\
\%\end{array}$} & \multicolumn{2}{|c|}{$\begin{array}{c}\text { Sujeitos } \\
\%\end{array}$} & \multicolumn{2}{|c|}{$\begin{array}{c}\text { Sujeitos } \\
\%\end{array}$} & \multicolumn{2}{|c|}{$\begin{array}{c}\text { Sujeitos } \\
\%\end{array}$} \\
\hline ND & C & & C & & C & & C & \\
\hline 2 & - & - & 3 & 6,98 & - & - & 6 & 6,98 \\
\hline 3 & 5 & 11,60 & 6 & 13,95 & - & - & 6 & 13.95 \\
\hline 4 & 8 & 18,60 & 7 & 16,28 & 11 & 25,60 & 9 & 20,93 \\
\hline 5 & 7 & 16.28 & 8 & 18,60 & 5 & 11,60 & 4 & 9,30 \\
\hline 6 & 11 & 25,60 & 12 & 27,90 & 11 & 25,60 & 14 & 32,56 \\
\hline 7 & 11 & 25,60 & 6 & 13.95 & 12 & 27,90 & 6 & 13,95 \\
\hline 8 & 1 & 2,32 & 1 & 2,32 & 1 & 2,32 & 1 & 2,32 \\
\hline Totais & 43 & 100,00 & 43 & 100,00 & 43 & 100,00 & 43 & 100,00 \\
\hline
\end{tabular}

* Significante ao nível de $\mathrm{p}<0,016$

ND $=$ Nível de desenvolvimento

$\mathrm{O}$ resultado apresentado pelo grupo com $\mathrm{IC}=1$ é muito próximo ao resultado obtido pelo total da amostra. As diferenças significativas aparecem em maior número nas condições onde se exigem alterações seqüenciais na ação (C2 e C4). Já para as demais condições elas só aparecem em casos muito especiais ou sob condições mais favoráveis, isto é, em condições onde só se exigem alterações paramétricas.

Dessa forma, pode-se dizer que a consistência apresentada pelos sujeitos é um fator preponderante para que transições de um nível de organização para outro ocorram como sugerem vários autores: BARELA \& BARELA (1997), 
KEOGH (1978), MANOEL \& PELEGRINI (1985), THELEN \& ULRICH (1991).

\subsection{Análise dos parâmetros da ação}

A velocidade linear $(\mathrm{m} / \mathrm{s})$ foi mensurada a cada tentativa. Além dela foram mensurados o número de ciclos de braçadas realizadas na distância nadada $\left(\mathrm{N}^{\circ}\right.$ de Ciclos), o comprimento médio das braçadas ( $\left.\mathrm{CMB}\right)$ medido em metros e a freqüência média de braçadas (FMB) medida pelo número de ciclos por segundo.Com essas variáveis foi possível avaliar as possiveis alterações paramétricas realizadas por cada indivíduo no padrão de ação.

\subsubsection{Comprimento médio da braçada}

O comprimento médio apresentou diferenças significativas em todos os níveis, com exceção dos níveis N2 e N5 $\left(\chi^{2}=107,135\right.$, $\left.\mathrm{p}<0,000\right)$. Para se saber em que condições e níveis os sujeitos alteravam o comprimento médio da braçada (CMB) foi aplicado o teste não-paramétrico para medidas pareadas de WILCOXON (1945) que apontou diferenças significativas para os niveis $\mathrm{N} 7(\mathrm{Z}=$ $-2,936, \mathrm{p}<0,002)(Z=-3,061, \mathrm{p}<0,002) ; \mathrm{N} 6(Z=-2,971, \mathrm{p}<0,003)$ e $(Z=-3,063$, $\mathrm{p}<0,002)$ e para $N 4(Z=-2,668, \mathrm{p}<0,008)$ e $(Z=-2,524, \mathrm{p}<0,012)$.

$\mathrm{O} \mathrm{CMB}$ foi afetado tanto nas condições em que a direção foi modificada (C2 e C4) quanto na condição em que só houve alteração na velocidade (C3). Em geral o $\mathrm{CMB}$ diminui quando se alteram as condições de execução da tarefa para todos os níveis. Quando houve mudança de direção, o CBM foi significativamente menor. Apenas no N5 houve uma inversão da tendência de diminuição do $\mathrm{CMB}$. Para esse nível houve um aumento do $\mathrm{CMB}$ 
em todas as condições, embora esse resultado pudesse ser confirmada estatisticamente.

A mudança de direção foi a restrição que mais afetou o $\mathrm{CMB}$ dos sujeitos em todos os níveis de desenvolvimento. Uma possível explicação para esse resultado parece estar na maior facilidade em conseguir mudança de direção através de pequenos ajustes na ação do braço que nesse caso consistiu na diminuição do comprimento.

Nas TABELAS de número 20 a 25 são apresentados o comprimento médio das braçadas e o seu desvio padrão em cada nível de desenvolvimento aquático nas condições de estudo.

TABELA20-Comprimento médio da braçada no Nível 7(m).

Condições Experimentais

Condição 1 Condição 2 Condição 3 Condição 4

$\begin{array}{lllll}\mathrm{N} & 12 & 12 & 12 & 12\end{array}$

$\begin{array}{lcccc}\text { Média } & 1,9 & 1,50^{*} & 1,8 & 1,40^{*} \\ \text { DP } & 0,66 & 0,54^{*} & 0,55 & 0,48^{*}\end{array}$

*Significante ao nível de $p<0,016$

TABELA21-Comprimento médio da braçada no Nível 6 (m).

Condições Experimentais

Condição 1 Condição 2 Condição 3 Condição 4

$\begin{array}{lcccc}\text { N } & 13 & 13 & 13 & 13 \\ \text { Média } & 1,9 & 1,50^{*} & 1,8 & 1,40^{*} \\ \text { DP } & 0,42 & 0,41^{*} & 0,67 & 0,40^{*}\end{array}$

*Significante ao nível de $\mathrm{p}<0,016$ 
TABELA22-Comprimento médio da braçada no Nivel 5 (m).

\section{Condições Experimentais}

Condição 1 Condição 2 Condição 3 Condição 4

$\begin{array}{lcccc}\text { N } & 8 & 8 & 8 & 8 \\ \text { Média } & 1,5 & 1,6 & 1,7 & 1,4 \\ \text { DP } & 0,60 & 1,5 & 1,4 & 1,3\end{array}$

*Significante ao nível de $\mathrm{p}<0,016$

TABELA23-Comprimento médio da braçada no Nivel 4 (m).

Condições Experimentais

Condição 1 Condição 2 Condição 3 Condição 4

\begin{tabular}{lcccc}
$\mathrm{N}$ & 10 & 10 & 10 & 10 \\
Média & 1,58 & $1,27^{*}$ & 1,51 & $1,15^{*}$ \\
$\mathrm{DP}$ & 0,32 & $0,31^{*}$ & 0,53 & $0,39^{*}$ \\
\hline
\end{tabular}

*Significante ao nível de $\mathrm{p}<0,016$

TABELA24-Comprimento médio da braçada no Nível 3 (m).

\section{Condições Experimentais}

Condição 1 Condição 2 Condição 3 Condição 4

\begin{tabular}{lcccc}
$\mathrm{N}$ & 9 & 9 & 9 & 9 \\
Média & 1,31 & $1,03^{*}$ & 1,24 & $0,96^{*}$ \\
$\mathrm{DP}$ & 0,50 & $0,37^{*}$ & 0,44 & $0,37^{*}$ \\
\hline
\end{tabular}

*Significante ao nível de $\mathrm{p}<0,016$ 
TABELA25-Comprimento médio da braçada no Nível 2 (m).

\begin{tabular}{lcccc}
\hline \multicolumn{4}{c}{ Condições Experimentais } \\
$\mathrm{N}$ & Condição 1 & Condição 2 & Condição 3 & Condição 4 \\
Média & 3 & 3 & 3 & 3 \\
DP & 1,60 & 1,28 & 1,56 & 1,18 \\
& 0,32 & 0,31 & 0,38 & 0,50 \\
\hline
\end{tabular}

*Significante ao nível de $\mathrm{p}<0,016$

\subsubsection{Freqüência média da braçada}

A freqüência média da braçada (FMB) entre os sujeitos dos diferentes grupos apresentou diferenças significativas de acordo com o teste de FRIEDMAN (1937) $\left(\chi^{2}=127,779, \mathrm{p}<0,000\right)$. Pode-se observar que houve diferenças significativas em todos os níveis com exceção dos níveis N2 e N5. Essas diferenças quase sempre foram observadas quando se comparou a condição inicial $\mathrm{C} 1$ com a condição que exigiu velocidade máxima $\mathrm{C} 3$; no entanto, para o nível N6 também foi observada a ocorrência de diferenças significativas na condição C4. O teste de WILCOXON (1945) apontou diferenças significativas para $N 7(Z=-2,981, p<0,003)$; N6( $Z=-2,691, p<$ $0,002)$ e $(Z=-2,981, p<0,003)$; $N 4(Z=-2,497, p<0,013)$ e para $N 3(Z=-2,431$, $\mathrm{p}<0,015)$.

A FMB aumenta sempre que há exigência de maior velocidade de deslocamento. Isso ocorreu de forma generalizada em todos os níveis, como se pode observar nas TABELAS 26 a 31 . 
TABELA 26-Freqüência média da braçada no nível 7 (n. ${ }^{\circ}$ de repetições p/s).

\section{Condições Experimentais}

Condição 1 Condição 2 Condição 3 Condição 4

$\begin{array}{lcccc}\mathrm{N} & 12 & 12 & 12 & 12 \\ \text { Média } & 0,500 & 0,519 & 0,580 & 0,615^{*} \\ \text { DP } & 0,139 & 0,122 & 0,143 & 0,144^{*}\end{array}$

* Significante ao nível de $\mathrm{p}<0,016$

TABELA 27-Freqüência média da braçada no nível N6 (n. ${ }^{\circ}$ de repetições p/s).

Condições Experimentais

Condição 1 Condição 2 Condição 3 Condição 4

\begin{tabular}{lcccc}
$\mathrm{N}$ & 13 & 13 & 13 & 13 \\
Média & 0,485 & 0,512 & $0,573^{*}$ & $0,560^{*}$ \\
DP & 0,138 & 0,158 & $0,163^{*}$ & $0,162^{*}$ \\
\hline
\end{tabular}

*Significante ao nível de $\mathrm{p}<0,016$

TABELA 28-Freqüência média da braçada no nível N5 (n. ${ }^{\circ}$ de repetições p/s).

Condições Experimentais

Condição 1 Condição 2 Condição 3 Condição 4

$\mathrm{N}$

8

8

8

8

Média

0,544

0,497

0,654

0,603

DP

0,184

0,237

0,280

0,259

*Significante ao nível de $\mathrm{p}<0,016$ 
TABELA 29-Freqüência média da braçada no nivel $\mathrm{N} 4\left(\mathrm{n} .^{\circ}\right.$ de repetiçōes $\mathrm{p} / \mathrm{s}$ ).

Condiçōes Experimentais

Condição 1 Condição 2 Condição 3 Condiçào 4

$\begin{array}{llll}\mathrm{N} & 10 & 10 & 10\end{array}$

$\begin{array}{lllll}\text { Média } & 0,511 & 0,474 & 0,608^{*} & 0,547\end{array}$

DP $\quad 0,145 \quad 0,126 \quad 0,205^{*} \quad 0,168$

* Significante ao nivel de $\mathrm{p}<0,016$

TABELA 30-Freqüência média da braçada no nivel N3 (n. ${ }^{\circ}$ de repetições p/s). Condições Experimentais

Condição 1 Condição 2 Condição 3 Condição 4

$\begin{array}{lcccc}\mathrm{N} & 9 & 9 & 9 & 9 \\ \text { Média } & 0,452 & 0,434 & * 0,503 & 0,488 \\ \mathrm{DP} & 0,130 & 0,082 & * 0,101 & 0,084\end{array}$

*Significante ao nível de $\mathrm{p}<0,016$

TABELA 31-Freqüência média da braçada no nível N2 (n. ${ }^{\circ}$ de repetições p/s).

Condições Experimentais

$$
\text { Condição } 1 \text { Condição } 2 \text { Condição } 3 \text { Condição } 4
$$

$\begin{array}{lcccc}\mathrm{N} & 3 & 3 & 3 & 3 \\ \text { Média } & 0,332 & 0,345 & 0,349 & 0,444 \\ \text { DP } & 0,043 & 0,113 & 0,127 & 0,2537\end{array}$

* Significante ao nivel de $\mathrm{p}<0,016$

Os indivíduos classificados nos níveis $\mathrm{N} 2$ e $\mathrm{N} 5$ foram os únicos a nào promover alterações significativas na FMB. As alterações significativas na 
freqüência da braçada ocorreram geralmente na condição C3 quando foi exigido aumento da velocidade. Houve apenas uma exceção no N6 quando houve uma alteração significativa também na condição $\mathrm{C} 3$ e C4. Esse resultado se complementa com aumento de freqüência da pernada indicado na análise do componente ação da pernada, nas situações em que a velocidade máxima foi exigida.

\section{7. 3 Número de ciclos de braçada}

A análise de variância simples de FRIEDMAN (1937) indicou diferenças significativas no número de ciclos de braçadas entre os sujeitos dos diferentes grupos e condições $\left(\chi^{2}=106,166, p<0,000\right)$.

De acordo com o teste não-paramétrico para medidas pareadas de WILCOXON (1945) as diferenças ocorreram nas condições em que ocorreu alteração da direção (C2) e também na condição C4 (mudança de direção e de velocidade). Dessa forma para N7 obteve-se $(Z=-2,953, p<0,003)$ e $(Z=-3,061$, $\mathrm{p}<0,002)$; para $N 6,(Z=-3,089, \mathrm{p}<0,002)$ e $(Z=-3,065, \mathrm{p}<0,002)$, para $N 4(Z=-$ $2,684, p<0,007)$ e $(Z=-2,527, p<0,012)$ e finalmente para $N 3(Z=-2,539, p<$ $0,011)$ e $(Z=-2,860, p<0,007)$.

Como já aconteceu com outras variáveis, as condições em que houve mudança de direção foram as que causaram mais mudanças significativas. A necessidade de mudar a direção do deslocamento levou a um aumento do número de ciclos de braçadas. Isso ocorreu em todos os grupos, como pode ser observado nas TABELAS 32 a 37. Apenas os grupos N2 e N5 nào apresentaram diferenças significativas . 
TABELA 32-Número de ciclos por segundo no nível 7 nas condições de estudo.

\section{Condições Experimentais}

\begin{tabular}{lcccc}
\hline & Condição 1 & Condição 2 & Condição 3 & Condição 4 \\
$\mathrm{N}$ & 12 & 12 & 12 & 12 \\
Média & 3,5 & $4,4^{*}$ & 3,7 & $5,0^{*}$ \\
$\mathrm{DP}$ & 1,3 & $1,4^{*}$ & 1,2 & $1,9^{*}$ \\
\hline
\end{tabular}

*Significante ao nível de $\mathrm{p}<0,016$

TABELA 33-Número de ciclos por segundo no nível 6 nas condições de estudo.

Condições Experimentais

Condição 1 Condição 2 Condição 3 Condição 4

$\begin{array}{lcccc}\mathrm{N} & 13 & 13 & 13 & 13 \\ \text { Média } & 3,1 & 3,9^{*} & 3,3 & 4,1^{*} \\ \text { DP } & 0,3 & 0,7^{*} & 0,8 & 0,7^{*}\end{array}$

*Significante ao nível de $p<0,016$

TABELA 34-Número de ciclos por segundo no nível nas condicões de estudo.

\section{Condições Experimentais}

Condição 1 Condição 2 Condição 3 Condição 4

$\begin{array}{lcccc}\text { N } & 8 & 8 & 8 & 8 \\ \text { Média } & 3,1 & 3,5 & 3,2 & 4,0 \\ \text { DP } & 0,7 & 1,1 & 1,2 & 1,7\end{array}$

*Significante ao nível de $\mathrm{p}<0,016$ 
TABELA 35-Número de ciclos por segundo no nível 4 nas condições de estudo.

Condições Experimentais

Condição 1 Condição 2 Condição 3 Condição 4

$\mathrm{N}$ 8 8 8 8

Média 3,1 $3,5^{*}$ 3,2 $* 4,0$

DP 0,7

$1,1^{*}$

1,2

$1,7^{*}$

*Significante ao nível de $\mathrm{p}<0,016$

TABELA 36-Número de ciclos por segundo no nível 3 nas condições de estudo. Condições Experimentais Condição 1 Condição 2 Condição 3 Condição 4

$\begin{array}{lcccc}\mathrm{N} & 10 & 10 & 10 & 10 \\ \text { Média } & 2,9 & * 3,6 & 3,1 & * 3,8 \\ \mathrm{DP} & 0,5 & * 0,7 & 0,7 & * 0,9\end{array}$

*Significante ao nível de $\mathrm{p}<0,016$

TABELA 37-Número de ciclos por segundo no nível 2 nas condições de estudo.

Condições Experimentais

Condição 1 Condição 2 Condição 3 Condição 4

\begin{tabular}{lcccc}
$\mathrm{N}$ & 3 & 3 & 3 & 3 \\
Média & 2,6 & 3,5 & 2,8 & 4,1 \\
$\mathrm{DP}$ & 0,5 & 0,8 & 0,6 & 1,9 \\
\hline
\end{tabular}

*Significante ao nível de $\mathrm{p}<0,016$

É interessante destacar que essas diferenças observadas no número de ciclos de braçada podem de certa forma estar sendo afetados pelo comprimento do braço dos sujeitos participantes do experimento. Nesse caso 
uma restrição organísmica estaria influindo na determinação de um comportamento dentro da tarefa nadar.

Foram observados quinze sujeitos cuja envergadura é maior do que a sua estatura. Sob essa condição o teste FRIEDMAN (1937) apontou diferenças significativas entre o número de ciclos por segundo dos sujeitos classificados nos diferentes níveis desenvolvimento aquático $\left(\chi^{2}=20,930, \mathrm{p}<0,00\right)$. O sítio dessa diferença foi observada no nível N6 na condição $C 2(Z=-2,836 p<0,005)$ e na condição $C 4(Z=-3,117 \mathrm{p}<0,002)$. Para esses grupo de sujeitos, verificou-se um número significativamente menor de ciclos de braçadas por segundo.

\subsubsection{Velocidade}

A velocidade média apresentada pelos diferentes grupos e condições teve diferenças significativas como foi indicado pela análise de variância simples de FRIEDMAN $(1937)\left(\chi^{2}=130,821, \mathrm{p}<0,000\right)$.

$\mathrm{O}$ teste não-paramétrico para medidas pareadas de WILCOXON (1945) apontou diferenças significativas para os níveis $N 7(Z=-3,059, p<0,002)$ e $(Z=-2,432, p<0,015)$; N6(Z=-3,970, p <0,003), $(Z=-3,111, p<0,002)$ e $(Z=-$ $2,900, \mathrm{p}<0,004) ; \mathrm{N} 5(Z=-2,521, \mathrm{p}<0,012) ; \mathrm{N} 4(Z=-2,803, \mathrm{p}<0,005) ;(Z=-2,684$, $\mathrm{p}<0,007)$ e $(Z=-2,527, \mathrm{p}<0,012)$; $\operatorname{para} \mathrm{N} 3(\mathrm{Z}=-2,668, \mathrm{p}<0,008) ;(Z=-2,549, \mathrm{p}<$ $0,011)$ e $(Z=-2,549, p<0,011)$.

Apenas o grupo N2 não apresentou diferenças significativas na velocidade de deslocamento entre as quatro condições do experimento. É interessante notar que o requisito mudança de direção tem maior efeito nas mudanças, como aconteceu com os grupos N3, N4, N5, N6 e N7: todos apresentaram diferenças significativas. 
Como se pode ver nas TABELAS 38 a 43, a mudança de direção ocasionou uma diminuição da velocidade média nos níveis já indicados. Já com o requisito velocidade na condição $\mathrm{C} 3$, não houve um aumento expressivo na velocidade apresentada pelos grupos. Apenas os níveis N3 e N6 apresentaram aumentos significativos de velocidade.

TABELA 38-Velocidade média (m/s) no nível 7.

\section{Condição Experimental}

Condição $1 \quad$ Condição $2 \quad$ Condição $3 \quad$ Condição 4

$\mathrm{N}$

12

12

12

12

Média

$0,91^{*}$

0,77

1,02

$0,81^{*}$

DP

$0,18^{*}$

0,19

0,32

$0,25 *$

*Significante ao nível de $\mathrm{p}<0,016$

TABELA 39-Velocidade média (m/s) no nível 6.

Condição Experimental

Condição 1 Condição 2 Condição 3 Condição 4

$\mathrm{N}$

13

13

13

13

Média

0,89

0,75

$1,0 *$

$0,78^{*}$

DP

0,26

0,19

$0,26^{*}$

$0,21^{*}$

*Significante ao nível de $\mathrm{p}<0,016$ 
TABELA 40-Velocidade média (m/s) no nível 5.

Condição Experimental

Condição 1 Condição 2 Condição 3 Condição 4

$\mathrm{N}$ 8

8

8

8

Média

0,74

$0,55^{*}$

0,84

0,63

DP

0,14

$0,09 *$

0,22

0,14

*Significante ao nível de $\mathrm{p}<0,016$

TABELA 41-Velocidade média (m/s) no nível 4.

Condição Experimental

Condição 1 Condição 2 Condição 3 Condição 4

$\mathrm{N}$

10

10

10

10

Média

0,75

$0,55^{*}$

0,80

$0,60 *$

DP

0,20

$0,15^{*}$

0,19

$0,15^{*}$

*Significante ao nível de $\mathrm{p}<0,016$

TABELA 42-Velocidade média (m/s) no nível 3.

Velocidade média no Nível 3 vs. Condições do estudo

Condição 1 Condição 2 Condição 3 Condição 4

$\mathrm{N}$

9

9

9

9

Média

0,55

$0,40 *$

$0,59 *$

0,46

DP

0,14

$0,10^{*}$

0,15 *

0,12

*Significante ao nível de $\mathrm{p}<0,016$ 
TABELA 43-Velocidade média $(\mathrm{m} / \mathrm{s})$ no nível 2

Velocidade média no Nível 2 vs. Condições do estudo

Condição 1 Condição 2 Condição 3 Condição 4

$\mathrm{N}$

3

3

3

3

Média

0,51

0,38

0,49

0,41

DP

0,05

0,05

0,08

0,07

*Significante ao nível de $\mathrm{p}<0,016$

$\mathrm{Na}$ condição 4 a velocidade foi menor do que aquela desenvolvida pelos sujeitos na condição C3. Houve aumentos significativos da freqüência e do número de ciclos de braçadas por segundo, mas o comprimento médio de braçada diminuiu em todos os níveis de forma significativa. Isso deve ter tido um impacto negativo na velocidade média na $\mathrm{C} 4$.

Outro ponto a ser observado é que na $\mathrm{C} 4$ houve mudança na direção exigindo uma alteração seqüencial. Assim, além da mudança de parâmetros houve a necessidade de alterações no programa de ação, o que por si só já torna mais dificil a condição. Dentro da literatura acerca da natação há unanimidade em afirmar que o acréscimo de movimentos laterais acarreta um aumento da resistência ao avanço do nadador e conseqüentemente uma diminuição na velocidade de nado (COSTILL, MAGLISHO \& RICHARDSON, 1992).

As FIGURAS 6,7 e 8 apresentam velocidade dos níveis de desenvolvimento aquático nas condições experimentais. 


\section{Velocidade Média em C1}

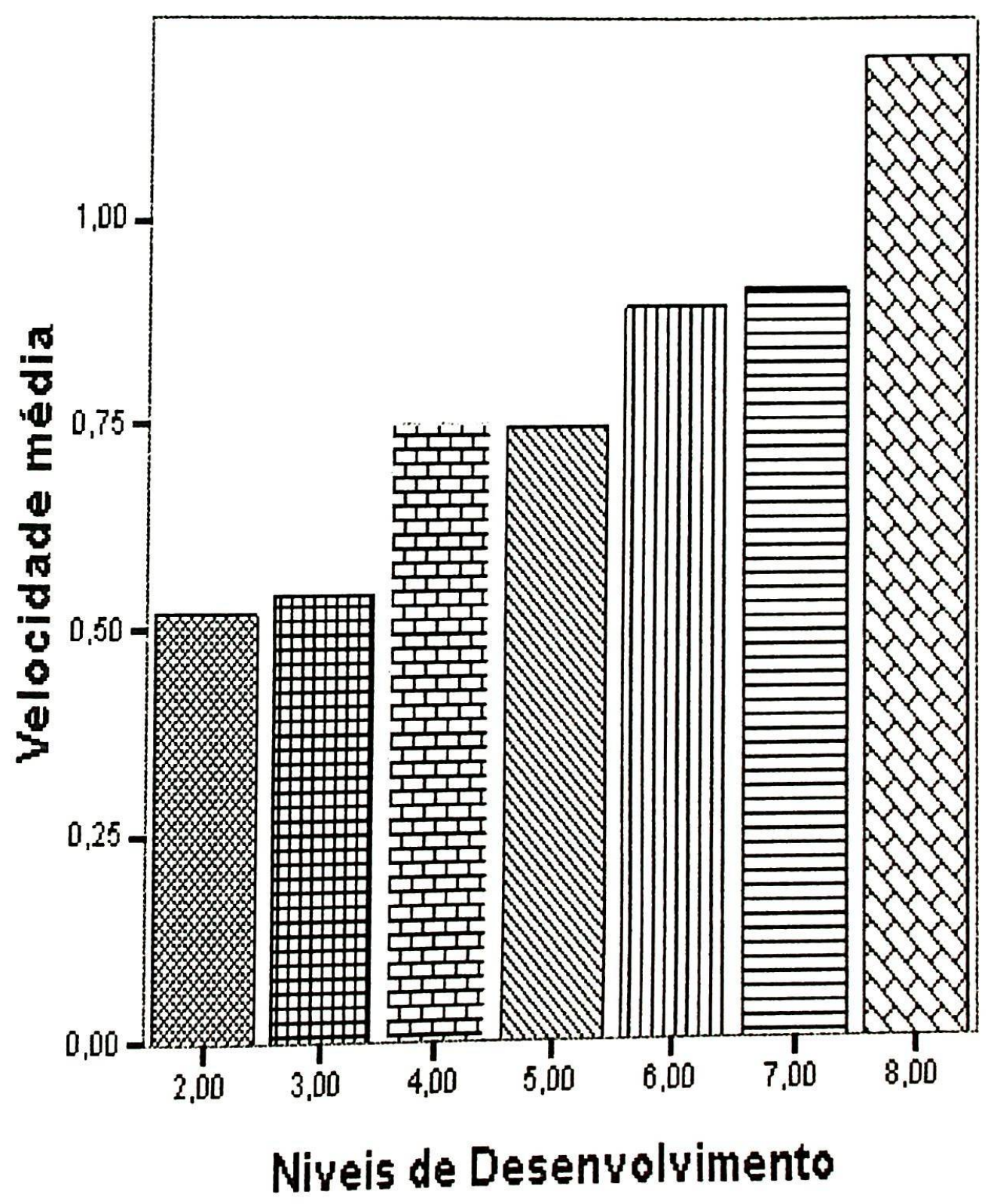

FIGURA 6-Velocidade (m/s) dos grupos na condição Cl. 


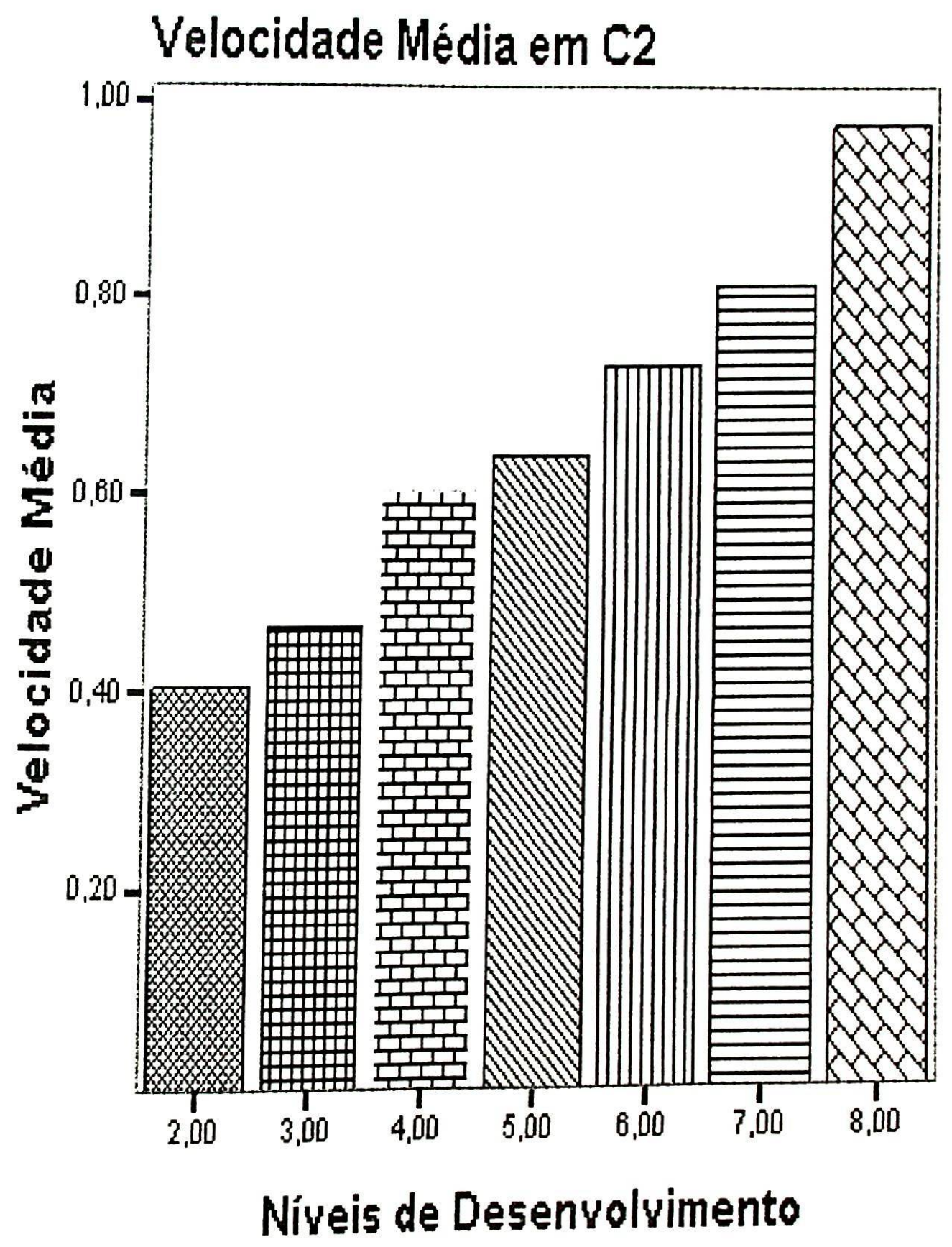

FIGURA 7-Velocidade (m/s) dos grupos na condicào C2. 


\section{Velocidade Média em C3}

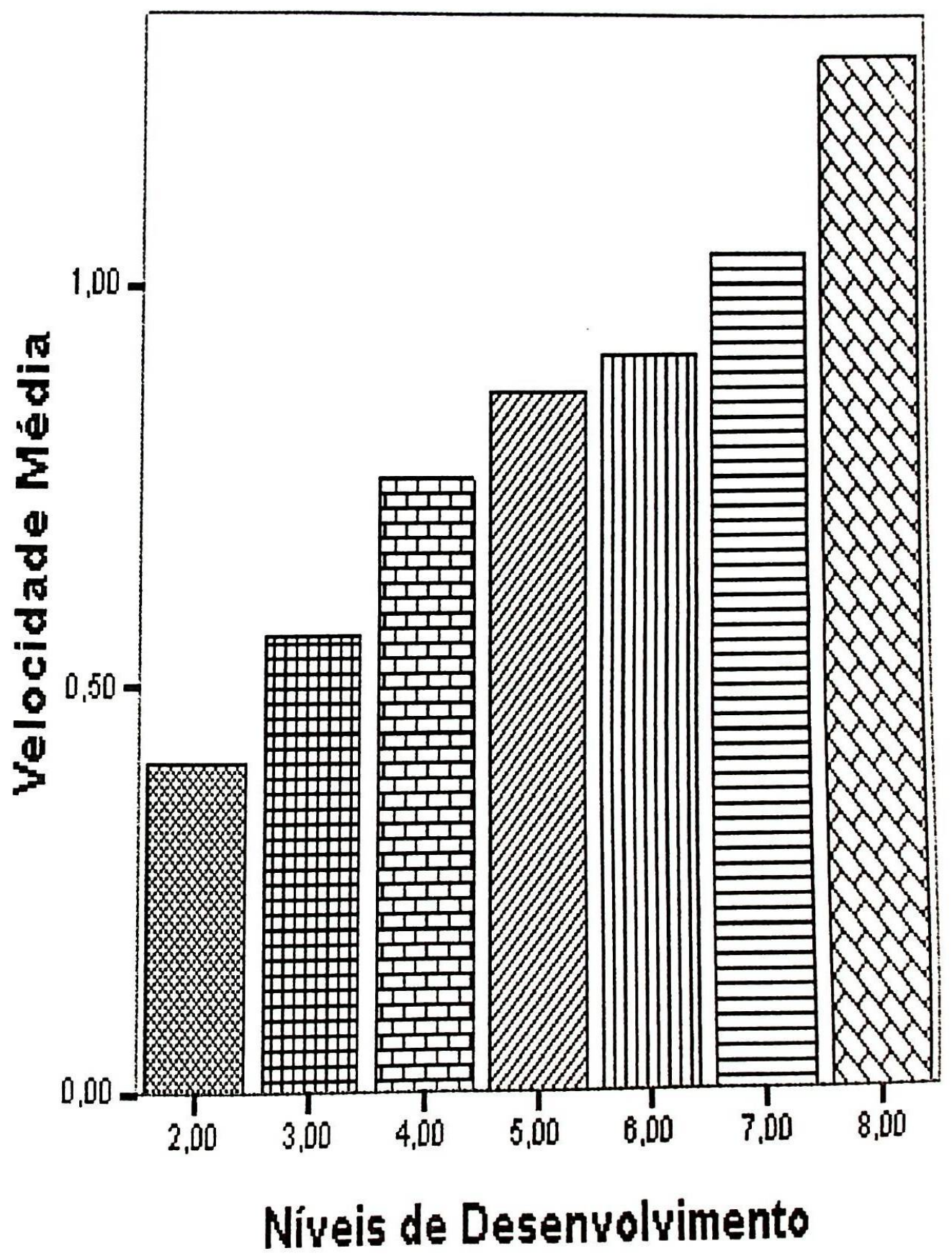

FIGURA 8-Velocidade (m/s) dos grupos na condição C3. 


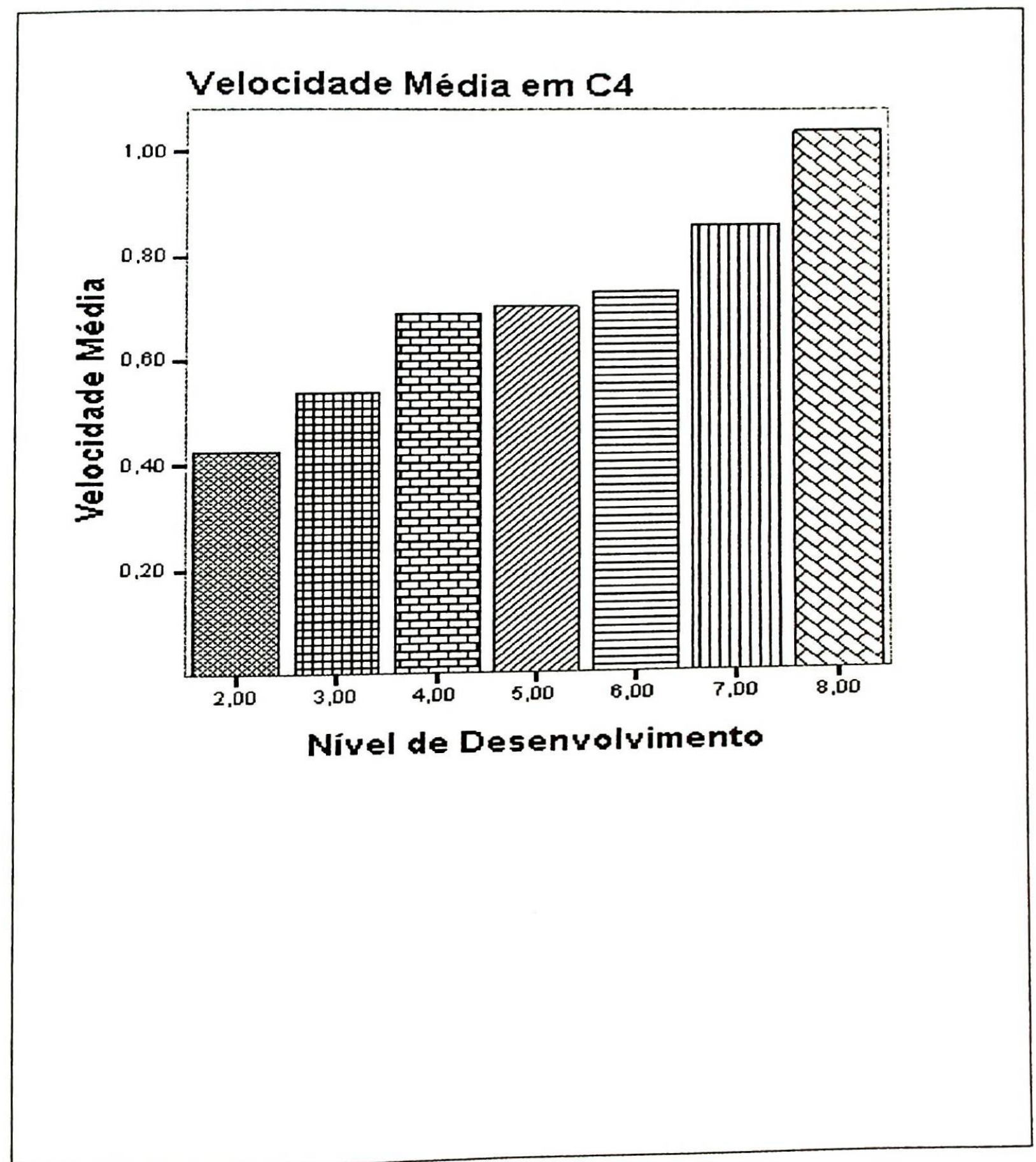

FIGURA 9-Velocidade (m/s) dos grupos na condição C4. 


\subsection{Análise comparativa das medidas qualitativas e quantitativas}

Como já foi apontado anteriormente, a principal tendência dos resultados foi de permanência em todas as condições. Quando as mudanças ocorrem, elas tendem a ser na direção descendente para as condições $\mathrm{C} 2$ e $\mathrm{C} 4$. Quando a condição exigia somente o aumento da velocidade (C3), a direção das mudanças que predominou é a ascendente.

Isso fica evidente quando se contabiliza o número e a direção das alterações adjacentes e não-adjacentes. $\mathrm{Na}$ transição $\mathrm{C} 1-\mathrm{C} 2$ ocorreram 16 alterações descendentes adjacentes e sete não-adjacentes (TABELA 44). Houve apenas uma mudança ascendente adjacente; 31 indivíduos permaneceram sem alteração. 
TABELA 44-Comparação da distribuição das migrações dos niveis de desenvolvimento entre $\mathrm{Cl}$ e $\mathrm{C} 2$.

\section{$\mathrm{C} 1$ vs. $\mathrm{C} 2$}

N. ${ }^{\circ}$ de Alterações

Nível

* $\tilde{\mathrm{n}}$

Sem

**

** กั

adjacente adjacente alteração adjacente adjacente

\begin{tabular}{cccccc}
\hline N2 & - & - & 3 & - & - \\
N3 & - & 4 & 4 & 1 & - \\
N4 & 1 & 3 & 6 & - & - \\
N5 & - & 3 & 5 & - & - \\
N6 & 1 & 3 & 9 & - & - \\
N7 & 2 & 4 & 6 & - & - \\
Total & 7 & 16 & 31 & 1 & - \\
* Mudança para níveis mais elementares & & & \\
* & & & &
\end{tabular}

Na transição C1-C3, 39 indivíduos permaneceram no mesmo nível. As mudanças foram principalmente na direção ascendente. Oito indivíduos apresentaram mudanças adjacentes e quatro não-adjacentes. Apenas quatro indivíduos mudaram na direção descendente adjacente (TABELA 45). 
TABELA 45-Comparação da distribuição das alterações dos niveis de desenvolvimento entre $\mathrm{Cl}$ e $\mathrm{C} 3$.

\section{Cl vs. C3}

N. ${ }^{\circ}$ de Alterações

Nível

$$
* \tilde{\mathrm{n}}
$$

Sem

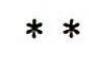

$* * \bar{n}$

adjacentes adjacentes alteração adjacente adjacentes

\begin{tabular}{|c|c|c|c|c|c|}
\hline N2 & & & 1 & 1 & 1 \\
\hline N3 & & & 4 & 4 & 1 \\
\hline $\mathrm{N} 4$ & & & 8 & & 2 \\
\hline N5 & & 2 & 4 & 2 & \\
\hline N6 & & 2 & 10 & 1 & \\
\hline N7 & & & 12 & & \\
\hline Total & 0 & 4 & 39 & 8 & 4 \\
\hline
\end{tabular}

*= Mudança para níveis mais elementares

**= Mudança para níveis mais avançados

Quando a mudança da tarefa envolvia direção e velocidade aconteceram 16 mudanças na direçào descendente adjacente e sete mudanças na mesma direção não adjacente. Apenas um indivíduo (no nível 3) progrediu apresentando uma mudança adjacente (TABELA 46) 
TABELA 46-Comparação da distribuição das alterações dos níveis de desenvolvimento entre $\mathrm{Cl}$ e $\mathrm{C} 4$.

\author{
Cl vs. $\mathrm{C} 4$
}

$N .^{\circ}$ de Alterações

Nivel $\quad * \tilde{n} \quad * \quad$ Sem $\quad * * \quad * * \tilde{n}$

adjacente adjacente alteração adjacente adjacente

$\begin{array}{lllll}\text { N2 } & & & 3 & \\ \text { N3 } & 4 & 3 & 1 & 1 \\ \text { N4 } & 1 & 2 & 7 & \\ \text { N5 } & 1 & 3 & 4 & \\ \text { N6 } & 1 & 2 & 10 & \\ \text { N7 } & & 6 & 6 & \\ \text { Total } & 7 & 16 & 31 \\ \text { Mudança para níveis mais elementares } \\ \text { Mudança para niveis mais avançados significativo }\end{array}$

Significante ao nivel de $\mathrm{p}<0,016$

Outro aspecto destacado é que todos os níveis apresentaram mudanças, sem tendência para mais ou para menos em qualquer grupo. Ou seja, 
não houve nenhum efeito aparente do nível desenvolvimentista na frequiência das mudanças.

Quando se consideram as mudanças nos componentes e parâmetros em conjunto. As transições Cl-C2 (QUADRO 18) e C1-C4 (QUADRO 19) causaram maior número de alterações em nível de componentes e parâmetros. A condição C3 (QUADRO 20) não causou qualquer mudança significativa nos componentes, apenas alterações paramétricas na freqüência média de braçada e na velocidade média (para os níveis $3,4,6$ ).

A condição 4, tida como a mais complexa, foi a que levou a um maior número de mudanças. Aqui fica evidente um efeito do nível de desenvolvimento, já que os indivíduos no N6 e N7 apresentaram mudanças significativas em todos os componentes e parâmetros da ação. Isso vai ao encontro da idéia de que quanto mais avançado no desenvolvimento maior é a capacidade para promover mudanças para ir de encontro às demandas da tarefa e do ambiente. 
QUADRO 18-Niveis de significância nos componentes e parâmetros da ação por grupo na transição $\mathrm{C} 1-\mathrm{C} 2$.

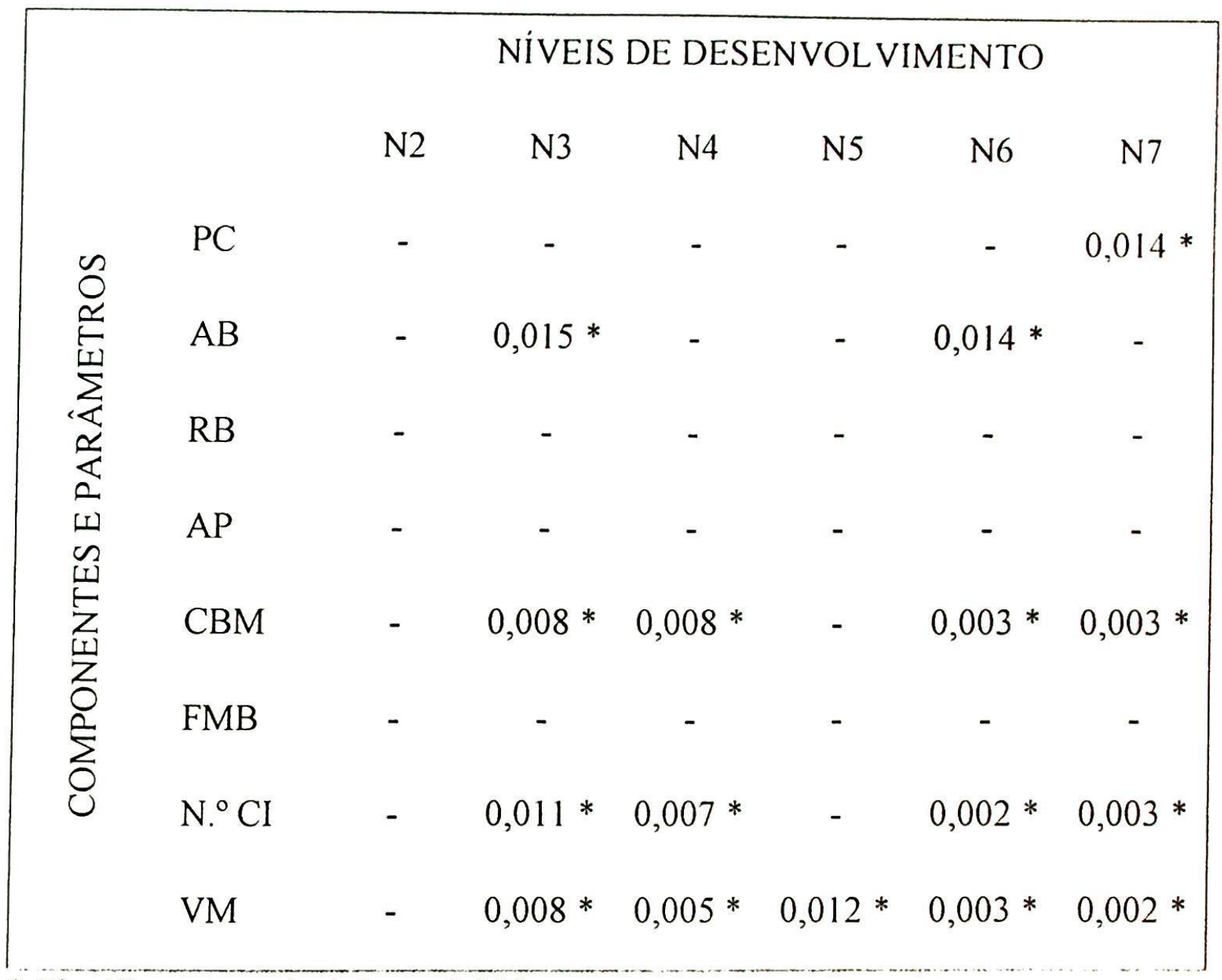

* Significante ao nível de $\mathrm{p}<0,016$

LEGENDA:

PC = Posição do corpo

$\mathrm{AB}=$ Ação do braço

$\mathrm{RB}=$ Recuperação do braço

AP = Ação da perna

$\mathrm{CBM}=$ Comprimento médio da braçada

FMB = Freqüência média de braçada

$\mathrm{N} .{ }^{\circ} \mathrm{CI}=$ Número de ciclos por segundo

$\mathrm{VM}=$ Velocidade média 
QUADRO 19-Niveis de significância nos componentes e parâmetros da ação por grupo na transição $\mathrm{Cl}$-C3.

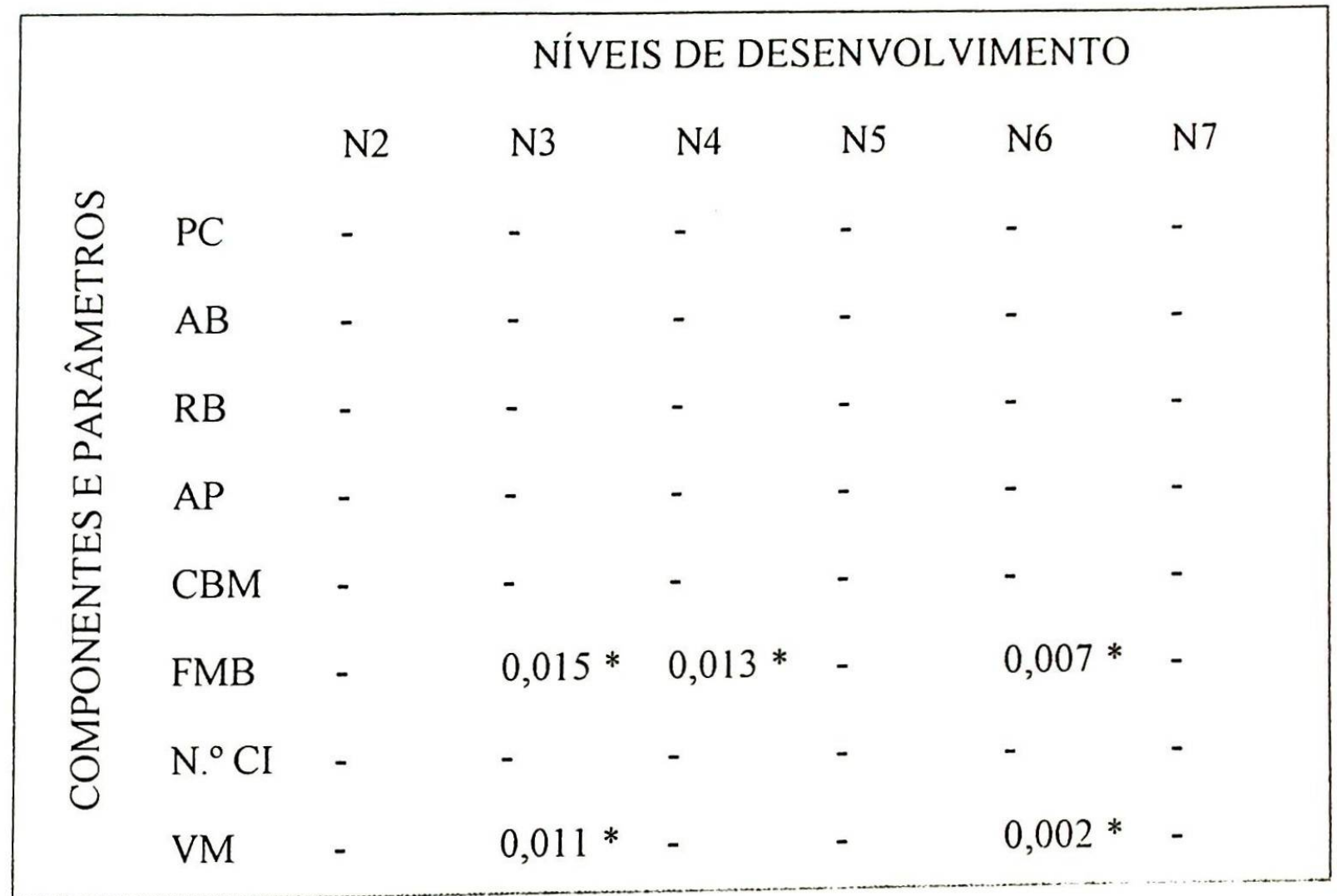

* Significante ao nível de $98.3 \%$

\section{LEGENDA:}

$\mathrm{PC}=$ Posição do corpo

$\mathrm{AB}=$ Ação do braço

$\mathrm{RB}=$ Recuperação do braço

$\mathrm{AP}=$ Ação da perna

$\mathrm{CBM}=$ Comprimento médio da braçada

$\mathrm{FMB}=$ Freqüiência média de braçada

$\mathrm{N} .{ }^{\circ} \mathrm{CI}=$ Número de ciclos por segundo

$\mathrm{VM}=$ Velocidade média 
QUADRO 20-Niveis de significância nos componentes e parâmetros da ação por grupo na transição $\mathrm{Cl}-\mathrm{C} 4$.

\begin{tabular}{|c|c|c|c|c|c|c|c|}
\hline \multirow{9}{*}{ 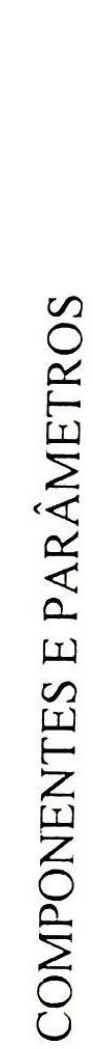 } & & \multicolumn{6}{|c|}{ NÍVEIS DE DESENVOLVIMENTO } \\
\hline & & N2 & N3 & N4 & N5 & N6 & N7 \\
\hline & $\mathrm{PC}$ & - & - & - & $* 0,010$ & $* 0,001$ & $* 0,002$ \\
\hline & $\mathrm{AB}$ & - & - & - & - & $* 0,002$ & $* 0,013$ \\
\hline & $\mathrm{RB}$ & - & * 0,008 & $* 0,014$ & - & $* 0,001$ & $* 0,002$ \\
\hline & AP & - & - & - & - & $* 0,002$ & $* 0,014$ \\
\hline & CBM & - & $* 0,008$ & $* 0,012$ & - & $* 0,002$ & $* 0,002$ \\
\hline & FMB & - & - & - & - & $* 0,002$ & $* 0,003$ \\
\hline & N. ${ }^{\circ} \mathrm{CI}$ & - & $* 0,007$ & $* 0,012$ & - & $* 0,002$ & $* 0,002$ \\
\hline & VM & - & - & $* 0,005$ & - & $* 0,004$ & $* 0,015$ \\
\hline
\end{tabular}

Significante ao nível de $\mathrm{p}<0,016$

LEGENDA:

$\mathrm{PC}=$ Posição do corpo

$\mathrm{AB}=\mathrm{Ação} \mathrm{do} \mathrm{braço}$

$\mathrm{RB}=$ Recuperação do braço

$\mathrm{AP}=$ Ação da perna

$\mathrm{CBM}=$ Comprimento médio da braçada

$\mathrm{FMB}=$ Freqüência média de braçada

$\mathrm{N} .{ }^{\circ} \mathrm{CI}=$ Número de ciclos por segundo

$\mathrm{VM}=$ Velocidade média 


\section{DISCUSSÃO}

A primeira preocupação do presente estudo foi verificar se a manipulação das restrições da tarefa e do ambiente iria atuar na geração de novos padròes de locomoção aquática. Tomando por referência a categorizaçào do comportamento baseada no modelo de configuração total do corpo, verificoul-se que a principal tendência foi a manutenção do mesmo estado de desenvolvimento apresentado na $\mathrm{Cl}$. Os únicos grupos em que a porcentagem de mudança foi maior do que a de permanência foram o N2 na transição Cl-C3 e o $\mathrm{N} 3$ em todas as transições. Os grupos N5 e N7 apresentaram equivalência entre as porcentagens de permanência e mudanças ( $50 \%$ a $50 \%$ ). Isso ocorre nas transições $\mathrm{C} 1-\mathrm{C} 3$ e C1-C4 para o N5 e entre C1-C2 e C1-C4 para N7.

É importante ressaltar que a mudança mais freqüente ocorreu na transição C1-C2 e C1-C4. Nesses casos, as mudanças foram na sua maioria, na direção descendente. Os indivíduos podem ter buscado um padrão mais estável para lidar com os novos desafios impostos. É possível também que eles tenham buscado um padrão mais apropriado para a constante mudança de direção. Isso implicaria modificar a posição da cabeça e, por conseguinte, a posição do corpo colocando em uma posição mais vertical a fiın de facilitar a visualizaçào dos obstáculos. Essas alterações geralmente contribuem para uma classificação num nível mais rudimentar.

Quanto à condição C3, ela registrou um alto índice de permanência. Isso indica que os indivíduos foram capazes de manter o mesmo padrão modificando parâmetros. De fato, vários grupos aumentaram a velocidade média de forma significativa na $\mathrm{C} 3$, o mesmo acontecendo para a freqüência média de braçadas. Não se pode deixar de lado as mudanças de seqüenciamento ocorrida na C3. Essas mudanças foram, na sua maioria, na direção ascendente. A velocidade é conhecida como um parâmetro de controle para padròes de 
locomoçào terrestre. A sua modificação, por exemplo, aumento da velocidade, leva a transições importantes nos padròes de coordenação (por exemplo KELSO, 1984; SHAPIRO, ZERNICKLE, GREGOR \& DISTEL, 1981; THELEN \& ULRICH, 1991). O fato de as mudanças no padrào terem ocorrido em sua maioria na direção descendente sugere que a velocidade pode atuar como um parâmetro de controle na coordenação da locomoção aquática.

Um resultado que denota um possivel efeito do estado de desenvolvimento registrado na $\mathrm{Cl}$ diz respeito aos componentes e aos parâmetros. Os indivíduos no N6 e N7 modificaram de forma estatisticamente significativa todos os componentes e parâmetros mensurados. Esse resultado vai ao encontro da noção de que quanto mais avançado é o nível de desenvolvimento maior será a disponibilidade para efetuar modificações no comportamento (cf. KEOGH, 1978; MANOEL, 1994; MANOEL \& OLIVEIRA, 2000).

O grau de estabilidade do comportamento motor foi alto para a maioria dos participantes do estudo $(\mathrm{IC}=1,0)$ a partir do registro e análise do seu comportamento na condição $\mathrm{Cl}$. Isso poderia explicar a tendência à permanência apresentada pelos grupos em geral. ROBERTON (1987), em um estudo com modificações no arremesso, encontrou alto grau de permanência entre as condições. Sua explicação para tal resultado foi que os indivíduos não estavam próximos à fase de transição. O alto grau de consistência pode ser indicativo de um padrão preferido de locomoção. Entretanto essa possibilidade deve ser considerada com cuidado, posto que os indivíduos dos grupos N6 e N7 apresentaram índice de consistência alto $(\mathrm{IC}=1,0)$, mas, ao mesmo tempo, modificaram o seu comportamento de forma significativa em todos os componentes, além dos parâmetros, na Condição C4.

Em relação ao tipo de ajuste poder-se-ia esperar que as condições C2 e C4 exigiriam mudanças no seqüenciamento e nos parâmetros. Já para a 
condiçào C3 poder-se-iam esperar mais ajustes paramétricos. Essas expectativas foram preenchidas em parte. Realmente as condições $\mathrm{C} 2$ e $\mathrm{C} 4$ foram as que mais mudanças causaram, tanto no seqüenciamento quanto nos parâmetros. A condição $\mathrm{C} 4$, em particular, foi a que mais mudanças gerou.

Na condição C3, como esperado, só houve mudanças significativas nos parâmetros ( freqüência média de braçadas e velocidade). Nào houve uma relação particular das mudanças com os grupos. A única exceção refere-se à condição C4 nos grupos N6 e N7 que apresentaram mudanças de seqüenciamento e nos parâmetros.

Portanto, fica claro que as restrições ambientais (inclusão de objetos no trajeto do nado) foram mais eficazes para causar perturbações no comportamento. Essas mudanças ocorreram no seqüenciamento das ações e nos parâmetros. Para lidar com as demandas das condições C2 e C4 houve mudanças de direção em níveis mais elementares, salvo raras exceções. Isso, de certa forma, indica que as condições dessa tarefa levaram os indivíduos a buscar um padrão mais rudimentar. Entretanto, esse padrão seria mais estável e de certa forma mais confiável como forma de lidar com essas novas demandas. Nào se pode descartar, porém, a possibilidade de que a característica apresentada por esses padrões estaria mais adequada às demandas da tarefa especifica. Assim. nào se trataria de retornar a um nível mais rudimentar, mas sim de buscar um estado mais estável na escala de desenvolvimento, para que se possa lidar com a perturbação originada dos requisitos da tarefa. Nos estudos conduzidos por LANGENDORFER (1990) e MANOEL \& OLIVEIRA (2000), observou-se essa mudança em direção a padròes mais rudimentares no arremesso ao alvo em comparação ao arremesso efetuado à distância. Nesses traballos, a conclusão dos autores foi que os indivíduos buscaram um padrào mais apropriado à tarefa. o qual coincidia com um nível rudimentar na escala de desenvolvimento do 
autores foi que os individuos buscaram um padrào mais apropriado à tarefa, o qual coincidia com um nível rudimentar na escala de desenvolvimento do arremesso efetuado com força ou à distância. A decisão sobre uına das alternativas demanda novos estudos em que restrições similares sejam manipuladas.

As restrições da tarefa (mudanças de velocidade normal) foi menos influente nesse ponto para perturbar o sistema. Ainda assim, é importante notar que indivíduos que mudaram os padrões o fizeram em direção ascendente, ou seja, utilizaram-se de padrões mais eficientes e apropriados às demandas da tarefa. Pode-se perguntar, entretanto, em que grau os indivíduos buscaram a velocidade máxima ou se já apresentaram velocidade submáxima na condição $\mathrm{C}$ 1. Isso se deve à ausência de modificações significativas de velocidade média nas transições $\mathrm{C} 1-\mathrm{C} 3$ ou Cl-C4. Novos estudos necessitam considerar mais de perto a forma como os indivíduos interpretaram as instruções dadas em $\mathrm{Cl}$ e $\mathrm{C} 3$.

\section{CONSIDERAÇÕES FINAIS}

A manipulação de restrições pode desencadear alterações na forma como os elementos interagem num dado sistema de ação motora. Isso pode inclusive gerar até mesmo um novo padrão coordenativo nesse sistema. $\mathrm{O}$ nadar é uma habilidade caracterizada por padrões de coordenação bem característico já que envolve alto grau de organização entre seus elementos (braçada, pernada e respiração). Por ser realizada no meio aquático, a tarefa exige uma orientação postural diferenciada, já que a cabeça necessita estar em constante movimentação para o aporte de oxigênio. Se a orientação postural já é um aspecto importante para as habilidades de locomoção e manipulação, na locomoção aquática ela assume grandes proporções já que o indivíduo nesse 
meio vive uma relação completamente nova de orientação (McGRAW, 1939; MANOEL 1995).

As variações promovidas nas restrições da tarefa e do ambiente tinham duas características que merecem reflexão. Primeiro, com o aumento da velocidade (C3) poderia haver uma modificação na posição do corpo aproximando-o da linha horizontal relativa à superficie da água. De fato, observou-se uma melhoria do padrão de locomoção nos individuos que apresentaram níveis de desenvolvimento rudimentares (N2 e N3). É possivel que essa melhoria só não foi mais predominante no grupo porque nem sempre se buscou a velocidade máxima na nova condição ou os indivíduos já teriam empreendido velocidade submáxima na condição $\mathrm{Cl}$ restando pouco a ser melhorado na condição C3.

Segundo, com os obstáculos no trajeto e com a necessidade de contorná-los criou-se uma condição com forte potencial para perturbar a posição do corpo ou a sua orientação postural de forma ampla. Os grupos em níveis rudimentares (N2 e N3) pouco mudaram na condição. O padrão por eles apresentado poderia estar mais adequado às características da tarefa. Em contrapartida, os indivíduos mais avançados apresentaram modificações na direção descendente, mostrando que a posição do corpo foi afetada. Eles migraram para um padrão mais rudimentar na escala de desenvolvimento, entretanto esse padrão pareceu ser o mais adequado para lidar com as demandas de mudança de direção. Observou-se ainda que cessada a perturbação ambiental, os indivíduos mais avançados retomavam o padrão anterior à perturbação, já os grupos mais elementares permaneciam com o mesmo padrão até o final da tentativa.

Em resumo pode-se concluir que: 
1. As modificações nas restrições da tarefa e do ambiente não geraram por si só mudanças nos programas ou parâmetros de todos os grupos devido à predominância da permanência entre os indivíduos, principalmente nos grupos de nível intermediário e avançado.

2. As condições que envolveram mudança de direção (restrição ambiental) no deslocamento tiveram maior impacto para gerar modificaçòes no padrão global de movimento. Isso evidencia um provável grau de dificuldade maior dessas tarefas. Para responder a essa dificuldade, os indivíduos empregaram um padrão mais rudimentar em busca de um padrão mais estável e resistente à perturbação ou organizaram um padrão mais adequado à situação que acabou coincidindo com um padrão rudimentar na escala de desenvolvimento aquático adotada. A escolha de uma dessas alternativas demanda novos estudos.

3. A condição que envolvia mudança de velocidade ( restrição da tarefa) parece ter desencadeado reorganizações na ação em direção a padrões mais avançados em indivíduos nos grupos N2 e N3. Isso pode ser um indicativo de que a velocidade pode ser um elemento de controle também na locomoção aquática, assim como é observado na locomoção terrestre. Novos estudos necessitam ser delineados para investigar essa possibilidade.

4. Os indivíduos mais avançados (N5, N6 e N7) apresentaram maiores índices de consistência e, ao mesmo tempo, promoveram mais mudanças (seqüenciamento e parâmetros) na condição $\mathrm{C} 4$. Isso pode ser um indicativo de que a estabilidade do padrão de locomoção aquática é importante para adaptações às demandas ambientais e da tarefa. Além de reforçar a idéia de que a noção de padrão maduro deve ser equivalente à de comportamento habilidoso. Ou seja, padrão maduro deve caracterizar-se por alta consistência e grande capacidade de promover ajustes microscópicos, por exemplo, parâmetros, e macroscópicos, por exemplo, seqüenciamento. 


\section{REFERÊNCIAS BIBLIOGRÁFICAS}

BARELA, A.M. F; BARELA, J. A. Restrições ambientais no arremesso de ombro. Motriz, v.3, n.2, p.65-72, 1997.

BRIL, B.C.; BRENIÉRE, Y.. Posture and independent locomotion in early childhood: learning to walk or learning dynamic postural control. In: SAVELSBERG, J., ed. The development of coordination. Amsterdam 1993.

CLARK, J.E.; WHITALL, J. What is motor development? the lessons of history. Quest, v.41, p.183-202, 1989.

CHOSHI, K. Aprendizagem motora como um problema mal definido. Texto traduzido da apresentação feita no Seminário do Laboratório de Comportamento Motor realizado na Universidade de São Paulo 2000.

CONNOLLY, K. Skill development: problems and plans In: Connolly, K.J., ed. Mechanisms of motor skill development. London, Academic Press, 1970. p.3-21.

COSTILl, D.L.; MAGLiSHO, E.W.; RICHARDSON, A.B. Swimming. Oxford, Blackwell Scientific 1992. p.43-75.

COUNSILMAN, J.E. The science of swimming, Englewood Cliffs, Prentice Hall, 1968.

ERBAUGH, S.J. Assessment of swimming performance of preschool children.

Perceptual and Motor Skill, v.47, p.1179-82, 1978.

The development of swimming skills of preschool children. In: HALLIWELL, C. et al. Psychology of motor behavior and sport. Champaign, Human Kinetics, 1980. p.324-35. 
. Effects of aquatic training on swimming skill development of preschool children. Perceptual and Motor Skills, v. 62, p. 439-46, 1986.

FORD, D.H.; LERNER, R.M. Developmental systems theory. Newbury Park, Sage, 1992.

FREUDENHEIM, A.M., coord. Seleção e avaliação. In: Nadar: uma habilidade motora revisitada. São Paulo, CEPEUSP, 1995. p.85-92

FRIEDMAN, M.. The use of ranks to avoid the assumption of normality implicit in the analysis of variance. Journal of the American Statistical Association, v.32, p.675-701, 1937.

GESELL, A. The ontogenesis of motor behavior. In: CARMICHAEL, L., ed.

Manual of child psychology. New York, John Wiley 1946.

GREEN, S.B.; SALKIND, N.J.; ANKEY, T.M. Using SPSS for Windows: analyzing and understanding date's. 2 ed. New Jersey, Prentice Hall, 2000.

HAY, J.G. Biomecânica das técnica desportivas. Rio de Janeiro Interamericana, 1981.

HAYWOOD, K.M. Life span motor development. Champaign, Human Kinetics, 1993.

HERKOWITZ, J. Developmental task analysis: the design of movement experiences and evaluation of motor development status. In: RIDENOUR, M., ed. Motor development. New Jersey, Princeton Book 1978. p. 139-64.

HIGGINS, J.R.; SPAETH, R. Relationships between consistency of movement and environmental conditions. Quest, v.17, p.61-9, 1972.

KELSO, J.A.S. Phase transitions and critical behavior in human bimanual coordination. American Journal of Physiology: Regulatory, Integrative and Comparative Physiology, v.15, R 1000 - R1004 1984. 
KEOGH, J Consistency and constancy in preschool motor development, In MUlleR, H.J.; DECKE, R.; SCHILling, F., eds. Motorik in Vorschulalter. Trad. LACOM-EEFEUSP Schorndorf, Verlag Karl Hoffman, 1978.

The study of movement skill development. Quest, v.28 p.76-88, 1977.

KEOGH, J; SUGDEN, D. Movement skill development. New York, Mc Millan, 1985.

LANGENDORFER, S.J. Children's movement in water: a developmental and environmental perspective. Children's Environments Quarterly, v.4, n.2, p.25-32, 1987a.

. Contemporary Trends in infant preschool aquatics into the 1990s and beyond. JOPERD, v.61, n.5, p.36-39, 1990.

. Prelongitudinal screening of overarm striking development performed under two environmental conditions. In: CLARK, J.; HUMPHREY, J.H., eds. Advances in motor development research-1. New York, MAS Press, 1987 b. p. 17-47.

LANGENDORFER, S.J.; BRUYA R. Aquatic readiness: developing water competence in young children. Champaign, Human Kinetics, 1995. P.19-84.

MAGLISHO, E. Swimming faster. Palo Alto, Mayfield, 1982.

MANOEL, E.J. Adaptive Control and variability in the development of skilled actions. Sheffield, 1993. Tese (Doutorado)- Universidade de Sheffield.

. Desenvolvimento motor: implicações para a educação física escolar.

Revista Paulista de Educação Física, v.8, n. 1, p.82-97, 1994. 
Desenvolvimento motor: padrões em mudança, complexidade crescente. [Artigo submetido à publicação, 1999].

Função, "Affordances" e Desenvolvimento Motor, São Paulo Boletim do LACOM, v.2, n.2, p.6-9, 1995.

MANOEL, E.J.; CONNOLLY, K. Variability and stability in the development of skilled actions. In: CONNOLLY K.J.; FORSBERG eds. Neurophysiology and neuropsyschology of motor development. London, Mc Keith Press Cambridge University, 1997.p.129-47.

MANOEL, E.J.; OLIVEIRA, J.A. Motor developmental status and task constraint in overarm throwing Journal of Human Movement Studies, v.39, p.358-78, 2000.

MANOEL, E.J.; PELEGRINI, A.M. Evolução do padrão fundamental de movimento frente a duas tarefas: dados preliminares. In: CONGRESSO BRASILEIRO DE CIÊNCIAS DO ESPORTE, Poços de Caldas, 1985. Anais. Poços de Caldas, CBCE, 1985. p.3-4.

MARQUES, I. Padrão Fundamental de movimento: uma análise universal ou contextual? Campinas, 1995.171p. Dissertação (Mestrado)- Faculdade de Educação Física, Universidade de Campinas.

McGRAW, M.B. The neuromuscular maturation of the human infant. New York, Hafner, 1961.

Swimming behavior of the human infant. Journal of Pediatrics, v.15, p.485-90, 1939. 
NEWELL, K.M.. Constraints on the development of coordination In: WADE,.M.G.; WHITHING, H.T.A., eds. Motor development in children: aspects of coordination and control. Amsterdam, Martinus Nijhooff, 1986. p.85-122.

Physical constrains to development of motor skills. In: THOMAS, J.R., ed. Motor development during childhood and adolescence. Trad. LABORDAN. Minneapolis, Burgess, 1984. P.1-14.

NEWELL, K.; van EMERIK, R.E. Are Gesell's developmental principles general principles for acquisition of coordination? In: CLARK, J.; HUMPHREY, J.H., ed. Advances in motor development research-3. New York, AMS, 1990. p.85-135.

OKA, H.; OKAMOTO, T.; YOSHIZAWA, M.; TOKUYAMA, H.; HUMAMOTO, M. Electromyography and cinematography study of the flutter kick in infants. In: TERUDO, J.; BEDRINFIELD, E.W. eds. International Behavior Sport Sciences. Baltimore, University Park Press, 1983. v.8, p.167-72.

OLIVEIRA, J.A. Estado de desenvolvimento no padrão fundamental de movimento arremessar frente a variações numa restrição da tarefa. São Paulo, 1997. 112p. Dissertação (Mestrado)- Escola de Educação Física e Esporte, Universidade de São Paulo.

REID, A.; BRUYA, L.D. Assessment of developmental motor patterns in preschool aquatics. Paper presented in the Biennial Conference of the Council for National Cooperation in Aquatics, Forth Worth, TX. 1984.

REIS, J.W. A natação na sua expressão psicomotriz. Porto Alegre Editora da Universidade, 1972. p.15-29.

REISCHELE, K. Biomecânica de la natation. Madrid, Editorial Gymnos, 1993. 
ROBERTON, M. Describing "stages" within and across, motor tasks .In: KELSO, J.A.S.; CLARK, J.E.; HUMPHREY, J.H., eds. The development of movement control and co-ordination. Chichester, John Wiley \& Sons, 1982. p.293-308.

Developmental level as a function of immediate environment .In: CLARK, J.E.; HUMPHREY, J.H., eds. Advances in motor development research-1, New York, AMS Press, 1987. p.1-15.

. Motor development: recognizing our roots, charting our future. Quest, v.41, p.213-23,1989.

SHAPHIRO, D.C.; ZERNICKE, R.T.;GREGOR, R. J.; DIESTEL, I.D. Evidence of generalised programs using gait analysis patterns. Journal of Motor Behaviour, v.13, p 33-47, 1981.

TANI, G. Aquisição da habilidade motora nadar: um processo. In: FREUDEMHEIM, A.M., coord. Nadar: uma habilidade motora revisitada. São Paulo, CEPEUSP, 1995. p.53-61.

Liberdade e restrição do movimento no desenvolvimento motor da criança. In: KREBS, R.J., coord. Discutindo o Desenvolvimento Infantil. Santa Maria, Pallotti, 1998. p.39-62.

THELEN, E. Development of coordinated movement: implications for early human development. In: WADE, M.G.; WHITING, H.T.A., eds. Motor development in children: aspects of coordination and control. Dordretch, Martinus Nyhoff, 1986. p.107-24.

. The hole of motor development in developmental psychology: a view of the past and an agenda for the future. In: EISENBERG, N., ed. Contemporary topics in developmental psychology. New York, John Wiley \& Sons, 1987. p.3-33. 
THELEN, E.; ULRICH, B,D. Hidden skills: a dynamic systems analysis of treadmill stepping during the first year. Monographs of Society for Research in Child, v.56, p.1-35, 1991. (serial n.223)

THOMAS, J. Acquisition of motor skills: information processing differences between children and adults. Research Quarterly for Exercise and Sport, V.51, p.158-73, 1980.

UGRINOWITSCH, H. Interferência contextual: manipulaçào de aspectos invariável e variável na aquisição da habilidade motora saque do voleibol. São Paulo, 1997. 113p. Dissertação (Mestrado)- Escola de Educação Física e Esporte, Universidade de São Paulo.

UGRINOWITSCH, H.; MANOEL, E.J. Interferência contextual: variação de programa e parâmetro na aquisição da habilidade motora saque do voleibol.

Revista Paulista de Educação Física, v.13, n.2, p.197-16, 1999.

VEREIJKEN,B.; BONGAARDT, R. Complex motor skill acquisition. In: AUWEEL, V.Y.; BAKER; F.; BIDLLE, S.; DURAND, M.; SEILER, R. eds. Psychology for physical educators. Champaign, Human Kinetics, 1999. p.223-55.

Von HOFSTEN, C. Development of goal-directed behavior. In KALVERBERG, A.; HOPKINS, B.; GUEZE, R., eds. Motor development in early and late childhood. Cambridge, Cambridge University Press, 1993. p.110-23.

WATSON, J. Psychology from standpoint of behaviourist. Philadelphia, J.B.

Lippincott, 1919. p.243.

WEIKI, C.; HOUBEN, M. Descriptions of leg movements of infants in an aquatic environment. In: BIOMECHANICS and medicine in swimming. Maryland, University Park of Maryland, 1983. v.14, p.66-71.

WILCOXON, F. Individual comparisons by ranking methods. Biometrica

Bulletin, v.1, p.80-3, 1945. 
ANEXO I- Lista de conferência de prontidão aquática

\section{LISTA DE CONFERÊNCIA DE PRONTIDÃO AQUÁTICA}

Orientação na água e componentes de ajuste

Nível-

1. Não demonstra comportamento voluntário de entrada na água, temem a água

2. Entrada voluntária com hesitação, mas medo mínimo

3. Entrada voluntária sem medo da água

Componentes de entrada na água.

Nome

I. Nenhuma entrada voluntária

2. Entrada com os pés com ajuda

3. Entrada com os pés sem auxilio

4. Entrada de cabeça com auxílio

5. Entrada de cabeça sem auxílio 


\section{ANEXO I- Lista de conferência de prontidão aquática (continuação).}

Componentes de controle respiratório.

Nome

1. Respiração reflexiva (controle)

2. Cuspir ou assoprar

3. Submersão voluntária da face

4. Manutenção repetida do controle respiratório

5. Controle respiratório estendido (alongado)

e / ou respiração rítmica com estilo

Flutuabilidade / Flutuação

Nome

1. Nenhuma flutuação

2. Flutuação com assistência

3. Flutuação com apoio

4. Flutuação sem assistência 


\section{ANEXO I- Lista de conferência de prontidão aquática (continuacão).}

Lista de checagem da posição do corpo

Nome

1. Vertical $\left(90^{\circ}\right.$ a $\left.45^{\circ}\right)$

2. Inclinado $\left(44^{\circ}\right.$ a $\left.20^{\circ}\right)$

3. Nivel $\quad\left(19^{\circ}\right.$ a $\left.10^{\circ}\right)$

4. Horizontal (menos que $10^{\circ}$ )

Lista de checagem da ação de propulsão de braços

Nome

1. Nenhuma ação de braço

2. Empurrão descendente pequeno

3. Empurrar- puxar longo

4-Tração com mudanças de direção

5-Propulsão com movimentos de sustentação 


\section{ANEXO I- Lista de conferência de prontidão aquática (continuacão).}

Lista de checagem de ação de recuperação do braço

Nome

1. Nenhuma ação de braço

2. Nenhuma recuperação de braço acima da água

3. Recuperação de braço rudimentar

4. Recuperação com braços estendidos

5. Recuperação de braços com cotovelo dobrado ou "alto"

Lista de Checagem da ação de perna

Nome

1. Nenhuma ação de perna

2. Empurra com flexão plantar " bicicleta "

3. Rudimentar "tremulo"

4. Joelho dobrado "tremulo"

5. Perna de estendida 
ANEXO I- Lista de conferência de prontidão aquática (continuacão).

Lista de checagem de movimentos combinados

Nome

1. Nenhum comportamento de locomotor

2. Cachorrinho

3. Novato iniciante (padrão humano )

4. Crawl rudimentar

5 Crawl avançado ou outro estilo formal avançado 


\section{ANEX() II- Instrucões para uso da lista de conferência A.R.A.}

\section{Como obter objetividade e consistência}

1. Familiarize-se com as regras de decisão para cada nivel dentro dos componentes de ARA. Pergunte-se qual é a característica marcante que define o comportamento de acordo com a regra de decisào.

2. Estude as FIGURAS para adquirir uma imagem visual do que as regras de decisão estão descrevendo. Só enfoque um componentes ou nível a cada observação.

3. Observe várias crianças de habilidades diferentes que estejam de fato nadando. Para os componentes de braço, perna e posição de corpo, é útil fazer esta observação sob a água com óculos de proteção ou máscara ou por um visor, se disponivel.

4. Peça para um co-instrutor que repita os passos de 1 a 3 novamente. Ambos observam as mesmas crianças a partir do item 3 ao vivo ou através de vídeo.

5. Compare as observações de ambos os instrutores em ambas as ocasiões na lista de conferência. Pegue o número total de acordos obtidos entre instrutores e divida pelo total de observações possíveis e multiplique por 100. Esta figura deverá ser $80 \%$ coincidente ou mais. Se não, repita os passos de 1 a 4 até que você concorde em $80 \%$ das vezes ou mais. Pode ser útil ir junto em cima das regras de decisão do item 2. Compare as primeiras e as segundas observações de cada instrutor nos itens 3 e 4 . De novo divida os acordos pelas observações totais possiveis e multiplique por 100 . Se o valor não é igual ou superior a $80 \%$, você necessita mais treinamento, pois a sua medida nào é consistente. 
Anexo III- Ficha de registro e análise de dados.

\section{FICHA DE REGISTRO E ANÁLISE DE DADOS}

Nome:

Masculino (

ESTATURA:

) Feminino ( CM

DATA DA COLETA

EXPERIÊNCIA ANTERIOR EM NATAÇÃO:

NEHUMA

6 MESES

6 MESES A 1 ANO

MAIS DE 1 ANO

OBSERVAÇÕES:
$\mathbf{N}^{\prime \prime}$ idade:

) Data de nascimento:

ENVERGADURA: CM 
Anexo III- Ficha de registro e análise de dados (continuacão). CONDIČ̃̃O-2 (V1-DIR2) MODA= INDICE DE CONSISTÊNCIA=

\begin{tabular}{|l|l|l|l|l|}
\hline Tentativa & Nivel & F & FB_ & Tempo em Seg. \\
\hline $1-$ & & & & - \\
\hline $2-$ & & & & \\
\hline 3 & & & & \\
\hline 4 & & & & \\
\hline 5 & & & & \\
\hline
\end{tabular}

CONDIÇÃO-3 (V1-DIR2) MODA= ÍNDICE DE CONSISTÊNCIA=

\begin{tabular}{|l|l|l|l|l|}
\hline Tentativa & Nível & F & FB_ & Tempo em Seg. \\
\hline $1-$ & & & & - \\
\hline $2-$ & & & & \\
\hline 3 & & & & \\
\hline 4 & & & & \\
\hline 5 & & & & - \\
\hline
\end{tabular}

CONDIÇÃO-4 (V1-DIR2) MODA= INDICE DE CONSISTÊNCIA=

\begin{tabular}{|l|l|l|l|l|}
\hline Tentativa & Nivel & F & FB_ & Tempo em Seg. \\
\hline $1-$ & & & & - \\
\hline $2-$ & & & & \\
\hline 3 & & & & \\
\hline 4 & & & & \\
\hline 5 & & & & \\
\hline
\end{tabular}




\section{Anexo IV- Tabela de classificacão dos níveis de desenvolvimento por}

\section{componentes.}

Posição do corpo:

I Vertical com apoio plantar $\left(90^{\circ}\right.$ a $\left.45^{\circ}\right)$

2 Vertical sem apoioplantar $\left(90^{\circ}\right.$ a $\left.45^{\circ}\right)$

3 Inclinado $\left(44^{\circ}\right.$ a $\left.20^{\circ}\right)$

4 Em nível $\left(19^{\circ}\right.$ a $\left.10^{\circ}\right)$

5 Horizontal (menos de $10^{\circ}$ )

Ação do braço:

1 Sem ação propulsiva do braço

2 Puxada curta e rápida para baixo e para traz

3 Puxada longa reta para traz

4 Puxada em "S" com palmateio

\section{Recuperação do Braço:}

1 Nenhuma ação braço

2 Recuperação sub aquática

3 Recuperação aérea intermitente

4 Recuperação com braço estendido

5 Recuperação com "cotovelo alto"

\section{Ação da Perna:}

1 Sem ação da perna

2 "Pedalada"

3 Pernada "Tremula" com flexão dos joelhos

4 Pernada de crawl rudimentar

5 Pernada formal do crawl

6 Pernada de dois tempos 
Anexo IV - Tabela de Classificacão dos Níveis de Desenvolvimento por

\section{componentes (continuacão).}

Configuração Total do Corpo:

1 Sem locomoção independente

2 Cachorrinho

3 Coordenação braço perna

4 Novato

5 Crawl Rudimentar

6 Crawl intermediário

7 Crawl Avançado pernada contínua de 6 tempos

8 Crawl pernada alternada de 2 tempos 
ANEXO V- Classificacão dos níveis de desenvolvimento aquático por componentes adaptado de ROBERTON, (1977).

nível 01

COMPONENTE

$\begin{array}{llllll}\text { POSIÇÃO CORPORAL A } & \text { B } & \text { C } & \text { D } & \text { E }\end{array}$

$\begin{array}{lllll}\text { AÇÃO DO BRAÇO } & \text { F } & \text { G } & \text { H } & \text { I }\end{array}$

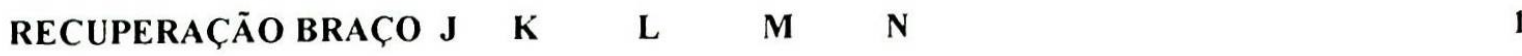

AÇÃO DA PERNA

$\begin{array}{llllll}\mathbf{O} & \mathbf{P} & \mathbf{Q} & \mathbf{R} & \mathrm{S} & \mathrm{T}\end{array}$

NIVEL CACHORRINHO

COMPONENTE

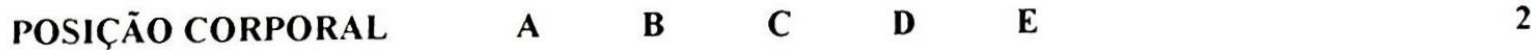

$\begin{array}{llllll}\text { AÇÃO DO BRAÇO } & \text { F } & \text { G } & \text { H } & \text { I }\end{array}$

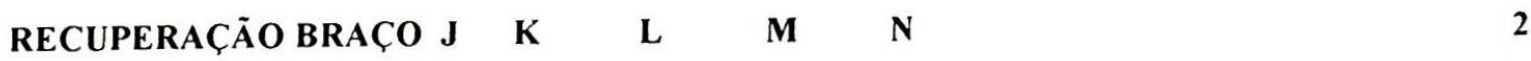

$\begin{array}{llllllll}\text { AÇÃO DA PERNA } & \text { O } & \text { P } & \text { Q } & \text { R } & \text { S } & \text { T } & 2\end{array}$

COORDENAÇÃO BRACCO PERNA

COMPONENTE

POSIÇÃO CORPORAL

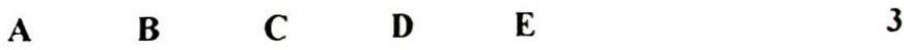

AÇÃO DO BRAÇO

F $\quad$ G $\quad$ H I

RECUPERAÇÃO BRAÇO

$\begin{array}{lllll}\text { J } & \text { K } & \text { L } & \text { M } & \text { N }\end{array}$

3

AÇÃO DA PERNA

$\begin{array}{lllll}\mathbf{O} & \mathbf{P} & \mathbf{Q} & \mathbf{R} & \mathrm{S}\end{array}$

NOVATO

COMPONENTE

POSIÇÃO CORPORAL

AÇÃO DO BRAÇO

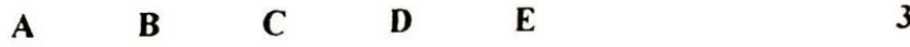

RECUPERAÇÃO BRAÇO

F $\quad$ G $\quad$ H $\quad$ I

3

AÇÃO DA PERNA

$\begin{array}{llllll}\mathbf{J} & \mathbf{K} & \mathbf{L} & \mathbf{M} & \mathbf{N} & \\ \mathbf{O} & \mathbf{P} & \mathbf{Q} & \mathbf{R} & \mathbf{S} & \text { T }\end{array}$

3

(RAWI, RUDININENTAR

CONPONENTE

POSIÇÃO CORPORAL

AÇÃO DO BRAÇO

RECUPERAÇÃO BRAÇO

AÇÃO DA PERNA

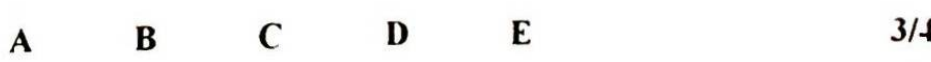

F $\mathbf{G}$ H I

$\begin{array}{llllll}K & \text { L } & \text { M } & \text { N } & 3 / 4\end{array}$

$\begin{array}{llllll}\mathbf{J} & \mathrm{K} & \mathbf{L} & \mathrm{M} & \mathrm{N} & \\ \mathbf{O} & \mathbf{P} & \mathbf{Q} & \mathbf{R} & \mathrm{S} & \mathrm{T}\end{array}$ 
ANEXO V-Classificacão dos níveis de desenvolvimento aquático por componentes adaptado de ROBERTON, (1977) continuacão.

CRAWL INTERMEDIÁRIO

COMPONENTE

POSIÇÃO CORPORAL

AÇÃO DO BRAÇO

$\begin{array}{llllll}\text { A } & \text { B } & \text { C } & \text { D } & \text { E } & 4 / 5\end{array}$

RECUPERAÇÃO BRAÇO

AÇÃO DA PERNA

$\begin{array}{lllll}\text { F } & \text { G } & \text { H } & \text { I } & 3 / 4\end{array}$

$\begin{array}{llllll}J & K & L & M & N & 4 / 3\end{array}$

CRAWL AVANCADO

COMPONENTE

POSIÇÃO CORPORAL

AÇÃO DO BRAÇO

RECUPERAÇÃO BRAÇO

$\begin{array}{lllll}\mathbf{O} & \mathbf{P} & \mathbf{Q} & \mathbf{R} & \mathbf{S}\end{array}$

AÇÃO DA PERNA

$\begin{array}{ccccccc}\text { A } & \text { B } & \text { C } & \text { D } & \text { E } & & \text { 5 } \\ & \text { F } & \text { G } & \text { H } & \text { I } & & \text { H } \\ \text { J } & \text { K } & \text { L } & \text { M } & \text { N } & & 5 \\ \text { O } & \text { P } & \text { Q } & \text { R } & \text { S } & \text { T } & 5\end{array}$

CRAWL PERNA $2 T$

COMPONENTE

POSIÇÃO CORPORAL

AÇÃO DO BRAÇO

$\begin{array}{ccccccc} & \text { A } & \text { B } & \text { C } & \text { D } & \text { E } & \text { 5 } \\ & & \text { F } & \text { G } & \text { H } & \text { I } & \text { 4 } \\ & \text { J } & \text { K } & \text { L } & \text { M } & \text { N } & 5 \\ \text { O } & \text { P } & \text { Q } & \text { R } & \text { S } & \text { T } & 6\end{array}$

RECUPERAÇÃO BRAÇO

AÇÃO DA PERNA 
ANEXO VI- Ambiente do experimento

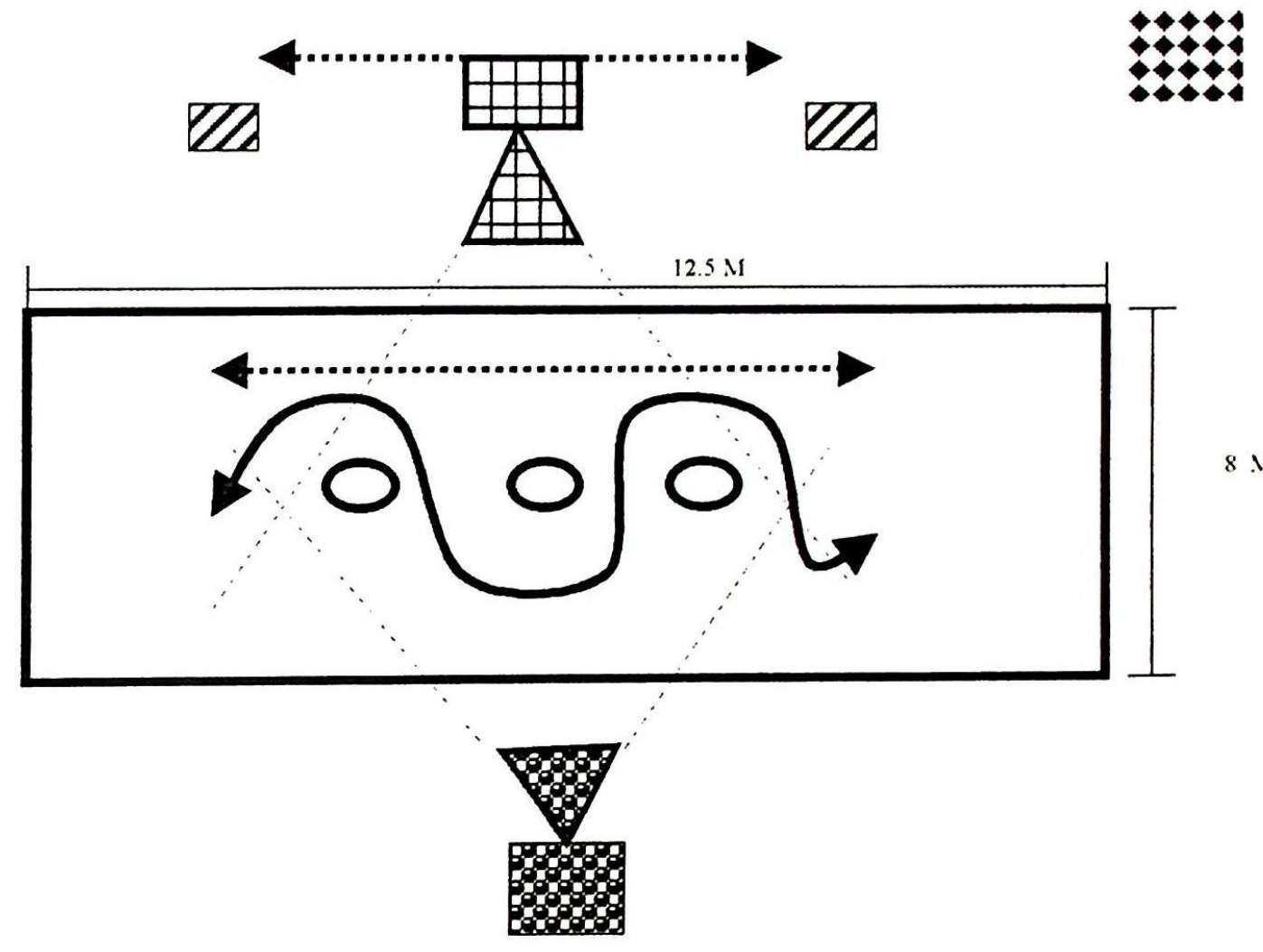

Inicio e final da filmagem (ponto de luz)

Camera subaquática (móvel)

Camera Aérea (fixa)

Distância total de nado $(8 \mathrm{~m})$

Distância analisada (6 m)

Bóias

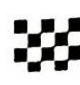

Mesa do Anotador

2

Operadores de camera

1

Cronometrista

1

Professor dentro da água

Anotador 